\title{
Investigating the analgesic properties of Kurkinorin, a novel mu-opioid receptor analogue of Salvinorin A
}

\section{Nirajmohan Shivaperumal}

Student ID: 300245096

2017

A thesis submitted to Victoria University of Wellington in fulfilment of the requirements for the degree of Master's of Biomedical Science 


\section{Abstract}

\section{Background}

The mu-opioid receptor (MOPr) activating drugs such as morphine, fentanyl, etorphine and methadone are used to treat moderate to severe pain. However, their long-term use produces serious adverse effects such as respiratory depression, sedation, tolerance, nausea, dependence, and constipation and this signifies the search for an alternate pain therapeutic agent. Here we report the investigation of antinociceptive and side effect profiles of a structurally unique MOPr-activating drug, kurkinorin from Salvinorin A (Sal A) that was compared with morphine and herkinorin.

\section{Methods}

Adult male B6-SJL mice (22-29 g) were used to investigate the antinociceptive effects of kurkinorin, herkinorin and morphine utilising the $50^{\circ} \mathrm{C}$ warm-water tail-withdrawal assay. The $2 \%$ intra-dermal formalin assay was used to evaluate acute nociceptive and inflammatory pain and paw oedema. The side effect profiles were evaluated by measuring core-body temperature and utilising behavioural tests of motor co-ordination (accelerating rotarod test). Kurkinorin's rewarding properties were assessed using the conditioned place preference (CPP) assay in male Sprague-Dawley rats (240-350 g).

\section{Results}

Kurkinorin produced significant antinociceptive effects in the tail-withdrawal assay at both $5(p<0.01,10 \mathrm{~min}, p<0.001,15-60 \mathrm{~min})$ and $10 \mathrm{mg} / \mathrm{kg}(p<0.001,5-90 \mathrm{~min}, p<0.01$, $120 \mathrm{~min}$ ) and attenuated both nociceptive and inflammatory pain in the $2 \%$ intra-dermal 
formalin model in mice. The analgesic effects of kurkinorin at $10 \mathrm{mg} / \mathrm{kg}$ were similar to the analgesic effects of morphine at the same dose. The decrease in pain score in the intra-dermal formalin assay with kurkinorin and morphine produced a corresponding reduction of paw oedema. In comparison, herkinorin had reduced analgesic effects in the tail-withdrawal assay $(10 \mathrm{mg} / \mathrm{kg}, p<0.05,30 \mathrm{~min})$ and attenuated inflammatory pain in the intra-dermal formalin assay $(10 \mathrm{mg} / \mathrm{kg}, p<0.001)$ with reduced paw oedema (10 $\mathrm{mg} / \mathrm{kg}, p<0.05)$. Morphine produced significant motor incoordination effects from 15-60 min post injection whereas kurkinorin produced no significant motor impairment. Kurkinorin and herkinorin $(5 \mathrm{mg} / \mathrm{kg}$, i.p) did not produce rewarding effects, whereas morphine produced a significant, rewarding effect in the CPP assay. Kurkinorin produced no change in the core body temperature while morphine significantly reduced the body temperature.

\section{Conclusions}

Kurkinorin is central acting and is as potent as morphine in attenuating acute nociceptive and inflammatory pain. It produced no significant sedative and rewarding effects. Therefore, kurkinorin has been identified as a structurally new class of mu-opioid analgesic, displaying improvements compared to morphine. 


\section{Acknowledgements}

First and foremost, I take great privilege in expressing my prime gratitude to my supervisor, Dr Bronwyn Kivell for the perseverance, advice, and support in guiding me throughout this research. Thank you very much for trusting and encouraging me to undertake this study programme.

I thank my colleague Nitin who taught me the experimental procedures during mice experiments at the beginning of my work, which was very helpful for me in the long run during my study period. I thank Kelly, for her constant support, encouragement and timely help throughout my thesis. I convey my thanks to Aimee for her incredible support in CPP experiments using rats and, to Amy, for the moral support throughout my thesis. I thank David for the timely help and for sparing his valuable time for me throughout my thesis. I thank all lab-mates Fraser, Adam, Diana, Susan, Jasleen, Varun for all their help throughout my entire study period.

I extend my special thanks to Patricia Stein, the Faculty of Science for her magnanimous support, help and for understanding my family situation throughout my thesis period, which cannot be expressed in words. I thank Shona, the Dean, who was very helpful in understanding my financial status and helping me to get through my difficult times. I also thank Dr Janet Pitman for the animal facility and Dr. Simon, head of the department for understanding my family situation during my study period. I also thank all my SBS staff including Mary and Mark for their support. 
I thank my wife and children, Ala, Vishvaa and Vijay for their patience. I thank God for having given me such a wonderful family. I am greatly indebted to the Freemasons NZ for offering me the post-graduate scholarship that supported my study.

Idedicate my dissertation work to my family and my supervisor 


\section{Table of contents}

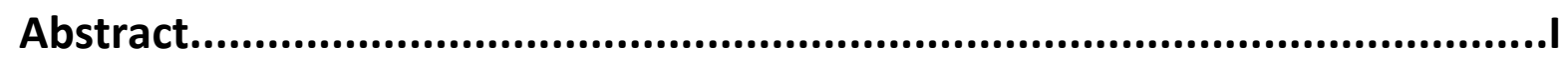

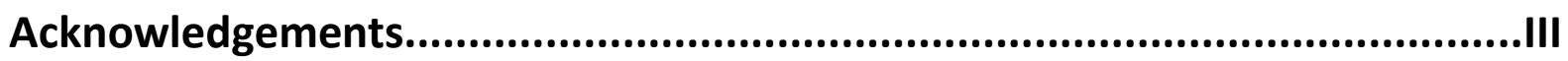

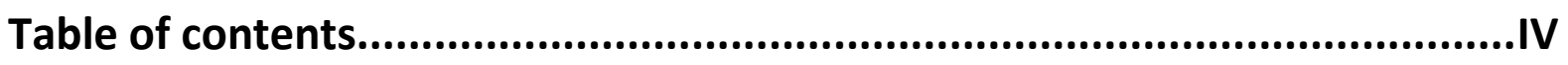

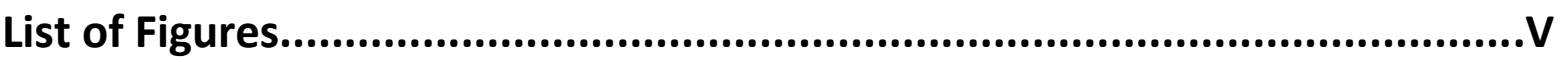

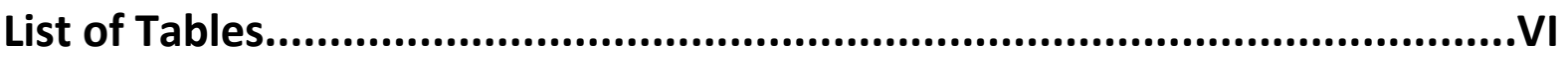

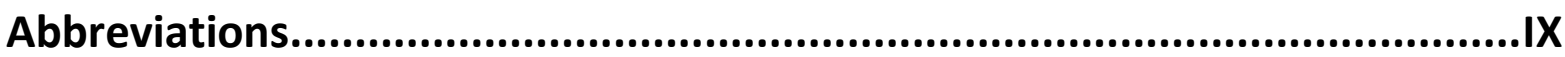

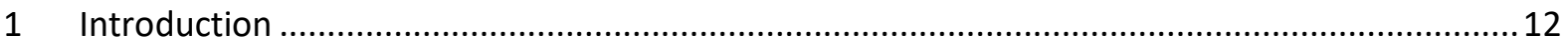

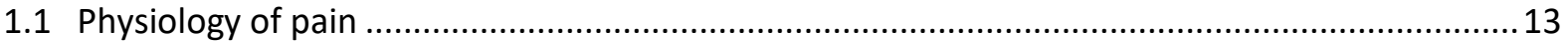

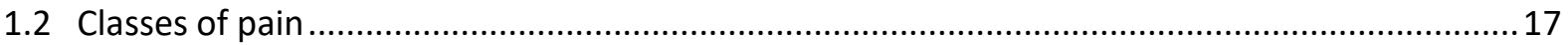

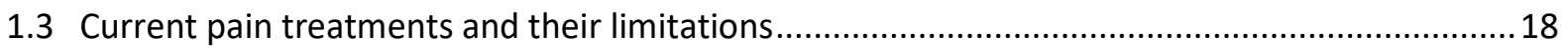

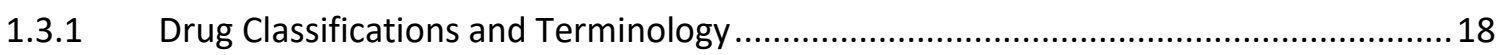

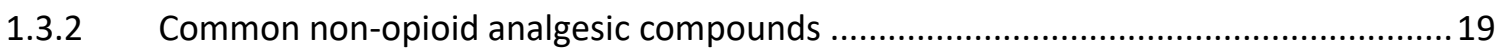

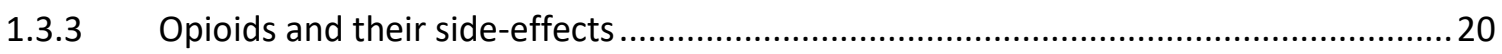

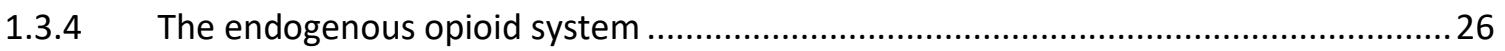

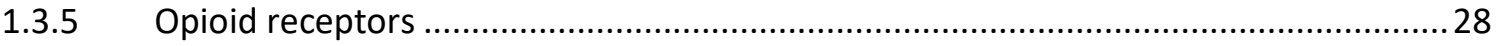

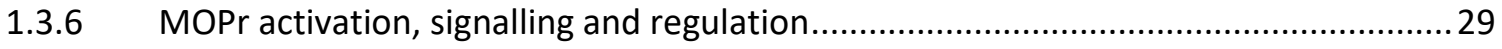

1.3.7 Functional selectivity or biased agonism .................................................................. 34

1.4 Strategies for developing safer, more effective MOPr agonists for treating pain ........................35

1.4.1 Herkinorin: a peripherally restricted MOPr agonist from Sal A .................................... 36

1.4.2 Current MOPr agonists under investigation ......................................................... 41

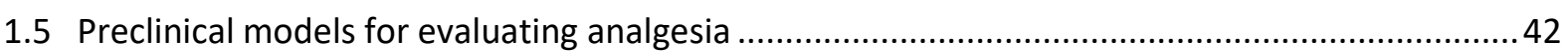

1.5.1 Assessment of thermal nociceptive pain models ..................................................... 42

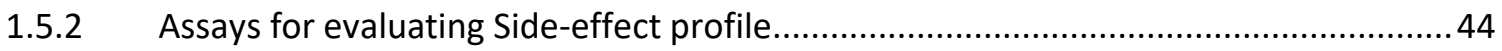

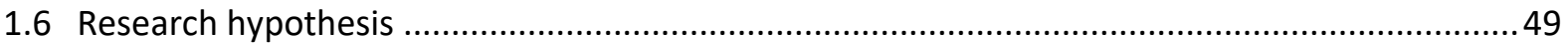

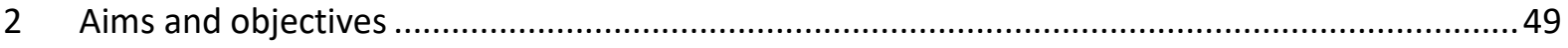

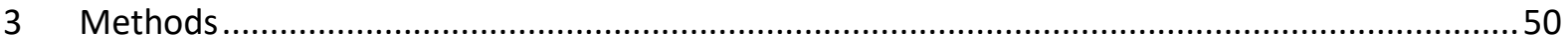

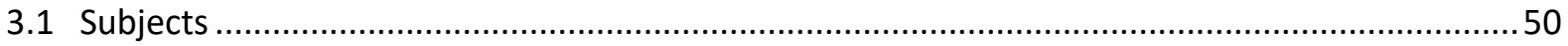

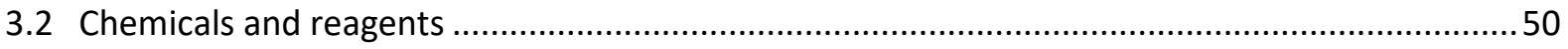

3.2.1 Measurement of analgesia using the warm-water tail-withdrawal test .....................52

3.2.2 Measurements of acute inflammatory pain using the $2 \%$ intra-dermal formalin model. 


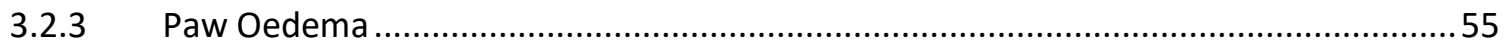

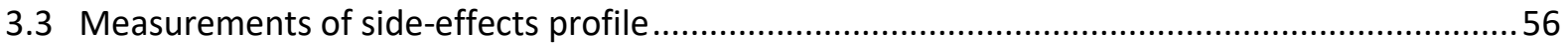

3.3.1 Measurement of locomotor activity and sedation: ................................................... 56

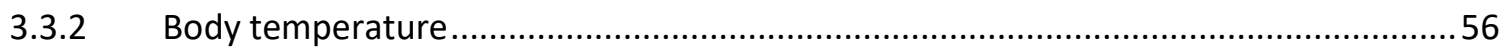

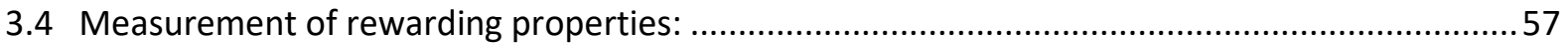

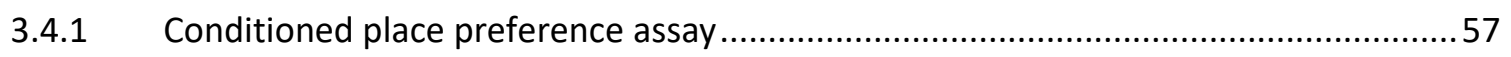

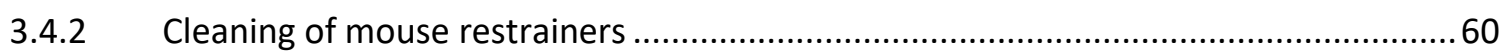

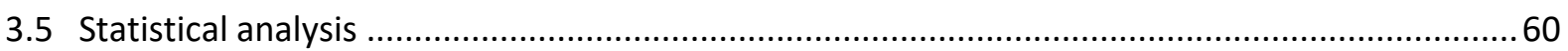

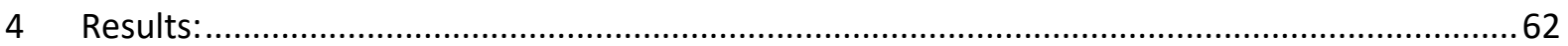

4.1 Analgesic properties of herkinorin and kurkinorin in the warm-water tail-withdrawal assay ......62

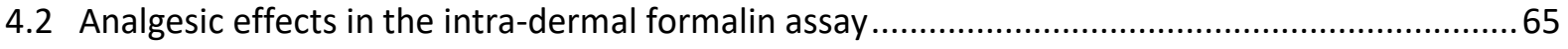

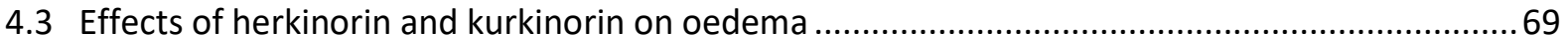

4.4 Measurement of locomotor activity and sedation using the accelerating rotarod assay ............71

4.5 Rewarding properties of herkinorin and kurkinorin using conditioned place preference ........... 73

4.6 Effects of herkinorin and kurkinorin on body temperature ................................................... 75

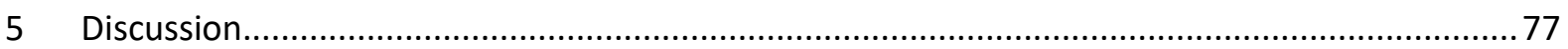

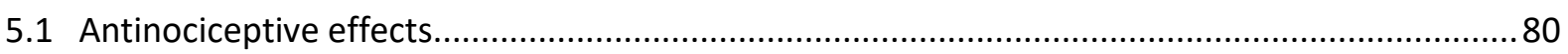

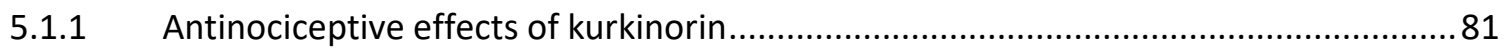

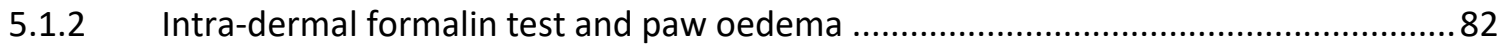

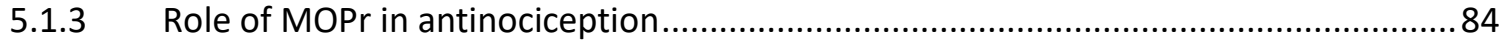

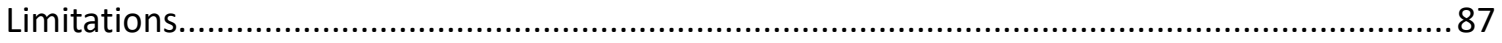

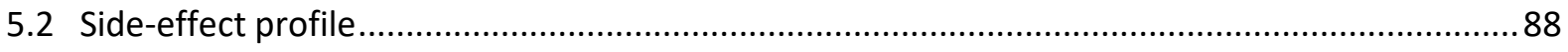

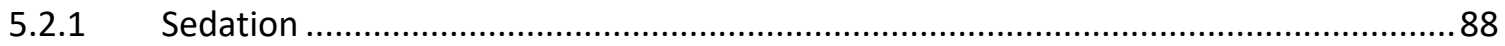

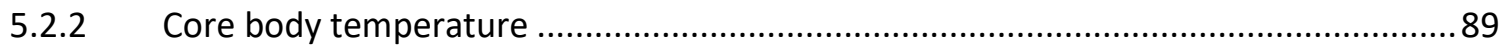

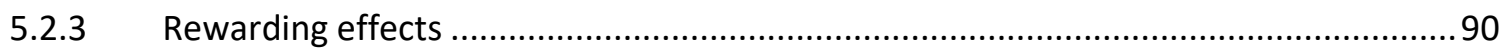

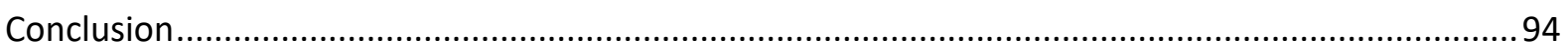

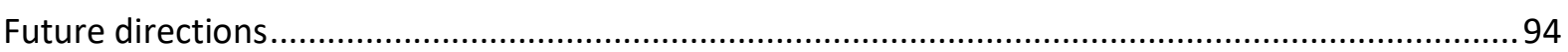

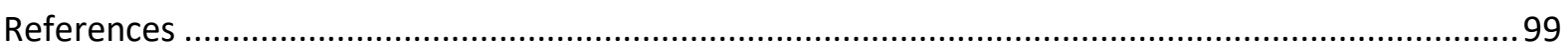




\section{List of Figures}

Figure 1: Physiological pain pathways ......................................................... 14

Figure 2: Mu opioid receptor signalling pathway .......................................... 30

Figure 3: Chemical structure of herkinorin, kurkinorin, Salvinorin A, morphine

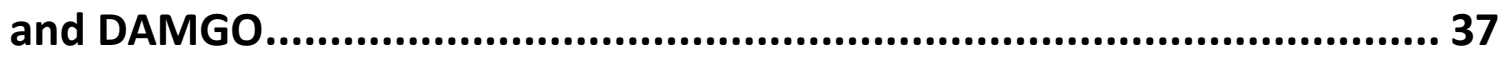

Figure 4: The areas of the brain contributed in reward pathway.................. 45

Figure 5: Intra-dermal Formalin Assay apparatus ..................................... 54

Figure 6: Conditioned Place Preference apparatus and procedure. .............. 58

Figure 7: Dose-dependent and time-course effects of herkinorin and

kurkinorin in the $50^{\circ} \mathrm{C}$ warm water tail-withdrawal assay. ..................... 64

Figure 8: Intra-dermal formalin assay in mice using morphine, herkinorin and

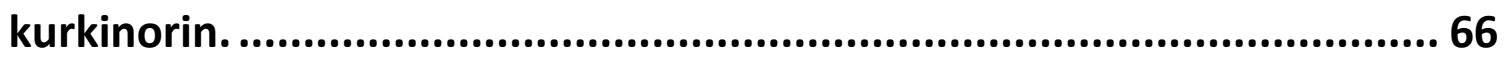

Figure 9: Kurkinorin showed antinociceptive effects in the $2 \%$ intra-dermal

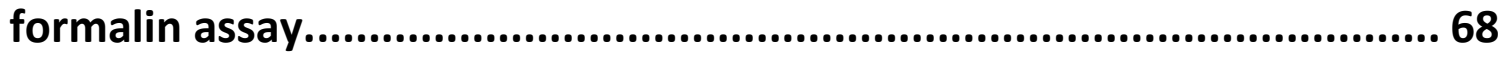

Figure 10: Effects of herkiorin and kurkinorin on paw oedema.................... 70

Figure 11: Measurement of locomotor activity and sedation using

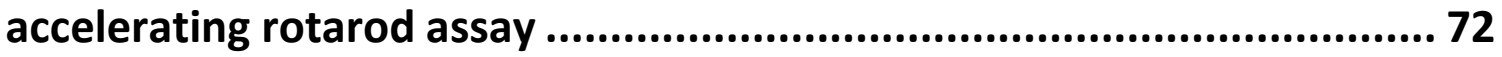

Figure 12: Conditioned place preference assay .......................................... 74

Figure 13: Effects of herkinorin and kurkinorin on core body temperature. . 76 


\section{List of Tables}

Table 1: Endogenous opioid peptides and their affinity towards receptors .. 27

Table 2: The binding affinity and potency of the mu-opioid agonists ${ }^{\wedge}$........... 38

Table 3: Potency, efficacy, and bias of mu opioid agonists in the $\beta$-arrestin

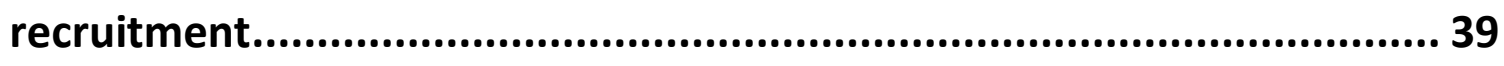

Table 4: Summary of antinociceptive and side effects of compounds used in

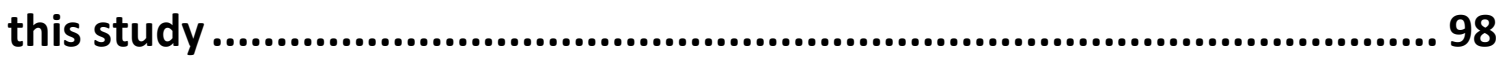




\section{Abbreviations}

$\begin{array}{ll}\text { Akt } & \text { Protein kinase B } \\ \text { CAMP } & \text { Cyclic adenosine monophosphates } \\ \text { CHO } & \text { Chinese hamster ovary } \\ \text { CNS } & \text { Central nervous system } \\ \text { CPP } & \text { Conditioned place preference } \\ \text { DA } & \text { Dopamine } \\ \text { DAT } & \text { Dopamine transporter } \\ \text { DAMGO } & \begin{array}{l}\text { [D-Ala2 }, \text { N-MePhe4, Gly-ol5 ]-enkephalin dyn-DN-dominant negative } \\ \text { dynamin peptide }\end{array} \\ \text { DMSO } & \text { Dimethyl sulfoxide } \\ \text { DOPr } & \text { Delta opioid peptide receptor }\end{array}$

ERK1/2 Extracellular signal-regulated kinase 1 and 2

GPCR G-protein coupled receptor

GRK G-protein receptor kinase

HEK Human embryonic kidney

Herkinorin $\quad(2 S, 4 a R, 6 a R, 7 R, 9 S, 10 a S, 10 b R)-9-($ benzoyloxy)-2-(3-furanyl)dodecahydro6a,10b-dimethyl-4,10-dioxo-2H-naphtho-[2,1-c]pyran-7-carboxylic acid methyl ester)

i.v. Intravenous

JNK c-Jun N-terminal kinase

KOPr Kappa-opioid peptide receptor

Kurkinorin $\quad(2 \mathrm{~S}, 4 \mathrm{aR}, 6 \mathrm{aR}, 7 \mathrm{R}, 10 \mathrm{aR}, 10 \mathrm{bR})-$ Methyl-9-(chlorobenzoyl)oxy)-2-(furan-3-yl)6a,10b-dimethyl-4,10-dioxo-2,4,4a,5,6,6a,7,10,10a,10b-decahydro-1Hbenzo[f]isochromene-7-carboxylate)

MAPK Mitogen-activated protein kinase

MOPr Mu opioid peptide receptor

NAc Nucleus accumbens 
PBS

Phosphate-buffered saline

PEG

Polyethylene glycol

PKC Protein kinase C

SalA Salvinorin A

s.c. Subcutaneous

VTA Ventral tegmental area 


\section{Introduction}

The International Association for the Study of Pain (IASP) defines pain as "an unpleasant sensory and emotional experience associated with actual or potential tissue damage" (IASP, 1986) which has been widely accepted by neurobiologists and other scientific communities. Pain requires expensive treatment and without adequate treatment pain impacts mental, emotional, cultural and social health and behaviours that ultimately affects the quality of life. The nature and severity of pain may be complex, and the complexity of pain differs based on several factors which include age and gender, ethnicity (Belfer, 2013; Montes-Sandoval, 1999), demographics (Keogh, McCracken, \& Eccleston, 2005), psychological conditions (Sturgeon, 2014), clinical afflictions (Belfer et al., 2013), heredity (Tremblay \& Hamet, 2010), socio-economic and other environmental factors (Todd, Deaton, D'Adamo, \& Goe, 2000). Around 19\% of the adult Europeans and 1 in 6 adult New Zealanders and Australians reportedly experience chronic pain (Blyth et al., 2001; Fishman, 2007; Health, 2008) which is a serious and major health concern worldwide (Breivik, Collett, Ventafridda, Cohen, \& Gallacher, 2006). Besides pain being a major health concern the consequences of pain are enormous, for example, in the United States, the cost of pain treatment was estimated to be around $\$ 635$ billion per annum (Gaskin \& Richard, 2012; Trang et al., 2015). Furthermore, studies have shown that nearly 495 million people visit their medical providers every year for pain management (Eisenberg et al., 1993; Gardea \& Gatchel, 2000). Around 116 million of these cases are due to chronic pain (Gaskin \& Richard, 2011; Loeser, 2012; C. Stein, 2013). 
Previous studies have shown that chronic pain impacts nearly $50 \%$ of the aged population (sixty and above) and approximately $25 \%$ of the adults in Australia suffer from chronic pain (Blyth et al., 2001; Ospina \& Harstall, 2003). Furthermore, around $\$ 12.5$ billion per annum was spent on chronic pain treatment in Canada (Moulin, Clark, Speechley, \& Morley-Forster, 2002). Besides the unpleasant experience and cost spent on treating chronic pain, yet another disheartening fact about chronic pain treatment is the addiction towards medications. For instance, $70 \%$ of the chronic pain sufferers are worried about getting addicted to pain relieving drugs, and due to this major concern, chronic pain cases are mostly under-treated in Canada as well as in Australia (Michael J Cousins, 2012). In addition to addiction issues, drug overuse has been shown to be a major cause of drug-related deaths while treating chronic pain where, in 2014 it was estimated that about 207,400 (range: $113,700-250,100$ ) drug-related deaths occurred worldwide and 43.5 (range: 23.8-52.5) deaths per million people were aged between 1564 (UNODC, 2014). Although many aspects of pain and its treatment including types of pain, drugs used for treating different types of pain and the consequences of these medications can be reviewed, this section discusses about the topics relevant to the present study.

\subsection{Physiology of pain}

Pain is a perception of unpleasant experience that is transmitted through a continuous stream of the physiological pathway, and the pathway is represented in Figure 1. 


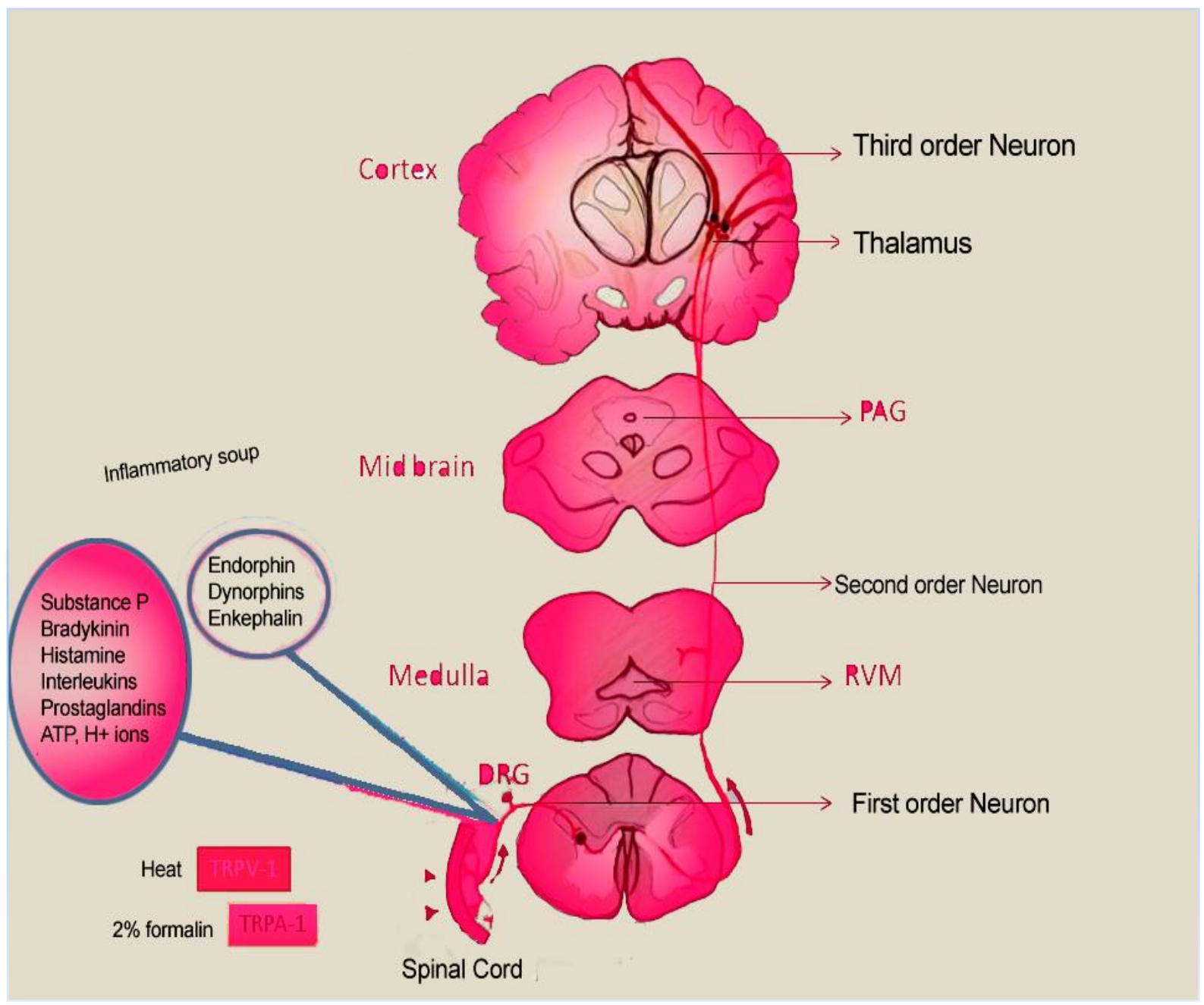

Figure 1: Physiological pain pathways

The figure describes the pain pathway that is activated when a thermal, chemical or inflammatory nociceptive stimuli is felt by the peripheral nociceptors (activates transient receptor family ion channels (TRPV1 and TRPA1) that are co-localized in a subgroup of dorsal root ganglion (DRG) and trigeminal neurons (Patapoutian, Tate, \& Woolf, 2009)) on the first-order neurons. In the dorsal horn of the spinal cord, the first-order neurons synapse with the second-order neuron and the synapse of the second order neuron synapses with third-order neurons in the lateral and medial nuclei of the thalamus. The areas in the brain namely the Periaqueductal Grey (PAG) and Rostroventral Medulla (RVM) are involved in the descending pathway of nociception. Some of the main components of the 'inflammatory soup' including peptides (bradykinin), lipids (prostaglandins), neurotransmitters (serotonin (5-HT), ATP and neurotrophils (NGF) are produced due to injury. The activated nociceptors transmit pain impulses to the dorsal horn of the spinal cord (and from there to the brain), via different neurons. Due to the consequent inflammation, the nociceptor terminals are excited by the interaction of cell-surface receptors expressed on the neurons. Nociceptors also initiate the process of neurogenic inflammation, which is an efferent function that leads to the release of neurotransmitters particularly, substance $P$, and calcitonin gene-related peptides (CGRP), as well as activation of mast cells and neutrophils. Figure and information modified from Julius and Basbaum (2001). 
In the pain pathway, the central nervous system (CNS) perceives pain. CNS involvement is required to feel the pain which is felt when the nociceptive transmission reaches the cortex (S. Marchand, 2008) that leads to pain perception. The critical areas of pain perception in the brain have been studied through imaging the brain which indicated that the perception is caused by the involvement of primary and secondary somatosensory cortices (SI and SII), anterior cingulate cortex, anterior insula, additional cortical areas such as supplementary motor area (SMA), and anterior insular (Coghill et al., 1994). The CNS responds to and interprets noxious stimuli through the first order neurons that are located in the dorsal root ganglion of the spinal cord. These neurons receive stimuli including physical, thermal, mechanical and chemical through the sensory transducer proteins (the cell bodies of the neurons are the sensory transduction channels (Benarroch, 2015; Geffeney \& Goodman, 2012)). Likewise, the peripheral branch of the axon innervates the peripheral tissues, and the central axon innervates the CNS to synapse on second-order neurons that are located in the lamina I and V of the spinal cord's grey matter (Clifford J. Woolf \& Ma, 2007). The second order neurons, in turn, form the spinal thalamic synapse in the contralateral thalamus where the third order neurons are located, and the collective pattern of the pain signal transmission is termed as nociception (Basbaum, Bautista, Scherrer, \& Julius, 2009; Steeds, 2009). The voltage-gated $\mathrm{Na}^{+}$sodium channels in the synapses have a pivotal role in generating an action potential (Geffeney \& Goodman, 2012) which causes the transmission of a chemical message into electrical pain impulses referred to as transduction. The nociceptive physiology includes the responses from peripheral and CNS structures of the cerebral cortex. Nociceptors are found in all tissues of the body except brain, and these nociceptors detect sensory noxious stimuli from the environment through acute thermal, 
mechanical, chemical and inflammatory injuries and transmit the impulses to the spinal cord, brain and other parts of the central nervous system (Julius \& Basbaum, 2001). The nociceptive fibres involved in pain transmission fall into two types: large A delta fibres and smaller $\mathrm{C}$ fibres where large delta A fibres transmit fast, sharp pain produced by physical injury, such as a cut. This pain is very well demonstrated in rodents (Basbaum et al., 2009). Whereas, the smaller $\mathrm{C}$ fibres with an unmyelinated sheath transmits dull aching and burning sensations (such as in formalin (Malmberg \& Yaksh, 1992)) which produce constant pain as reviewed in detail by Helms and Barone (2008); Malmberg and Yaksh (1992); Rosenberg and Heinonen (1983).

The largest group of nociceptive receptors that respond to noxious stimuli are the Transient Receptor Potential (TRP) channels, which have been implicated in the physiological and behavioural responses in the intra-dermal formalin model (McNamara et al., 2007; Patapoutian et al., 2009). Formalin-induced pain (inflammatory) activates C fibres (Dickenson \& Sullivan, 1987) and has two distinct phases; phase I relates to nociceptors with TRPA-1 mediated excitation followed by subsequent transient decline of pain behaviours and the phase II that follows phase I which lasts for 30-60 min (Abbott, Franklin, \& Westbrook, 1995; McNamara et al., 2007; Tjølsen, Berge, Hunskaar, Rosland, \& Hole, 1992). During tissue injury mast cells, macrophages and neutrophils are activated. This happens through the release of immune cell mediators including tumour

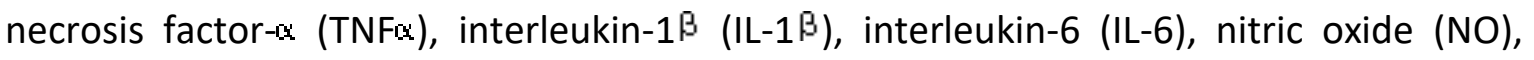
bradykinin, nerve growth factor (NGF) and protons that act on nociceptors (Brack \& Stein, 2004; F. Marchand, Perretti, \& McMahon, 2005). These factors (including mast cells, basophils, platelets, macrophages, neutrophils, endothelial cells, keratinocytes, and 
fibroblasts) collectively known as inflammatory soup, along with the neurotransmitters, vaso-amines and peptides (including substance $\mathrm{P}$, calcitonin-gene-related peptide (CGRP), bradykinin, histamine and serotonin) cause inflammatory pain (Basbaum et al., 2009).

\subsection{Classes of pain}

Pain is a multidimensional phenomenon and a complex sensory process. There have been differences of opinions in the classification of pain and pain has been classified based on the anatomy and aetiology causing pain by Nagasako, Oaklander, and Dworkin (2003). Pain is classified based on the mechanism of causation of pain, by C. J. Woolf et al. (1998) and this classification is useful to identify pain in different disease conditions. For instance, pain experienced by post-operative patients and arthritic patients is similar with respect to the process and nature, as the pain is due to the process of inflammation. This type of pain can be treated with a compound that can bring down the inflammation in both cases (Christoph Stein \& Küchler, 2013; Eugene R Viscusi, Reynolds, Chung, Atkinson, \& Khanna, 2004) and this type of classification is useful in providing effective treatment.

Pain can be short in duration which is termed as acute pain whereas chronic pain is defined as pain that lasts longer than 3 months or persists after the healing process (Clifford J. Woolf, 2010). Further to this classification, yet another classification categorises pain as physical, inflammatory, pathological, nociceptive and neuropathic pain (Clifford J. Woolf \& Salter, 2000). Here we focus on nociceptive and inflammatory pain only, as it is relevant to our present study, which uses acute preclinical behavioural animal models to evaluate 
analgesia. Nociceptive pain is complex, and there is persistent stimulation of $\mathrm{C}$ fibres due to tissue injury by physical, chemical, and mechanical stimuli that leads to intense and continuous pain (Helms \& Barone, 2008; Ignatavicius DA \& Workman, 2006; Ochoa, 2009). Nociceptive pain is protective in nature where it initiates the withdrawal reflex from the pain stimuli, and it is centrally mediated (Clifford J. Woolf, 2010). Inflammatory mediators produce inflammatory pain as a result of tissue damage (Kidd \& Urban, 2001). Inflammatory pain usually appears after nociceptive pain and is usually longer in duration. In acute inflammation phases, cytokines appear to sensitise receptor-associated kinases and intracellular targets which include ion channels (Kidd \& Urban, 2001).

\subsection{Current pain treatments and their limitations}

Treatment strategies for pain are broadly classified into pharmacological and nonpharmacological.

\subsubsection{Drug Classifications and Terminology}

Analgesics are broadly classified as (1) non-opioid analgesics including acetaminophen and nonsteroidal anti-inflammatory drugs (NSAIDs), such as aspirin and other salicylic acid derivatives; (2) Opioid analgesics those that activate the mu opioid receptors (MOPr) such as morphine - (3) Adjuvant analgesics or co-analgesics, those that typically are used for other conditions but possess analgesic properties, such as antiepileptic drugs (AEDs), tricyclic antidepressants (TCAs), and local anesthetics (LAs). For a detailed review see (Berry et al., 2001). One in five Americans were reported to take over-the-counter (OTC) or non- 
prescribed prescription analgesics on a daily basis (American Pain Society, 2000). Nonprescribed analgesics are typically the first choice of pain relief (Gallup \& Organization, 1999).

\subsubsection{Common non-opioid analgesic compounds}

Non-opioid compounds such as NSAIDs act through inhibition of the enzyme cyclooxygenase-2 (COX-2) which blocks prostaglandin synthesis (Berry et al., 2001). The COX has two isoforms, COX-1 and COX-2; COX-1 has been shown to be expressed in most normal tissues while playing a critical role exclusively in the gastrointestinal (GI) tract, kidneys, and platelets primarily producing prostaglandins that help in the regulation of blood flow to the gastric mucosa and kidneys. Whereas COX-2 is induced in response to an inflammatory stimulus that results in the production of $\operatorname{COX}-2$ that in turn activates and sensitises nociceptors (Max et al., 1995; Pediatrics, 2001). Acetaminophen is an active compound included in most of the OTC and prescription medicines that relieve pain and acts through a central mechanism (FDA, 2014; Teoh \& Stjernsward, 1992).

In general, these NSAIDs possess anti-inflammatory, antipyretic, and analgesic effects. The analgesic effects are rapid, from minutes to hours, whereas the anti-inflammatory effect may last for 1-2 weeks or longer (Field \& Cassel, 1997). The anti-inflammatory effect indirectly relieves pain by reducing inflammatory swelling in the tissues. Non-opioids are used to alleviate a broad range of acute and chronic pain including trauma, postoperative, cancer and arthritis pain and they are particularly effective for somatic pain (Meghani, Byun, \& Gallagher, 2012; Schug \& Manopas, 2007). Acetaminophen and NSAIDs are often used to 
treat mild pain to moderate pain and are often co-administered with opioids to lower the opioid dose required to manage pain (Ortiz et al., 2012). Some of the limitations of NSAIDs and acetaminophen include gastrointestinal upset leading to ulcers and bleeding, liver damage and severe skin reactions (FDA, 2014).

\subsubsection{Opioids and their side-effects}

Opioids act on opioid receptors that are present in the spinal cord and brain which inhibit or reduce the intensity of pain-signal perception $(\mathrm{NIH}, 2016)$. Natural opioids are derived from the structural scaffold of opium, isolated from the opium poppy, Papaver somniferum. Opioids used for pain management widely include illicit heroin and other prescription pain medications such as oxycodone, hydrocodone, codeine, morphine, meperidine, tramadol, methadone and fentanyl (Dowell, Haegerich, \& Chou, 2016). Various opioid receptors regulate different actions of opioids namely mu (MOPr), delta (DOPr) and kappa (KOPr) opioid peptide receptors, respectively (Brownstein, 1993; Goldstein \& Naidu, 1989; B. L. Kieffer \& Evans, 2009).

MOPrs have been used to treat pain, cough, and diarrhoea for centuries where, in modern days, MOPr activating drugs have become common in treating severe acute pain and chronic pain, although they are often ineffective in treating chronic pain. A wide range of MOPr compounds includes morphine and morphine derivatives such as oxycodone, hydromorphone, oxymorphone, levorphanol, buprenorphine and, the fully synthetic opioids such as fentanyl, sufentanil, meperidine, and butorphanol and other semi-synthetic drugs including etorphine, meperidine, methadone and tramadol (Zöllner \& Schäfer, 2008). Although MOPr activating compounds are widely used drugs as 
powerful analgesics, they are also associated with undesirable adverse side-effects. For example, a phenomenon called hyperalgesia or an increased sensitivity to pain often occurs after chronic opioid treatment (Tumati et al., 2012). Mu-opioid analgesics also activate the reward pathway and cause euphoria that can lead to drug abuse and addiction (NIH, 2016). These drugs produce drowsiness, mental confusion, nausea, constipation, and respiratory depression in addition to inhibiting the pain signals. Furthermore, tolerance produced by chronic use of MOPr agonists necessitates the increase of dose rates to control pain (Freye \& Latasch, 2003). As a result, patients experience increased side-effects (Marderstein \& Delaney, 2008).

\subsubsection{Sedation}

Sedation is one of the commonly reported major side-effects produced by MOPr analgesics (Young-McCaughan \& Miaskowski, 2001). Opioid-induced sedative effects can be evaluated preclinically by measuring cognitive, motor coordination and performance impairments (Clemons, Regnard, \& Appleton, 1996). A study conducted in the United Kingdom in 2009 showed opioid medications have the second highest level of adverse effects in patients (Davies et al., 2009). This situation has changed over the years to $107 \%$ between 2012 - 2015 according to the Office for National Statistics for England and Wales (Middleton, McGrail, \& Stringer, 2016). The sedative effect of opioids is transient and is dose dependent, with increased sedation at higher doses (McNicol et al., 2003). Sedation due to MOPr agonist is reported to involve different neurotransmitter systems where sedation, in general, is reported to indirectly involve the dopaminergic system (Manzanedo, Aguilar, Rodríguez-Arias, \& Miñarro, 2005; Rodríguez-Arias, Broseta, 
Aguilar, \& Miñarro, 2000). Morphine dose-dependently caused sedation in mice, and this sedative effect was prevented by pretreatment with the dopamine (DA) - 1 (D-1) antagonist SCH 23390, or DA - 2 (D-2) antagonist sulpiride, or the non-specific opioid receptor antagonist naloxone (M.-R. Zarrindast \& Zarghi, 1992). Hence, dopaminergic transmission changes lead to the changes in the sedative effects produced by morphine. The interaction of drugs with the inhibitory $y$-aminobutyric acid (GABA) neurotransmitter system is also involved in the sedative activity. Morphine targets opioid receptors at GABAergic terminals and by inhibiting presynaptic glutamate release and blocking longterm potentiating of $\mathrm{GABA}_{\mathrm{A}}$-mediated synaptic transmission (Nugent, Penick, \& Kauer, 2007). Also, the augmentation of synaptic activity within the neocortex seems to contribute to sedation during analgesia (Bonin \& Orser, 2008). It was also evidenced that $\alpha_{2}$-adrenergic receptors ( $\left.\alpha_{2} A R s\right)$ in the central nervous system to be involved in sedation (Ruffolo Jr, Nichols, Stadel, \& Hieble, 1993). Several drugs have been used to treat opioid-induced sedation and methylphenidate is the most common medication indicated for opioid-induced sedation (Bruera, Chadwick, Brenneis, Hanson, \& MacDonald, 1987; Wilwerding et al., 1995). However, dextroamphetamine, donepezil, modafinil, and caffeine have also been studied for sedation treatment (Reissig \& Rybarczyk, 2005; Slatkin, Rhiner, \& Bolton, 2001; Webster, Andrews, \& Stoddard, 2003). In addition, opioid dose reduction, use of psychosomatic stimulants and opioid rotations (Ahmedzai, 1997) have also been suggested for treating opioid-induced sedation. Therefore, it is essential for us to evaluate the MOPr agonist, kurkinorin for its sedative effects to be used as a safe analgesic for which knowledge about MOPr induced sedation is mandatory. 


\subsubsection{Addiction}

Addiction to opioids results in adaptations and structural changes within the brain. Brain reward pathways are complex, and in general, neurons are found to respond to repeated natural exposures to rewarding stimuli including food and sexual activity (Contet, Kieffer, \& Befort, 2004; Koob \& Moal, 1997). In the case of opioid addiction, addiction occurs with initiation followed by maintenance of opioid consumption, withdrawal episodes, protracted abstinence and relapse (Ahmed, Kenny, Koob, \& Markou, 2002). Several neurotransmitter systems are involved in the rewarding pathways of which DA systems are the most critical (Bonci, Bernardi, Grillner, \& Mercuri, 2003). Furthermore, endogenous opioid systems are also found to play a central role in the mood modulation and physiology of well-being (Bonci et al., 2003). Particularly, MOPr's analgesic and addictive properties are well documented in mice. Mice lacking the MOPr receptors do not display analgesic or rewarding effects when administered MOPr activating drugs (Matthes et al., 1996) and has also been reviewed by Contet et al. (2004).

\subsubsection{Constipation}

In addition to addiction, constipation is another significant side effect resulting from MOPr activation. MOPrs are also located in the gut where they regulate motility (Herndon, Jackson, \& Hallin, 2002; Kurz \& Sessler, 2003). Often constipation is regarded trivial, dismissing the fact that long-term constipation can lead to serious consequences, require surgery and it impacts the quality of life adversely (reviewed by (Kumar, Barker, \& Emmanuel, 2014). Long-term constipation leads to haemorrhoid formation, rectal pain and burning, bowel obstruction, and possible bowel rupture and death (Koulousakis, Kuchta, 
Bayarassou, \& Sturm, 2007; Ruan, 2007). MOPr drug-induced constipation effects are mediated via both central as well as peripheral nervous systems, as opioids acts directly on the CNS and enteric nervous system (Mori et al., 2013; Shook, Pelton, Hruby, \& Burks, 1987; Sternini, 2001; Stewart, Weisbrodt, \& Burks, 1978; Tavani, Bianchi, Ferretti, \& Manara, 1980). Naloxone methiodide has been shown to suppress the inhibition of colorectal transit induced by morphine, oxycodone, and fentanyl (Mori et al., 2013). A range of alternative novel MOPr drugs are in development for reducing constipation effects including alvimopan and TD-1211 which are peripherally restricted MOPr antagonists, (reviewed by (Camilleri, 2011; DePriest \& Miller, 2014; Nelson \& Camilleri, 2015).

\subsubsection{Respiratory depression}

With all MOPr drugs, respiratory depression and death are the most feared complications. An extensive review of medical records over a period of eight years (2000-2008) reported an incidence of 3.6 per 10,000 adult patients succumbing to opioid-induced critical respiratory events (Ramachandran et al., 2011). These patients were said to have been rescued by naloxone and with endotracheal intubation, or cardiopulmonary resuscitation assistance. Respiration depression can be vulnerable during sleep and sedation because, the protective mechanisms are absent including wake mechanism and respiratory drive (Hudgel \& Devadatta, 1984; Hudgel, Martin, Johnson, \& Hill, 1984). Opioids have been recognised to work synergistically with these mechanisms and suppress the respiratory centres in the brain during sedation by blunting the chemoreceptor response to rising carbon dioxide, particularly in patients with sleep-disordered breathing (Bernards et al., 2009; Blake, Yew, Donnan, \& Williams, 2009; Choi et al., 2008; Mogri, Desai, Webster, Grant, \& Mador, 2009; Ramachandran et al., 2011; D. Wang et al., 2005). 


\subsubsection{Tolerance}

Tolerance is yet another major adverse consequence of repeated activation of MOPr's. Tolerance results in increasing the doses being administered to maintain analgesic effects over time (Collett, 1998; Chad E Groer et al., 2007; Kirsten M Raehal et al., 2011). Tolerance or dependence is a state that is exhibited by autonomic and somatic hyperactivity during withdrawal. A review by (Kirsten M Raehal et al., 2011) has summarised the mechanisms of actions of MOPr and has detailed how the extended use of MOPr agonists for analgesia may lead to tolerance. They stated that based on in vitro and in vivo studies, the degree of tolerance developed over long-term MOPr usage in vivo is inversely related to the ability of the opioid agonist to promote desensitisation and internalisation in vitro. The example being morphine that promotes very small levels of desensitisation and internalisation in vitro in cell cultures but produces a greater degree of tolerance in vivo in rodents compared to drugs like etorphine. Pharmacokinetic tolerance occurs due to alterations in the metabolism during repeated drug usage, including induction of a specific enzyme when the drug is administered, while pharmacodynamic tolerance is due to the decreased effectiveness of a drug over time, due to the down-regulation of the corresponding receptors. However, one particular opioid drug tolerance does not always initiate tolerance for another; for example in mice, NMDA receptor antagonists blocked the development of morphine tolerance while it was not the case with fentanyl and similar studies in humans have been performed (Athanasos et al., 2006). 


\subsubsection{The endogenous opioid system}

The widely studied innate pain-relieving system is the endogenous opioid system, which consists of neurons through which opioids mediate their action (Holden, Jeong, \& Forrest, 2005). The endogenous opioid system consists of four families of endogenous peptides which include enkephalins (possess great binding affinity for MOPr and DOPr), endorphins (selective for MOPr and DOPr), endomorphins (potent and highly selective agonists for $\mu$ Endomorphin-1 and endomorphin-2) and dynorphins (selective agonists for KOPr) that act upon the opioid receptors (Hughes, 1975). Table 1 shows the receptors and their corresponding endogenous peptides sources. The peptide families are derived from precursors such as proopiomelanocortin, proenkephalin, proendomorphin and prodynorphin (Przewłocki \& Przewłocka, 2001). Other receptors have also been cloned, which include orphan opioid-like receptor (ORL1) which has about 70\% sequence homology with the classical opioid receptors and the endogenous ligand called nociceptin or orphanin FQ that has an affinity for the ORL1 receptor (Meunier, 1997; Reinscheid et al., 1995). The non-selective opioid receptor agonist, naloxone has less affinity for the ORL1 receptor in the endogenous opioid system. In general, endomorphin-1 and endomorphin-2 produce antinociception the same as morphine, but they do not produce any adverse effects (Hackler, Zadina, Ge, \& Kastin, 1997; Horvath, 2000). 
Table 1: Endogenous opioid peptides and their affinity towards receptors

\begin{tabular}{|c|c|c|c|}
\hline Precursor & Peptides & $\begin{array}{l}\text { Affinity to } \\
\text { receptors }\end{array}$ & References \\
\hline \multirow[t]{2}{*}{ Proopiomelanocortin } & Endorphins & $\begin{array}{l}\text { MOPr and } \\
\text { DOPr }\end{array}$ & \multirow[t]{2}{*}{$\begin{array}{l}\text { Przewłocki and } \\
\text { Przewłocka (2001), } \\
\text { Hughes (1975) }\end{array}$} \\
\hline & $\beta$-endorphin & $\begin{array}{l}\text { MOPr and } \\
\text { DOPr }\end{array}$ & \\
\hline Proenkephalin, & $\begin{array}{l}\text { Enkephalins } \\
\text { Met-Enkephalin } \\
\text { Leu-Enkephalin- } \\
2\end{array}$ & $\begin{array}{l}\text { MOPr and } \\
\text { DOPr }\end{array}$ & $\begin{array}{l}\text { Przewłocki and } \\
\text { Przewłocka (2001), } \\
\text { Hughes (1975) }\end{array}$ \\
\hline Proendomorphin & $\begin{array}{l}\text { Endomorphins } \\
\text { Endomorphin-1 } \\
\text { Endomorphin-2 }\end{array}$ & MOPr & $\begin{array}{l}\text { Przewłocki and } \\
\text { Przewłocka (2001), } \\
\text { Hughes (1975) }\end{array}$ \\
\hline Prodynorphin & Dynorphins & $\mathrm{KOPr}$ & $\begin{array}{l}\text { Przewłocki and } \\
\text { Przewłocka (2001), } \\
\text { Hughes (1975) }\end{array}$ \\
\hline Pro-nociceptin & $\begin{array}{l}\text { Orphanin- } \\
\text { FQ/Nociceptin }\end{array}$ & ORL-receptors & $\begin{array}{l}\text { Meunier (1997); } \\
\text { Meunier et al. (1995) }\end{array}$ \\
\hline
\end{tabular}




\subsubsection{Opioid receptors}

The classical opioid receptors KOPr, DOPr and MOPr, are categorised based on ligand binding studies and biological assays, and all have varying analgesic properties (Raynor et al., 1994; Raynor et al., 1996). Physiologically, these three receptors contribute to the relief of various types of pain (Dhawan et al., 1996; Morley, 2000). However, the MOPr has a potent anti-nociceptive function with a greater degree of dependence, whereas the KOPr gives peripheral analgesic effects and the DOPr provides mild analgesic effects with less addiction (Bruijnzeel, 2009; Janecka, Fichna, \& Janecki, 2004; Lalanne, Ayranci, Kieffer, \& Lutz, 2014). Investigations were carried out to reveal the distribution, localisation and proportions of MOPr, DOPr, KOPr binding sites using autoradiography in laminae I and II (superficial layers). It was shown that the highest proportion of MOPr binding sites (approx. 70.4-74.3\%) were found in the dorsal horn of the rat spinal cord (Besse, Lombard, \& Besson, 1991; Gouardères, Cros, \& Quirion, 1985) which is a major nociceptive, somatosensory input receiving centre associated with nociceptive transmission (Coggeshall \& Carlton, 1997).

The MOPr is located in the cerebral cortex, amygdala, caudate putamen of the basal ganglia and the dorsal horn of the spinal cord (McDonald \& Lambert, 2005). The genes encoding opioid receptors were cloned and named Oprm1, Oprd1 and Oprk1 (Y. Chen, Mestek, Liu, Hurley, \& Yu, 1993; B. L. Kieffer, Befort, Gaveriaux-Ruff, \& Hirth, 1992; Minami et al., 1993). These opioid receptors belong to a superfamily of guanine proteincoupled receptors (GPCR) (Y. Chen et al., 1993). The receptors share approximately $60 \%$ identity with the intracellular loops, between $86-100 \%$ identity within the 
transmembrane domains and $73-76 \%$ identity in other regions. The extracellular loops, Cterminal and $\mathrm{N}$-terminal regions show great variability (Y. Chen et al., 1993).

\subsubsection{MOPr activation, signalling and regulation}

Activation of the MOPr mediates both desirable analgesic effects as well as side-effects, demonstrating that these side-effects are on-target (Porreca \& Ossipov, 2009; Zubieta et al., 2001). This section describes the MOPr signalling pathway, the studies conducted on MOPr agonists, their analgesic effects, side-effects, biased agonists, antagonists and efforts for developing safer drugs adequately as required. Figure 2 describes the MOPr signalling pathway. 


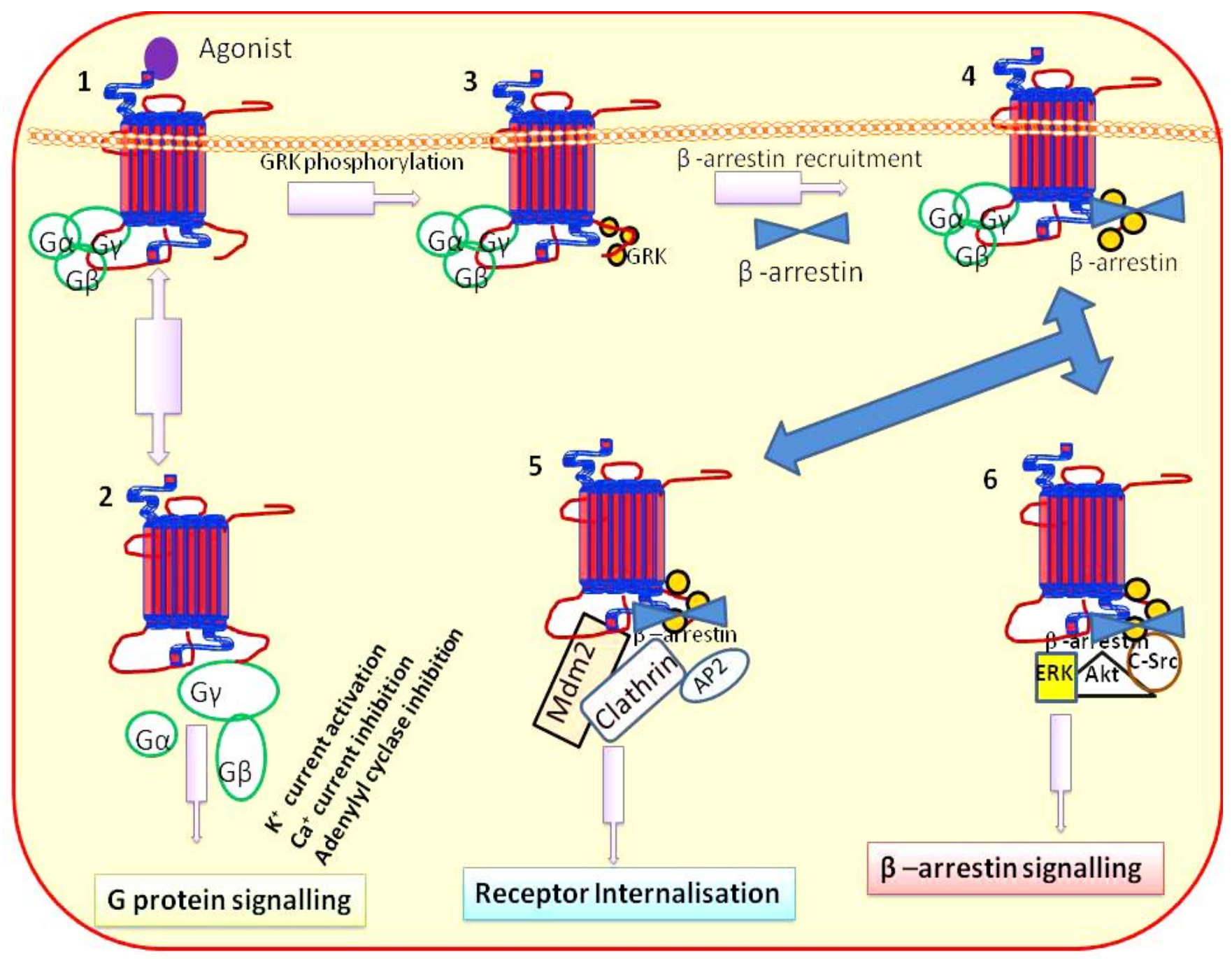

Figure 2: Mu opioid receptor signalling pathway

Figure 2 describes the MOPr signalling pathway. (1-2): describes the G-protein signalling, 1. An agonist is binding to the MOPr, which stabilises the conformation of the receptor, 2 . Dissociation of subunits takes place, and this modulates the potassium activation, calcium inhibition and adenylyl cyclase inhibition leading to downstream effector system activities producing secondary messengers including inositol; (3-6): describes the $\beta$-arrestin signalling, 3. Desensitisation - phosphorylation is brought about by messenger-dependent protein kinase $A$ or C or GPCR kinase (GRK), 4. There is subsequent $\beta$-arrestin recruitment, 5. Receptor internalisation and then the receptor bound $\beta$-arrestin interacts with an adaptor protein (AP2), clathrin and ubiquitinylation by E3 ubiquitin ligase Mdm2 and 6. Describes the $\beta$-arrestin signalling effectors including Src family tyrosine kinases, components of extra cellular regulated (ERK) 1/2 kinases and C-Jun-N-Terminal Kinase 3 (JNK3) and mitogenactivated protein kinase (MAPK) and Akt (serine/threonine kinases). Adapted and modified from Zoran Rankovic et al., (2016). 
MOPr agonists, bind to the receptor to elicit a range of ligand-directed signalling pathways. Agonist binding to the receptor causes conformational changes, and this dissociates Gprotein subunits ( $G \alpha$ subunit from the $G \beta \gamma$ subunits) (Rosenbaum, Rasmussen, \& Kobilka, 2009) and this, in turn, activates different effector systems, modulates potassium channels, inhibits voltage-gated calcium channels and activates secondary messenger systems (Pierce \& Lefkowitz, 2001). The inhibition of the adenylyl cyclase/cyclic adenosine monophosphate (CAMP) pathway is a well-studied opioid affected effector system (E. Kelly, 2013). In general, MOPr activates two signalling pathways including G-Protein mediated and $\beta-$ arrestin signalling pathways. As MOPr is a G-protein coupled receptor (GPCR) it couples with heterotrimeric G-proteins that are inhibitory where opioids activate the inhibitory Gi/oproteins, which then alters the intracellular signalling proteins and ion conductance (Deng et al., 2000; Chad E Groer et al., 2007; Schulz et al., 2004; Zhang et al., 1998). The receptor mediated events include phosphorylation, intracellular sorting, endocytosis of receptors and recycling (Bohm, Grady, \& Bunnett, 1997; Kohout \& Lefkowitz, 2003; Luttrell \& Lefkowitz, 2002; Kirsten M Raehal \& Bohn, 2005; Reiter \& Lefkowitz, 2006; Sternini, 2001). Figure 2 describes the MOPr signalling pathways in detail.

MOPr mediated analgesia, and rewarding properties were demonstrated in MOPr knockout mice where the analgesic and the rewarding properties of morphine were absent suggesting the MOPr mediated activity (Contet et al., 2004; Brigitte L Kieffer, 1999; Matthes et al., 1996). Coupling to G-proteins differ depending on the type of MOPr agonist, for example morphine, etorphine, fentanyl and methadone elicit different responses in receptor trafficking even though all of them promote MOPr coupling to G proteins (L. Bohn et al., 2004) and morphine-induced poor receptor internalisation compared to fentanyl and 
DAMGO (E Kelly, Bailey, \& Henderson, 2008; Shenoy \& Lefkowitz, 2005). The underlying reason for morphine's poor internalisation is due to negative MOPr ubiquitination by morphine (Laura M. Bohn et al., 2000). Ubiquitination is a post-translation modification that involves three enzymes: E1 (ubiquitin activating enzyme), E2 (ubiquitin conjugating enzyme), and E3 (ubiquitin ligase) (Joazeiro \& Hunter, 2000; Wojcik \& Di Napoli, 2004). Interactions between an E3 ligase and its target molecule are considered a key step in determining the selectivity of the ubiquitin-proteasome system (UPS). UPS is a major nonlysosomal proteolytic pathway that is important to degrade cellular proteins that play important roles in regulatory functions (Coux, Tanaka, \& Goldberg, 1996) for target molecules and its subsequent proteasomal degradation for internalisation or intracellular modulation. However, antinociceptive tolerance induced by chronic morphine is mediated by two processes, one being through the recruitment of $\beta$-arrestin2 and partially due to the central glutamatergic mechanism, an altered glutamate transporter expression (Mao, Price, \& Mayer, 1994; Sung, Lim, \& Mao, 2003; Thomson, Zeng, \& Terman, 2006). Glutamate transporters are crucial for physiological glutamate homoeostasis, neurotoxicity, and glutamatergic regulation of opioid tolerance (Mao, Sung, Ji, \& Lim, 2002).

The phosphorylation induces the $\beta$-arrestin recruitment which depends on the MOPr agonists action with the receptor (Luttrell \& Lefkowitz, 2002). $\beta$-arrestin2 potentially contributes to the regulation of MOPr and the MOPr agonists induced receptor signalling. This was demonstrated in mice lacking $\beta$-arrestin2 which showed decreased constipation and tolerance, respiratory suppression and enhanced antinociception following morphine treatment (Kirsten M Raehal, Walker, \& Bohn, 2005). The continuous MOPr agonists administration such as morphine-induced signalling leads to desensitisation and 
development of tolerance and dependence (Allouche, Noble, \& Marie, 2014; Kirsten M Raehal \& Bohn, 2005; Sim, Selley, Dworkin, \& Childers, 1996). Previous studies demonstrated that MOPr signalling without $\beta$-arrestin2 produced robust antinociceptive effects with diminished tolerance and other side-effects including respiratory depression and constipation as evidenced by the effects displayed in $\beta$-arrestin2 knockout mice (Kirsten M Raehal \& Bohn, 2005; K. M. Raehal \& Bohn, 2011). The posttranslational modification of $\beta$-arrestin (carried out by specific E3 ubiquitin ligases and reversed by deubiquitinases and these take place in a receptor- and agonist-specific manner (Kirsten M Raehal \& Bohn, 2005)) is important for internalisation during receptor trafficking and signalling which is linked to endocytosis (Shenoy \& Lefkowitz, 2005). $\beta$-arrestin may also play a role in the GPCRs and the intracellular signalling proteins such as non-receptor tyrosine kinase, c-Src extracellular signal-regulated kinases (ERK) and c-Jun N-terminal kinase (JNK) (Review by (Kirsten M Raehal \& Bohn, 2005). The JNK signalling was also shown to be involved in analgesic tolerance. For example, morphine's tolerance was diminished by the inhibition of JNK signalling (Melief, Miyatake, Bruchas, \& Chavkin, 2010) but failed to prevent the tolerance to fentanyl using GRK3 knock-out mice as fentanyl produced more GRK3 dependent effects than morphine (Terman et al., 2004).

Finally, it is concluded that MOPr agonists that modulate recruitment of $\beta$-arrestins differently in addition to modulation of downstream signalling pathways may explain in time the variety of effects seen with different MOPr agonists (Lefkowitz \& Shenoy, 2005). MOPr agonists that do not induce receptor internalisation may be a potential molecular target for the better analgesia (Berger \& Whistler, 2010). In vivo studies demonstrated that morphine recruits $\beta$-arrestin2 whereas fentanyl and methadone recruit both $\beta$ - 
arrestin1 and 2 pathways. Therefore considering the facts about $\beta$-arrestin recruitment and the significant side-effects, it is very crucial to design a MOPr agonist that retains robust antinociceptive effect with the diminished rewarding and side-effects.

\subsubsection{Functional selectivity or biased agonism}

The ability of any ligand to differentially modulate selective downstream pathways in a unique pattern is termed as ligand bias or functional selectivity (Kenakin, 1995). To date, several GPCRs have been reported to exhibit functional selectivity, some of them include $\beta_{1}$ and $\beta_{2}$ adrenergic receptors (Kim et al., 2008; James W. Wisler et al., 2007), $D_{2}$ subtype of the dopamine receptor (Park et al., 2016), $\beta 2$ adrenergic receptor (Shenoy et al., 2006), and serotonin 2A receptor (5HT2AR) (Schmid, Raehal, \& Bohn, 2008). However, it is relevant to discuss MOPr biased agonists as relevant for our study. If an agonist is biased towards a certain pathway, in this instance, G-protein biased signalling pathway, the agonist binds to MOPr and couples to the G-proteins, which modulate a cascade of downstream reactions. This includes reactions in adenylyl cyclase (CAMP) inhibition, ion channels, and signal cascades such as mitogen-activated protein kinases (MAPK). The $\beta$-arrestin pathway is activated along with GPCR pathway by drugs like morphine leading to several downstream mechanisms such as phosphorylation by GRKs or PKC, $\beta$-arrestin binding, receptor desensitization, internalization, down-regulation, and resensitization as discussed above in Figure 2 (reviewed by (Ferguson, 2001; Kirsten M Raehal et al., 2011)). $\beta$ arrestins play a significant role in mediating the receptor trafficking (Luttrell \& Lefkowitz, 2002; Kirsten M Raehal \& Bohn, 2005). The pathways are activated depending on the selectivity of the agonist towards those pathways, and downstream reactions are determined to further 
down the process. Thus, the functional selectivity of ligands can be either $G$ proteinmediated dependent signalling (example: herkinorin, oliceridine/TRV-130 and PZM21) or independent through $\beta$ arrestin-mediated signalling (DAMGO) or both (morphine). This concept has been widely accepted, and this has revolutionised the development of selective and biased agonist for pain, particularly those that can target GPCRs as exemplified above in this section (elaborately reviewed by Pradhan, Smith, Kieffer, and Evans (2012). Recently, the first MOPr biased ligand was developed from Salvinorin A known as herkinorin, which is discussed further in the following section.

\subsection{Strategies for developing safer, more effective MOPr agonists for treating pain}

Salvinorin A, isolated from the sage plant Salvia divinorum is a potent and selective KOPr agonist (T. E. Prisinzano, 2005; T. E. Prisinzano, Tidgewell, \& Harding, 2005; Roth et al., 2002; Yan \& Roth, 2004). Sal A is unique as it was the first natural compound to activate opioid receptors that did not contain a basic nitrogen atom where a basic nitrogen was previously believed to be essential for opioid receptor binding. Our research group has collaborative access to this structurally unique class of opioid. Sal A is a selective and potent KOPr agonist and the unique structure of salvinorin A has been utilised as a novel template for developing semi-synthetic opioid analogues with varying selectivity and potency targeted at opioid receptors (Thomas E Prisinzano \& Rothman, 2008). 


\subsubsection{Herkinorin: a peripherally restricted MOPr agonist from Sal A}

Herkinorin was the first MOPr selective ligand developed based on the Sal A structure (Harding et al., 2005). Herkinorin has 4 fold selectivity for MOPr over KOPr and approximately 98 fold selectivity for MOPr over DOPr receptors in in vitro assays using $\left[{ }^{125} \mathrm{I}\right] \mathrm{IOXY}$ as Radioligand and $\left.\left[{ }^{35} \mathrm{~S}\right] \mathrm{GTP}\right\} \mathrm{S}$ Functional assays (Lamb, Tidgewell, Simpson, Bohn, \& Prisinzano, 2012) . Herkinorin does not induce robust phosphorylation of the MOPr in Human Embryonic Kidney 293 cells (HEK293) stably expressing MOPr or induce receptor internalisation (Chad E Groer et al., 2007). Using HEK-293 cells transiently expressing $\beta$-arrestin2 and MOPr showed reduced $\beta$-arrestin2 recruitment. Confirming that herkinorin is a G - protein biased MOPr agonist (Chad E Groer et al., 2007). Activation of $\beta$-arrestin2, as mentioned above in section 1.4.3, plays a crucial role in the development of side-effects including tolerance, respiratory depression and constipation (Kirsten M Raehal et al., 2005) and is, therefore, important in the development of safe and effective analgesic pharmacotherapies.

The binding affinity, potency and the bias factor of the MOPr are described in Table $2 \& 3$. Figure 3 represents the development and chemical structures of the Sal A, herkinorin and kurkinorin. 


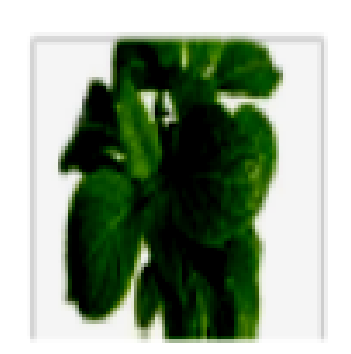

Salvia divinorum

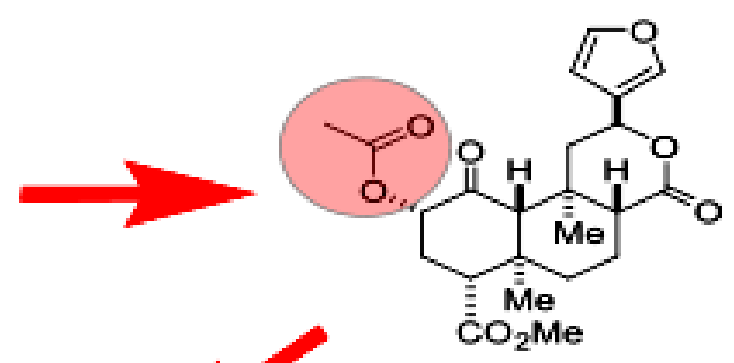

Salvinorin A

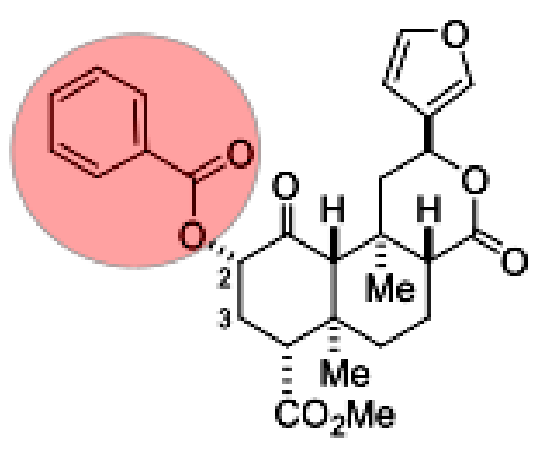

Herkinorin
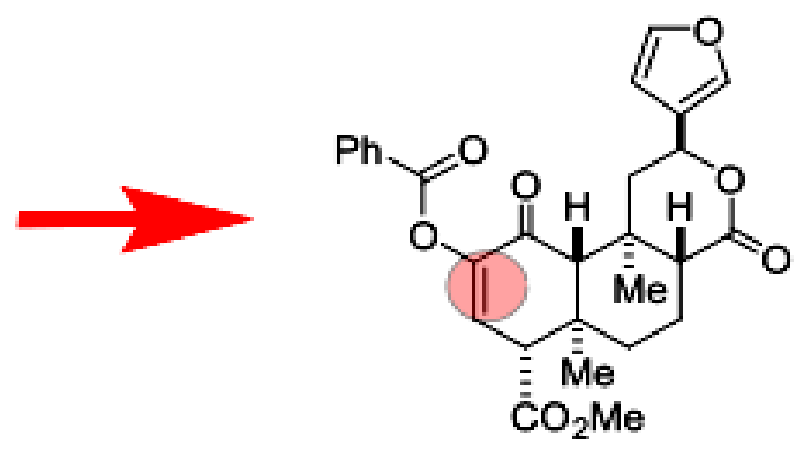

Kurkinorin<smiles>CN1CC[C@]23c4c5ccc(O)c4O[C@H]2[C@@H](O)C=C[C@H]3[C@H]1C5</smiles>

Morphine

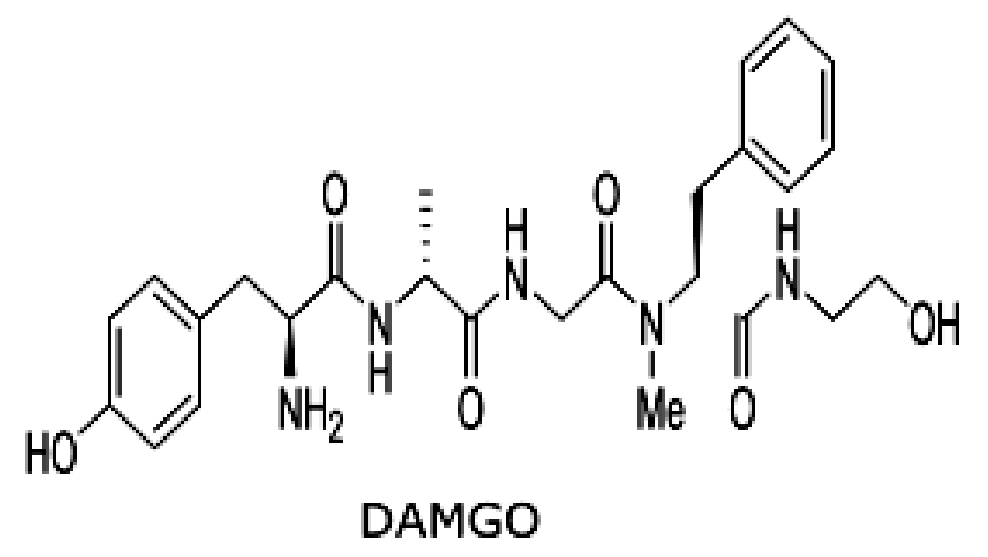

Figure 3: Chemical structure of herkinorin, kurkinorin, Salvinorin A, morphine and DAMGO 
Table 2: The binding affinity and potency of the mu-opioid agonists^

\begin{tabular}{|c|c|c|c|c|c|c|}
\hline \multirow[b]{2}{*}{ Compound } & \multicolumn{3}{|c|}{ Binding affinity $\mathrm{EC}_{50} \pm \mathrm{SD}^{a, b}(\mathrm{nM})$} & \multicolumn{2}{|l|}{ Selectivity } & \multirow[t]{2}{*}{ References } \\
\hline & MOPr & $\mathrm{KOPr}$ & DOPr & KOPr/MOPr & $\mathrm{DOPr} / \mathrm{MOPr}$ & \\
\hline DAMGO & $0.60 \pm 0.4$ & $>10000^{c}$ & ----- & $>16000$ & & (Crowley et al., 2016) \\
\hline Morphine & $5.0 \pm 3$ & $330 \pm 200$ & $780 \pm 150^{e}$ & 66 & 150 & (Crowley et al., 2016) \\
\hline \multirow{3}{*}{ Herkinorin } & $40 \pm 10$ & $170 \pm 70^{d}$ & $>10000^{c}$ & 4.25 & 250 & (Crowley et al., 2016) \\
\hline & $12 \pm 1^{1}$ & $90 \pm 2^{1}$ & $1170 \pm 60^{1}$ & $\mathrm{MOPr} / \mathrm{KOPr}^{1}: 0.13$ & $\mathrm{DOPr} / \mathrm{KOPr}^{1}: 12$ & $\begin{array}{l}\text { Harding et al. (2005); Kevin } \\
\text { Tidgewell et al. (2008) }\end{array}$ \\
\hline & $500 \pm 140^{2}$ & $1320 \pm 150$ & - & $\mu \mathrm{Emax} \pm \mathrm{SD}^{\mathrm{a}}: 130 \pm 4$ & KEmax $\pm S D: 140 \pm 2$ & Kevin Tidgewell et al. (2008) \\
\hline Kurkinorin & $1.2 \pm 0.6$ & $>10000^{c}$ & $74 \pm 10$ & $>8000$ & 63 & (Crowley et al., 2016) \\
\hline
\end{tabular}

${ }^{a}$ Mean \pm standard deviation; ${ }^{b} E_{\max }=100 \% ;{ }^{c} E_{\max }=0 \%$ up to $10 \mu \mathrm{M} .{ }^{d} \mathrm{E}_{\max }=64 \pm 18 \%$. ${ }^{\mathrm{e}} \mathrm{Emax}=90 \pm 2 \%$. ${ }^{1}$ Binding affinities using $\left[{ }^{125} \mathrm{I}\right] \mathrm{IOXY}$ as radioligand. ${ }^{2}$ using $\left[{ }^{35} \mathrm{~S}\right] \mathrm{GTP}$ S functional assay. ${ }^{\wedge}$ The binding affinity and potency of the opioid Inhibition of forskolin-induced cAMP accumulation 
Table 3: Potency, efficacy, and bias of mu opioid agonists in the $\beta$-arrestin recruitment

\begin{tabular}{|c|c|c|c|c|l|}
\hline Compound & $\begin{array}{c}\mathrm{EC}_{50} \pm \\
\mathrm{SEM}^{1} \\
\text { (nM) } \\
\text { Potency }\end{array}$ & $\begin{array}{c}\% \\
\text { Efficacy } \\
\pm \text { SEM }^{2}\end{array}$ & $\begin{array}{c}\text { Bias } \\
\text { Factor }\end{array}$ & $\begin{array}{c}\text { Selectivity } \\
\text { MOPr/KOPr }\end{array}$ & Reference \\
\hline DAMGO & $42 \pm 5$ & $97 \pm 0.9$ & 1.0 & $>16,000$ & $\begin{array}{l}\text { (Crowley } \\
\text { et al., } \\
\text { 2016) }\end{array}$ \\
\hline Morphine & $380 \pm 40$ & $38 \pm 1$ & 0.36 & 38 & $\begin{array}{l}\text { (Crowley } \\
\text { et al., } \\
\text { 2016) }\end{array}$ \\
\hline Herkinorin & $3400 \pm$ & $72 \pm 3$ & 0.95 & 4.4 & $\begin{array}{l}\text { (Crowley } \\
\text { et al., } \\
2016)\end{array}$ \\
\hline Kurkinorin & $140 \pm 40$ & $96 \pm 3$ & 0.57 & $>8000$ & $\begin{array}{l}\text { (Crowley } \\
\text { et al., } \\
\text { 2016) }\end{array}$ \\
\hline
\end{tabular}

${ }^{1}$ Mean \pm SD of the mean; ${ }^{2}$ Maximum efficacy values calculated based on DAMGO maximum stimulation. Values $<1$ indicate a bias towards the G-protein pathway and values $>1$ indicate a bias towards the $\beta$-arrestin2 pathway. The reference drug was DAMGO. 
Since herkinorin activates G-protein coupling pathway and does not significantly recruit $\beta$-arrestin (Chad E Groer et al., 2007), it is classified as a G-protein biased agonist. Further, to assess the herkinorin agonist activity, the phosphorylation of the downstream MAP kinases (ERK1/ERK2) has been used as an indicator of receptor activation (Chad E Groer et al., 2007). Chad E Groer et al. (2007) showed that herkinorin dose-dependently phosphorylated the MAP kinases ERK1/ERK2 in an opioid receptor antagonist naloxonereversible manner and did not involve $\beta$-arrestin2 signalling. In cellular assays, however, both chronic treatment with the GPCR biased MOPr agonist herkinorin (10 $\mu \mathrm{M})$ (noninternalizing) and non-biased MOPr agonist DAMGO (10 $\mu \mathrm{M})$ (internalizing) produced tolerance, dependence and receptor desensitization of Chinese Hamster Ovary (CHO) cells expressing hMOR in: (1) assays evaluating $\left[{ }^{35} \mathrm{~S}\right]-\mathrm{GTP}-\gamma-\mathrm{S}$ binding and (2) in assays evaluating attenuation of cyclic AMP. This, in turn, suggested that these effects were related to an increased activity of adenylyl cyclase with herkinorin (H. Xu et al., 2007). The first in vivo study evaluating herkinorin in non-human primates (rhesus monkeys) measured prolactin release, a neuroendocrine biomarker assay (Butelman et al., 2008) and revealed that herkinorin has limited ability to induce prolactin release, indicating that it acted only outside of the blood-brain barrier (Butelman et al., 2008).

The preliminary investigation of the antinociceptive effects of herkinorin $(10 \mathrm{mg} / \mathrm{kg}$, intraplantar, i.pl) in rats used the $1.25 \%$ intra-dermal formalin test to evaluate nociceptive, and inflammatory pain and the effects were compared to morphine (Lamb et al., 2012) . Lamb et al. (2012) has concluded that herkinorin produced less tolerance and maintained antinociceptive effects in the morphine-treated rats and that these 
effects may be due to KOPr and MOPr interactions as herkinorin also has KOPr affinity. The systemic administration of herkinorin did not produce any antinociceptive effects in rats and mice (Chad E Groer et al., 2007). Hence, the lack of selectivity and potency of herkinorin, poor metabolism and pharmacokinetic properties despite decreased tolerance, limits its therapeutic development.

\subsubsection{Current MOPr agonists under investigation}

As a result of an advanced understanding of biased agonism, a variety of novel MOPr agonists has been investigated for their analgesic and other associated side-effects. Oliceridine or TRV-130 is a G-protein biased agonist (DeWire et al., 2013) with reduced CNS depression and gastrointestinal dysfunction compared to morphine. Another compound, mitragynine pseudoindoxyl found in the natural plant product Mitragyna speciosa is also a G- protein biased MOPr agonist with some KOPr and DOPr antagonist properties. It has been shown to reduce recruitment of $\beta$-arrestin2. While producing antinociceptive effects in the rat using tail flick and hot-plate assays, it showed reduced tolerance, less respiratory depression, constipation and reward compared to morphine (Váradi et al., 2016). Therefore, G-protein biased MOPr agonists hold promise for the development of analgesics with reduced side-effects.

\subsubsection{Kurkinorin: a novel selective MOPr agonist derived from Sal A}

It is prudent to develop a more potent and selective MOPr agonist with enhanced antinociceptive effects (GPCR biased signalling) with reduced side-effects. An analogue of Sal A, kurkinorin has been designed and synthesised by T. E. Prisinzano and his group 
(Crowley et al., 2016). Kurkinorin was developed by introducing an additional degree of unsaturation between carbon 2 and carbon 3. Structure-activity relationship studies revealed that kurkinorin was extremely selective and potent activator of MOPrs with no activity at KOPrs (>8000 MOPr/KOPr). Kurkinorin is a G-protein biased MOPr agonist and recruits $\beta$-arrestin2 to a very minimal extent than herkinorin (Crowley et al., 2016). The binding affinities, potency, and biased factor for MOPr agonists such as kurkinorin, herkinorin, morphine and DAMGO are shown in Table $3 \& 4$. However, no prior in vivo study has been conducted with kurkinorin. Therefore, our aim was to evaluate kurkinorin in comparison to herkinorin and morphine for behavioural analgesic effects and side-effects.

\subsection{Preclinical models for evaluating analgesia}

No one behavioural test is sufficient to evaluate pain pre-clinically. Hence, multiple animal models are utilised to screen analgesic compounds. In this section, nociceptive pain and inflammatory pain models evaluated in this study are discussed.

\subsubsection{Assessment of thermal nociceptive pain models}

In the acute thermal pain model, thermal stimuli $\left(50-55^{\circ} \mathrm{C}\right)$ via light, hot-plate or warm water and the time taken to withdrawal from the heat sources are measured. In the warm-water tail-withdrawal assay, the response is mediated by spinal reflex, whereas in the hot-plate assay, the response is mediated via a supraspinal reflex (Grossman, Basbaum, \& Fields, 1982; Hayes, Bennett, Newlon, \& Mayer, 1978). 
In the tail-withdrawal assay, the spinal reflex is established by the rapid tail-withdrawal from the heat source. The warm water tail-withdrawal assay is a very useful preclinical model for screening analgesic drugs as the response is short, transient, fast, it allows multiple measurements. However, for performing behavioural, pharmacological evaluation and time-courses effects, additional tests are needed to study the tonic pain modulation in the central nervous system (Tjølsen et al., 1992). Furthermore, the combination of several tests is important in determining the potential antinociceptive properties of novel drugs.

Several compounds and substances which induce inflammation and hyperalgesia have been studied to understand the peripheral pain responses including the intra-dermal injections of, carrageenan, capsaicin or formalin and complete Freund's adjuvant (CFA) (Kwak, Jung, Hwang, Lee, \& Oh, 1998). Each compound has a unique mechanism to produce inflammation and hyperalgesia. Responses produced by formalin have two phases, which can be easily distinguished (Calvino, 1990; Dubuisson \& Dennis, 1978; Wheeler-Aceto \& Cowan, 1991). Phase I lasts up to $10 \mathrm{~min}$ immediately after the injection of formalin due to sensory neuron excitability (pain fibres- sensory C fibres) whereas the Phase II starts at $15-20$ min and lasts for at least $60 \mathrm{~min}$. Phase II is a result of inflammation mediated by central sensitization and increased spinal cord neuronal sensitivity (Dickenson \& Sullivan, 1987; Hunskaar \& Hole, 1987; Shibata, Ohkubo, Takahashi, \& Inoki, 1989). The manifestation of the phase I pain response is caused by the involvement of substance $\mathrm{P}$ and bradykinin whereas the phase II pain response is caused by histamine, serotonin, prostaglandin and bradykinin (Otuki et al., 2001; A. Santos \& J. Calixto, 1997; A. R. Santos \& J. B. Calixto, 1997). The nociceptive response to 
formalin is concentration dependent; $5.0 \%$ formalin produces strong, constant and increasingly long-lasting flinch response compared to lower doses (Abbott et al., 1995; Aloisi, Albonetti, \& Carli, 1995; Clavelou, Dallel, Orliaguet, Woda, \& Raboisson, 1995; Yaksh et al., 2001). Low formalin concentrations (0.02-0.2\%) induce only phase I pain responses (Rosland, Tjølsen, Mæhle, \& Hole, 1990; Sakurada et al., 1993), whereas concentrations of $1 \%$ or greater triggers both phase I and phase II pain responses (Luccarini, Childeric, Gaydier, Voisin, \& Dallel, 2006; Rosland et al., 1990). A study by Luccarini et al. (2006) showed that the maximum effects were seen with $2.5 \%$ formalin (Yaksh et al., 2001). Morphine's dose-dependent and formalin's concentrationdependant biphasic responses in the intra-dermal formalin assay are well documented (Hajhashemi, Ghannadi, \& Jafarabadi, 2004; Hosseinzadeh \& Younesi, 2002; Khan, Saeed, Khan, Dar, \& Khan, 2010; Monsef, Ghobadi, Iranshahi, \& Abdollahi, 2004; Pang, Tsang, \& Yang, 2001; Sayyah, Saroukhani, Peirovi, \& Kamalinejad, 2003; Shannon, Eberle, \& Peters, 2005). Collectively, the intra-dermal formalin test along with tail-withdrawal assay are robust pre-clinical assays to evaluate the antinociceptive properties of novel drugs.

\subsubsection{Assays for evaluating Side-effect profile}

\subsubsection{Reward evaluated in Conditioned Place Preference test}

Conditioned Place Preference (CPP) is a commonly used preclinical model that evaluates the rewarding properties of a drug.

In this procedure, rats are placed in an environment with different tactile, olfactory or visual cues in association with a drug-paired environment (Perks \& Clifton, 1997; Spyraki, Nomikos, \& Varonos, 1987). Several conditioning sessions are required so that the rats 
form an association with the distinct environment cues during the drugged state and their subjective effects. Drug injected rats spend more time in the paired compartment if the drug has significant, rewarding effects (Schechter \& Calcagnetti, 1993; Tzschentke, 1998). Nonetheless, yet another study showed that drugs such as cocaine, morphine, heroin and amphetamine induce CPP after several conditioning processes in the drugpaired sides (Carr, Phillips, \& Fibiger, 1988). CPP method is much easier to adopt than other procedures to study the rewarding effect such as drug self-administration procedures (Bozarth, 1987).

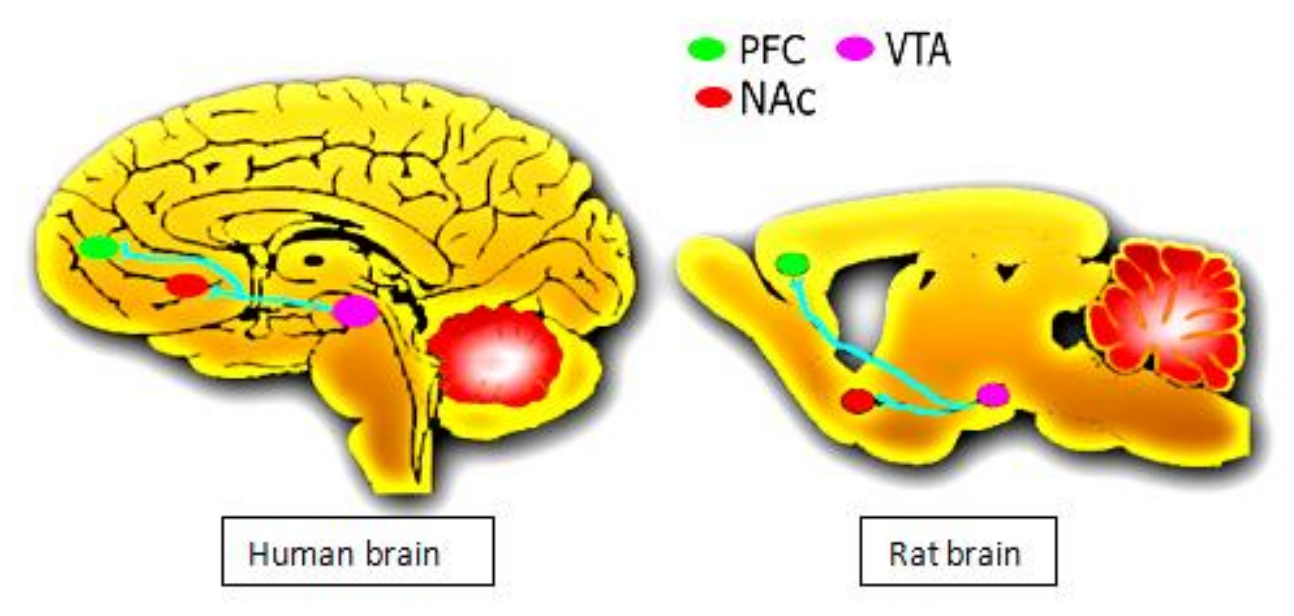

Figure 4: The areas of the brain contributed in reward pathway.

The mesolimbic and mesocortical dopaminergic projections of the ventral tegmental area (VTA) in the reward pathway. The projections from VTA to the nucleus accumbens (NAc) region lead to mesolimbic pathway whereas the projections from VTA to the prefrontal cortex (PFC) lead to the mesocortical pathway.

$\mathrm{NAC}=$ nucleus accumbens, $\mathrm{PFC}=$ prefrontal cortex, $\mathrm{VTA}=$ ventral tegmental area

In general, the majority of the drugs produce CPP through mesolimbic DA system thereby releasing DA from the mesolimbic dopamine neurons. Figure 4 represents the different areas of the brain involved in rewarding effects. 
Previous studies evidenced that the involvement of DA during opioids treatment causes positive reinforcement of rewarding effects (Fields \& Margolis, 2015; Salamone \& Correa, 2012). For example, the opioid drugs such as morphine produces rewarding effects mediated by MOPr when injected into ventral tegmental area (VTA), the nucleus accumbens (NAc), periaqueductal gray (PAG), hippocampus and into systemic circulation (Corrigall \& Linseman, 1988; Jaeger \& van der Kooy, 1996; Olds, 1982; Olmstead \& Franklin, 1997; Rezayof, Zarrindast, Sahraei, \& Haeri-Rohani, 2003; Tzschentke \& Schmidt, 1995; M.-R. Zarrindast, Farajzadeh, Rostami, Rezayof, \& Nourjah, 2005; M.-R. Zarrindast, Rezayof, Sahraei, Haeri-Rohani, \& Rassouli, 2003). This occurs due to the release of DA released into the nucleus accumbens, and it reduces the release of gammaaminobutyric acid (GABA) by the disinhibitory effect on dopaminergic neurons in VTA (Johnson \& North, 1992; Rainer Spanagel, Albert Herz, \& Toni S Shippenberg, 1992). DA's role in CPP is described in a previous study where intra-VTA injections of morphineinduced CPP and a subsequent injection of a DA antagonist, haloperidol blocked the CPP activity (Shippenberg, Bals-Kubik, \& Herz, 1993). The release of DA is dependent on the dose of morphine where injection of morphine directly into VTA produces a dosedependent increase of a CPP through increased level of DA in NAc (Bals-Kubik, Ableitner, Herz, \& Shippenberg, 1993; Latimer, Duffy, \& Kalivas, 1987; Shoaib, Spanagel, Stohr, \& Shippenberg, 1995; R. Spanagel, A. Herz, \& T. S. Shippenberg, 1992). The serotonincontaining neurons present in the NAc are contributing factors for the CPP produced by morphine in a different way (Spyraki, Nomikos, Galanopoulou, \& Daïfotis, 1988). The $\mathrm{GABA}_{B}$ receptor agonist (for example baclofen) activates the VTA GABA receptors, and in turn, it blocks morphine-induced CPP (Tsuji et al., 1996). Therefore, opioid drugs have a 
negative impact on GABA by inhibiting the VTA GABAergic interneurons and disinhibiting VTA DA neurons. This results in an increase of Nac DA release (Xi \& Stein, 1998) and subsequent side effects.

Self-administration is an alternative method for assessing the rewarding property of drugs. Even though CPP and self-administration are equally sensitive to study the drugs of abuse property, the methods and the procedures are different. Self-administration requires extensive training and time including a pre-determined class of response such as lever press and surgical implantation of the catheter for the intravenous administration and the repeated drug infusions to establish the learning behaviour. Hence, we have chosen the CPP to study the subjective and affective effects of Kurkinorin.

\subsubsection{Sedation assessment models}

In humans, the Richmond Agitation-Sedation Scale (RASS) a questionnaire that measures arousal, intellectual ability, agitation, alertness and in turn the calmness, drowsiness, restlessness, cognition and sustainability of responses following drug administration, such as morphine (Patel \& Kress, 2012; Sessler et al., 2002) is used to assess the patients' mental stability after morphine injection. Likewise in animals, the rotarod performance assay is widely used to measure the effects of opioids and other drugs on motor co-ordination and motor ability (the role of MOPrs on DA that has a link with motor coordination is discussed in section 1.3.3.1) (Romero, Miranda, \& Puig, 2010; Stone, German, Kitto, Fairbanks, \& Wilcox, 2014). 


\subsubsection{Assessing core body temperature}

Administration of centrally acting MOPr agonists decreases the core-body temperature or causes hypothermia in mice (A. Baker \& Meert, 2003; A. K. Baker \& Meert, 2002; Rosow, Miller, Pelikan, \& Cochin, 1980; Trulson \& Arasteh, 1985; M.-R. Zarrindast \& Zarghi, 1992). Furthermore, hypothermia has been documented in morphine and fentanyl administration. The hypothermia produced by these two compounds were reversed by the non-specific opioid antagonist naloxone (Adler, Geller, Rosow, \& Cochin, 1988; A. Baker \& Meert, 2003). The core body temperature is maintained by the monoaminergic neurotransmitter systems that include dopaminergic neurotransmitters and opioids are known to alter DA release inducing hypothermia (Adler et al., 1988; Bligh, 1979; M. R. Zarrindast \& Tabatabai, 1992). DA blockade impairs heat balance, metabolic rate, and exercise performance in rats (Balthazar, Leite, Ribeiro, Soares, \& Coimbra, 2010). Cold and warm receptors are found in various parts of the body, and the signals from cold receptors pass on to the A-delta fibre nociceptors whereas the warm receptors traverse through $C$ fibre nociceptors. The impulses are integrated into the spinal cord and then transferred to the hypothalamus (Kurz, 2008; Satinoff, 1978) as hypothalamus is the controller of thermoregulation (Kurz, 2008). Exceeding warm and cold temperature triggers the thermoregulatory response, and it is prudent to include this test in our study as opioids impair body temperature. Hence, the body temperature has been measured using rectal probe before and after administering opioids to know whether the drug produces hyperthermia or hypothermia. With this introduction, the following section discusses the research hypothesis, aims and objectives. 


\subsection{Research hypothesis}

Kurkinorin is a potent and selective MOPr agonist derived from the novel structural scaffold of Salvinorin A. We hypothesise that kurkinorin may possess bias signalling and exhibit analgesic effects with reduced side-effects. Therefore, we aim to evaluate kurkinorin in preclinical studies.

\section{Aims and objectives}

This thesis aims to evaluate the pre-clinical analgesic effects of kurkinorin, in comparison to morphine and investigate the side-effects of sedation, reward and core body temperature.

To measure the analgesic activity, we utilised the warm water tail-withdrawal assay for evaluating acute thermal pain and the $2 \%$ intra-dermal formalin assay of inflammatory pain in mice.

To evaluate sedation, we used the accelerating rotarod assay in mice and to evaluate the rewarding effects of kurkinorin we used the CPP assay in rats. 


\section{Methods}

\subsection{Subjects}

Adult male B6-SJL protein tyrosine phosphatase receptor type c allele a (ptprca) mice (22-30 g) and Male Sprague-Dawley rats (Rattus norvegicus) (250 - $360 \mathrm{~g}$ ) were bred and housed within the School of Biological Sciences Animal Facility Unit, Victoria University of Wellington. Animals were housed in temperature-controlled rooms $\left(19-21^{\circ} \mathrm{C}\right)$ at $55 \%$ relative humidity with a $12 \mathrm{hr}$ light: dark cycle with the light cycle starting at 0700 hours Food (Diet 86, Sharpes Stock Feed) and water was available ad libitum, except during testing. All experiments were carried out in the presence of white noise and were approved by the Victoria University of Wellington Animal Ethics Committee (Ethics Approval AEC 2012-R34).

\subsection{Chemicals and reagents}

Herkinorin and kurkinorin were kindly provided by Prof. T. Prisinzano, (University of Kansas, Lawrence, KS). Sal A was extracted and purified from the leaves of plant Salvia divinorum according to previously described procedures (Butelman et al., 2008). All analogues were tested for purity using High-Performance Liquid Chromatography (HPLC) and were >95\% pure. The synthesis of herkinorin (2S,4aR,6aR,7R,9S,10aS,10bR)-9-(benzoyloxy)-2-(3furanyl)dodecahydro-6a,10b-dimethyl-4,10-dioxo-2H-naphtho-[2,1-c]pyran-7-carboxylic acid methyl ester) has been described previously (Harding et al., 2005). Kurkinorin (2S,4aR,6aR,7R,10aR,10bR)-Methyl-9-(chlorobenzoyl)oxy)-2-(furan-3-yl)-6a,10b-dimethyl- 
4,10-dioxo-2,4,4a,5,6,6a,7,10,10a,10b-decahydro-1H-benzo[f]isochromene-7-carboxylate) was synthesized from herkinorin $\left(\Delta^{2,3}-\right.$ a double bond in the 2, 3 position of herkinorin) (REF). All compounds were stored at $4^{\circ} \mathrm{C}$ in the dark.

For tail-withdrawal, formalin, core body temperature and paw oedema experiments in mice, fresh herkinorin and kurkinorin solutions were prepared daily and dissolved in a vehicle of dimethyl sulfoxide (DMSO) (Sigma-Aldrich, St. Louis, MO), Tween 80 (Sigma-Aldrich, St. Louis, MO) and sterile milliQ water in a ratio of 2:1:7. They were weighed and dissolved in DMSO before adding Tween 80 followed by sterile MiliQ water. Saline was used instead of milliQ water for accelerating rotarod experiment in mice. All MOPr agonists were administered via intraperitoneal (i.p.) injection. The non-specific opioid receptor antagonist naloxone hydrochloride (MP Biomedicals, NZ) $(\mathrm{mg} / \mathrm{kg}$ ) was dissolved in $0.9 \%$ saline and delivered via subcutaneous (s.c.) injection 45 min before MOPr agonist treatment.

Experiments evaluating reward (CPP assay) was performed in rats. Herkinorin and kurkinorin ( $5 \mathrm{mg} / \mathrm{kg}$ i.p) were dissolved in a vehicle consisting of 25\% DMSO: $75 \%$ Polyethylene Glycol (PEG) (Sigma-Aldrich, St. Louis, MO) in a volume of $1 \mathrm{~mL} / \mathrm{kg}$. Morphine hydrochloride was pre-prepared in $0.9 \%$ Saline (New Zealand Ltd., NZ). Therefore, to accommodate this vehicle, morphine-treated rats also received vehicle (25\% DMSO:75\% PEG, i.p.). Whereas vehicle-treated rats were injected with both vehicles (25\% DMSO:75\% PEG, i.p. and 0.9\% Saline). 


\subsubsection{Measurement of analgesia using the warm-water tail-}

\section{withdrawal test}

The warm-water tail-withdrawal test was performed according to previously published methods (Horan, Taylor, Yamamura, \& Porreca, 1992; Pacheco et al., 2009). Briefly, mice were habituated for $1 \mathrm{hr}$ in the behavioural room with the male observer before starting the experiment as male observers are known to modulate rodent stress-induced analgesia (Calixto, Scheidt, Otuki, \& Santos, 2001).

Mice were habituated to the restrainer ( $24 \mathrm{~mm}$ internal diameter, custom-made mouse restrainers from School of Biological Sciences workshop, Victoria University of Wellington) for 10 min before obtaining a baseline tail-withdrawal latency measurement. Baseline measurements were averaged from 3 measurements taken at 3 min intervals. Mice with control latencies greater than 4 seconds were excluded from testing to avoid the false positive data as previously described by Horan et al. (1992). The distal end of the tail $(2 \mathrm{~cm})$ was immersed in water heated to $50^{\circ} \mathrm{C}\left( \pm 0.5^{\circ} \mathrm{C}\right)$ and the time for the animal to show a tail-withdrawal response was recorded. To avoid any tissue damage, a maximum cut-off time of $10 \mathrm{sec}$ was used. The tail-withdrawal latencies were recorded over time at 1, 5, 10, 15, 30, 45, 60, 90, 120 and 150 min. The Maximum Possible Effect of analgesia was calculated using the following formula:

$$
\begin{gathered}
\% M P E=100 x(\text { Test Latency }- \text { Control Latency }) /(10 \\
- \text { Control Latency })
\end{gathered}
$$




\subsubsection{Measurements of acute inflammatory pain using the $2 \%$ intra-dermal formalin model}

The $2 \%$ intra-dermal formalin assay was carried out according to methods previously described (Dubuisson \& Dennis, 1978; Hunskaar \& Hole, 1987; Sawynok, Reid, \& Liu, 2013) with slight modifications. In brief, adult male mice were allowed to habituate in the test chamber which consisted of a box $(27.5 \times 18.5 \times 30)$ with an open top and an elevated glass floor in which a mirror was placed underneath an angle of $45^{\circ} \mathrm{C}$. A video camera (Bosch, Stuttgart, Germany) was placed facing the mirror to allow visualisation of pain behaviour (Figure 5). 


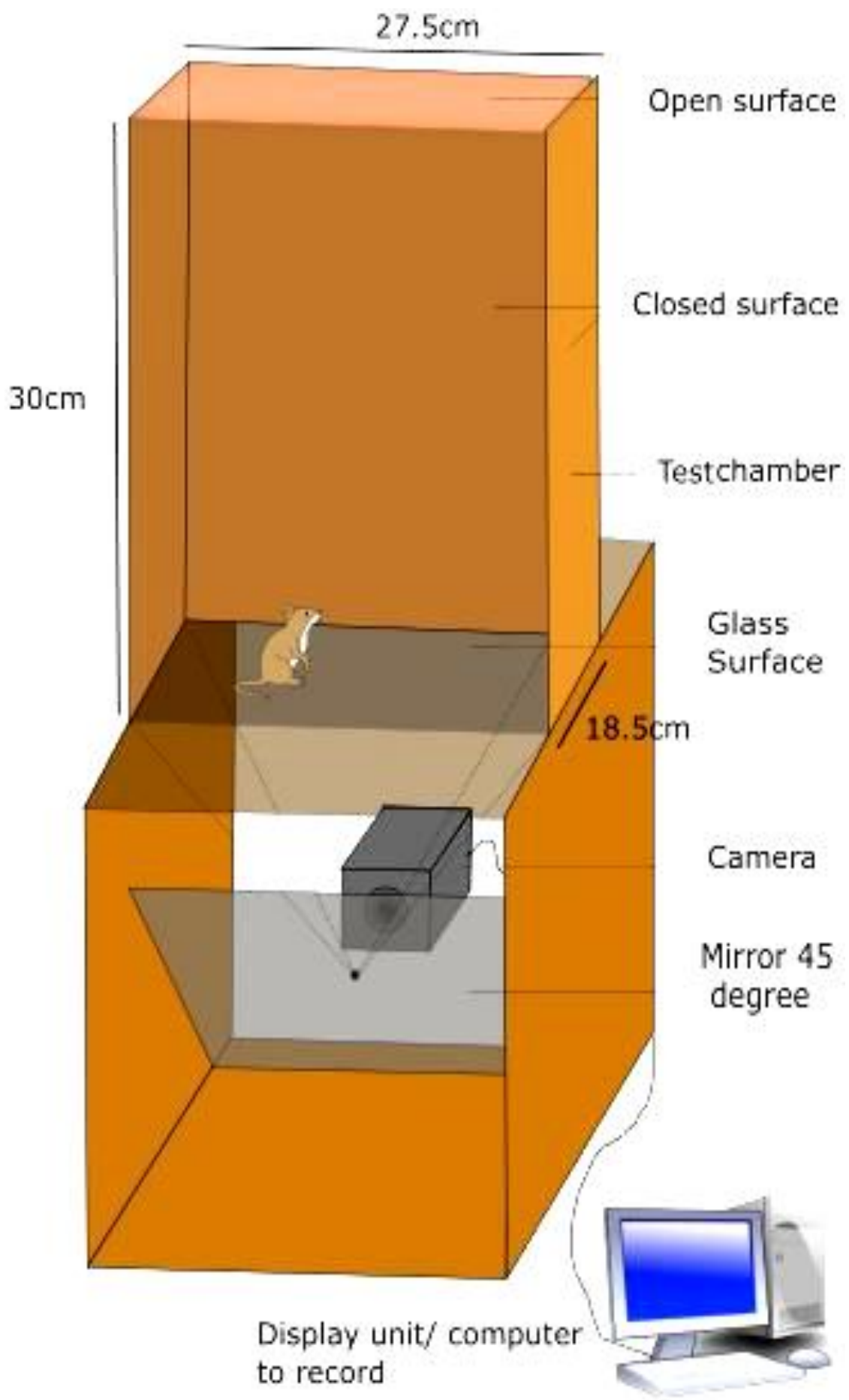

Figure 5: Intra-dermal Formalin Assay apparatus

Pain behaviours were assessed after intra-dermal formalin (2\%) administration. The mouse was kept on the glass surface of the bottom wooden box and covered with another wooden box ( 27.5 $X 18.5 \times 30$ ) with an uncovered bottom and top surface. The pain behaviour was monitored through the attached camera with the help of a mirror, and it was connected to the computer. 
Mice were administered herkinorin or kurkinorin $(1 \mathrm{mg}, 5 \mathrm{mg}$ or $10 \mathrm{mg} / \mathrm{kg}$, i.p) or vehicle (DMSO, Tween 80 and sterile milliQ water, 2:1:7) and placed back into the chamber for 4 $\min$. At $5 \mathrm{~min}, 20 \mu \mathrm{l}$ of a $2 \%$ formalin solution was injected intra-dermally into the dorsal surface of the right hind paw and the mice immediately placed into the test chamber. Pain behaviour was continuously recorded via digital cameras for $60 \mathrm{~min}$. The behavioural activity of mice was analysed at $5 \mathrm{sec}$ intervals where the degree of pain was determined by pain scores, by an individual who was blinded to treatment groups. A pain score of $0=$ indicates no pain response and the injected paw is fully weight bearing. $A$ pain score of 1 = partial weight bearing; pain score of $2=$ no weight bearing of injected paw, a pain score of $3=$ biting, flinching or licking the injected paw. The average pain scores at each $5 \mathrm{sec}$ interval calculated and the scores averaged in 5 min bins.

\subsubsection{Paw Oedema}

Mice, prior to undergoing the formalin test had the length, width, and height of the hind paw measured by 0-150 mm digital calipers (Whitworth, Inspec Inc., Michigan, USA). Following the formalin test, at $60 \mathrm{~min}$ ( $\pm 10 \mathrm{~min}$ ) post formalin injection, the paw height, length, and width was measured. The percentage change in paw oedema was calculated using the following formula where $y 1$ is the paw height before formalin injection, and $y 2$ is the height of the paw after formalin injection.

$$
\% \text { change }=\left(\frac{y 2-y 1}{y 1}\right) \times 100
$$




\subsection{Measurements of side-effects profile}

\subsubsection{Measurement of locomotor activity and sedation:}

Motor-coordination, locomotor, and sedative activities were assessed using the accelerating rotarod assay of motor performance according to the protocols of Spetea, Bohotin, Asim, Stübegger, and Schmidhammer (2010). Mice were trained in 16 training sessions over a 4 day period on an accelerating rotarod (Harvard Apparatus, Massachusetts, USA, $60 \mathrm{~mm}$ width, $30 \mathrm{~mm}$ diameter) set to increase from $4-40 \mathrm{rpm}$ over $300 \mathrm{~s}$. On the test day, initial baseline latencies were measured and averaged from three runs for each mouse. Mice that were unable to remain on the apparatus for $240 \mathrm{~s}$ were excluded from the experiments. The test latencies were recorded as the time at which the mouse fell off the apparatus. The initial baseline data was used to compare latencies following drug treatment at $15,30,45$, $60,90,120$ and $180 \mathrm{~min}$. The latency was expressed as a percent of baseline according to the following calculation.

$$
\% \text { baseline }=\left(\text { test } \frac{\text { latency }}{\text { baseline }} \text { latency }\right) x 100
$$

\subsubsection{Body temperature}

The rectal temperature of mice was recorded at set times in mice undergoing tests of tail-withdrawal before and after i.p. administration of vehicle, morphine, kurkinorin and herkinorin at $0,10,30,60,90,120$ and 150 min using a lubricated rectal thermal probe (Acorn series, Singapore) inserted $2 \mathrm{~cm}$ into the anal canal of mice and the temperature recorded. The probe was calibrated daily. 


\subsection{Measurement of rewarding properties:}

\subsubsection{Conditioned place preference assay}

We utilised the 3-chamber conditioned place preference (CPP) apparatus to evaluate the rewarding properties of herkinorin, kurkinorin and morphine in male Sprague-Dawley rats. The apparatus (Figure 6A) consisted of two large outer compartment chambers ( $30 \mathrm{x} 30 \mathrm{x}$ $34 \mathrm{~cm}$ ) connected by a central corridor $(8 \times 10 \times 34 \mathrm{~cm})$ (PanLab, Harvard Apparatus, USA). One large outer compartment had a smooth white floor with black and white striped walls while the other chamber had white walls with black dots and a textured black floor. The small central compartment had a smooth grey floor and grey walls. A camera was mounted above the apparatus and movement tracked using SMART 3.0 software (PanLab, Harvard Apparatus, Massachusetts, USA). Each CPP chamber was individually lit with a freestanding LED light placed in the middle of the central corridor (average light intensity was 20 lux in each conditioning chamber and 60 lux in the corridor) so that the illumination was even in 2 outer chambers. All experiments were performed in the presence of white noise (approximately $60 \mathrm{~dB}$ ). 

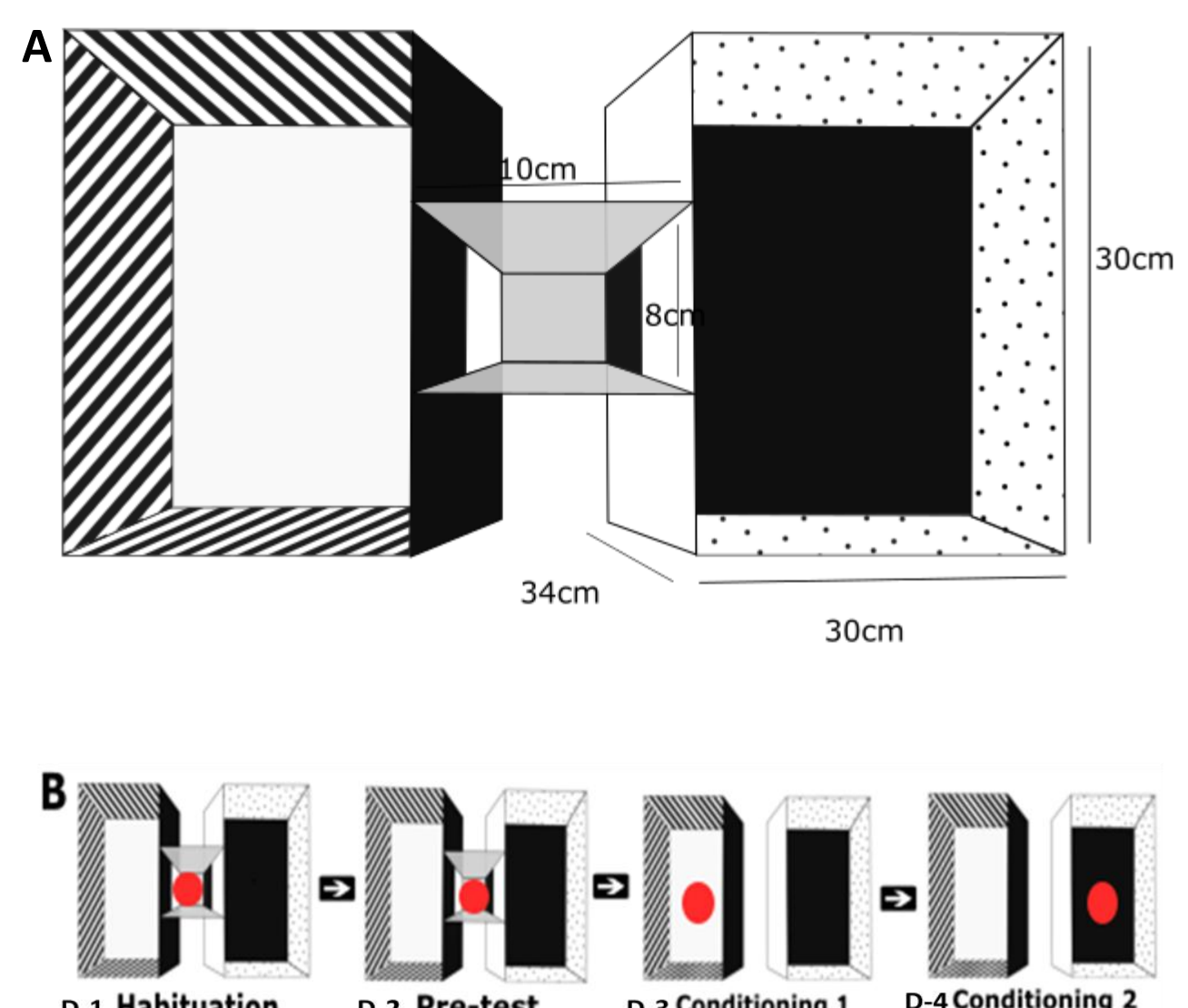

D-1 Habituation

D-2 Pre-test

D-3 Conditioning 1

D-4 Conditioning 2
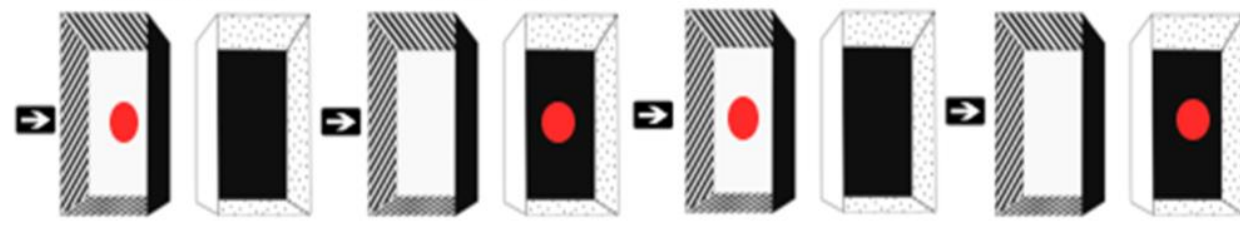

D-5 Conditioning 3

D-6 Conditioning 4

D-7 Conditioning 5 D-8 Conditioning 6

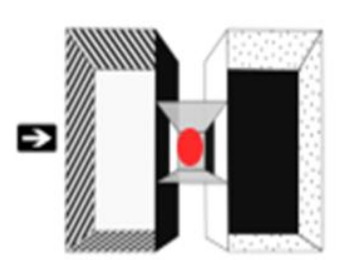

Black floor

White floor

D Day

D-9 Post -test

Figure 6: Conditioned Place Preference apparatus and procedure.

\section{A: CPP apparatus.}

B: Rats were habituated, with free access to the 3 chambers on day 1 . Baseline preference to chambers was collected in the pre-test on day 2. Rats were grouped into vehicle and treatment (herkinorin, kurkinorin and morphine). From days 3-8 (conditioning phase), rats were received treatment and confined to one compartment in the least preferred box (Days 3, 5 and 7) and the vehicle in the preferred box (Days 4, 6 and 8). On day 9 , post-test was carried out whereby rats were allowed free access the 3 chambers to assess the time spent in the drug-paired chamber. 
The CPP procedure was performed according to methods described by Piepponen, and Kivastik (1997) with slight modifications. The test consisted of four different phases: habituation; a preconditioning test; conditioning; and a post-conditioning test. Habituation phase - Day 1: During the habituation phase, the rats were acclimatised to each chamber and allowed to freely explore the entire apparatus for $15 \mathrm{~min}$. The textured black floor was removed to prevent latent inhibition to the different textured floors. Pre-conditioning test - Day 2: The textured floor was inserted, and the rats were placed in the small central compartment and were allowed to freely explore the entire apparatus for 15 min to determine bias and baseline preferences. Rats that spent more than $80 \%$ of their time in one of the two outer compartments or over $40 \%$ in the central compartment were excluded from the experiment. Conditioning phase - days 3- 8: The conditioning phase took place over 6 days from days 3-8. A balanced protocol with the biased procedure was followed whereby the test compound, reference analgesic, or vehicle-treated controls were administered in the least preferred compartment and confined for $45 \mathrm{~min}$. The experiments were conducted once a day. On days three, five and seven, rats were injected with test compounds, reference analgesic or vehicle and placed in the least preferred compartment for $45 \mathrm{~min}$. Whereas, on days four, six and eight, rats were administered with the vehicle and placed in the opposite compartment for $45 \mathrm{~min}$. Virkon (DuPont Limited, New Zealand) solution on a damp sponge was used to clean the floors and sides of the box before placing another rat to remove odours between each animal. Post-conditioning phase - day 9: On day 9 rats were allowed to freely access the apparatus for $15 \mathrm{~min}$, and the amount of time spent in each chamber was recorded. Results were calculated as the difference in the times spent on the drug- 
paired side versus the vehicle-paired side. Positive values demonstrated the animals' preference for the drug-paired side, while a negative value indicates aversion.

\subsubsection{Cleaning of mouse restrainers}

Custom made mouse restrainers were used to restrain mice for antinociceptive experiments. Mice were habituated to the restrainer for $10 \mathrm{~min}$ before starting the experiments everyday. The tube type mouse restrainers were more suitable for placing the mice inside and for placing the stopper door above the base of the tail to give enough space for the mice to breathe comfortably. Individual restrainer was used to restrain each mouse, and the restrainer was cleaned by using virkon followed by water and dried with paper towels to reduce restrain related-stress.

\subsection{Statistical analysis}

All statistical data were analysed using Prism v5.0c (GraphPad Prism Software Inc., La Jolla, CA, USA). Repeated Measures Two-way Analysis of Variance (ANOVA) followed by Bonferroni post-tests were used in tail-withdrawal, intra-dermal formalin assays, rotarod and rectal temperature tests to compare drug-treated mice to vehicle treated controls. Two-way ANOVA followed by Dunnet's Multiple Comparison tests were used in the measurements of oedema to compare drug-treatment to vehicle treated controls. A value of $p \leq 0.05$ was considered statistically significant for all experiments. The data were validated for normal distribution using Kolmogorov-Smirnov (K-S) normality test. CPP data was analysed by one-way Analysis of Variance (ANOVA) followed by Newman-Keuls Multiple Comparison tests. CPP experiments express the dependent variable as the 
difference in time spent in the drug- and vehicle-paired compartments. The difference between the time that rats spent in the drug-paired compartment and the vehicle compartment a conditional score. Data is expressed as a mean \pm standard error of mean (mean \pm SEM). Prism computes area-under-the-curve using the trapezoidal rule which calculates the area of each trapezoid by calculating the area of the equivalent rectangle (below, right). The area under the curve is the sum of areas of all the rectangles. Prism uses the following formula repeatedly for each adjacent pair of points defining the curve $\Delta X^{*}(Y 1+Y 2) / 2$ (GraphPad Prism Software Inc., La Jolla, CA, USA). 


\section{Results}

\subsection{Analgesic properties of herkinorin and kurkinorin in the warm-water tail-withdrawal assay}

The warm-water tail-withdrawal assay, activating the thermal spinal reflex was used to measure analgesia in mice. This was used to determine both the analgesic effect and duration of action of our novel drugs in vivo. The dose-dependant antinociceptive effects produced by herkinorin and kurkinorin at 1,5 and $10 \mathrm{mg} / \mathrm{kg}$ were compared with a known analgesic, morphine $(10 \mathrm{mg} / \mathrm{kg})$. Herkinorin showed no significant antinociceptive effects at 1 , or $5 \mathrm{mg} / \mathrm{kg}$. A significant effect was seen at $10 \mathrm{mg} / \mathrm{kg}$ at a single time point, $30 \min (p<0.05)$ when compared to vehicle-treated mice $[F(4,270)=59.17, p<0.0001]$ (repeated measures two-way ANOVA followed by Bonferroni's post-test, Figure 7A). Total antinociceptive effects of herkinorin for all doses were assessed using the area under the curve $(A \cup C)$ based on tail-withdrawal latencies where herkinorin at a larger dose $(10 \mathrm{mg} / \mathrm{kg})$ produced a significant effect $(\mathrm{p}<0.05$, one-way ANOVA followed by Dunnett's test, figure 5B) when compared with vehicle.

Kurkinroin produced significant spinal analgesia at 5 and $10 \mathrm{mg} / \mathrm{kg}$, and tail-withdrawal latencies were significantly increased when compared to vehicle-treated mice $[F(5,300)=$ $81.72, p<0.0001$ ] (repeated measures two-way ANOVA with Bonferroni's post-test, Figure $\underline{7 C \& D)}$. Kurkinorin and morphine produced similar tail-withdrawal latencies at the 10 
$\mathrm{mg} / \mathrm{kg}$ dose (Figure $7 C \& D)$. Kurkinorin $(5 \mathrm{mg} / \mathrm{kg}$, i.p) produced a significant increase in tail-withdrawal latency at $10 \mathrm{~min}(p<0.01)$ and this analgesia was maintained for $60 \mathrm{~min}$ $(p<0.001)$. Similarly, kurkinorin at $10 \mathrm{mg} / \mathrm{kg}$ (i.p) produced a significant increase in tailwithdrawal latencies after 5 min of administration maintained for $90 \mathrm{~min}(p<0.001)$. Kurkinorin's antinociceptive effect was confirmed by pretreating the mice with the opioid receptor antagonist naloxone $(10 \mathrm{mg} / \mathrm{kg}$, s.c) 45 minutes before kurkinorin treatment (Figure 7C) which showed no significant difference compared to vehicle-treated controls.

The dose-dependence and time-course effects of both kurkinorin and morphine were assessed using the area under the curve (AUC) analysis. Compared to vehicle treated controls, kurkinorin showed no significant analgesic effect at $1 \mathrm{mg}$ but significant antinociceptive effects following both 5 and $10 \mathrm{mg}$ doses (one-way ANOVA followed by Dunnett's test for multiple comparisons). The analgesic effect of kurkinorin was blocked by pretreatment with naloxone indicating the opioid dependent mechanisms (Figure 7D). 
A

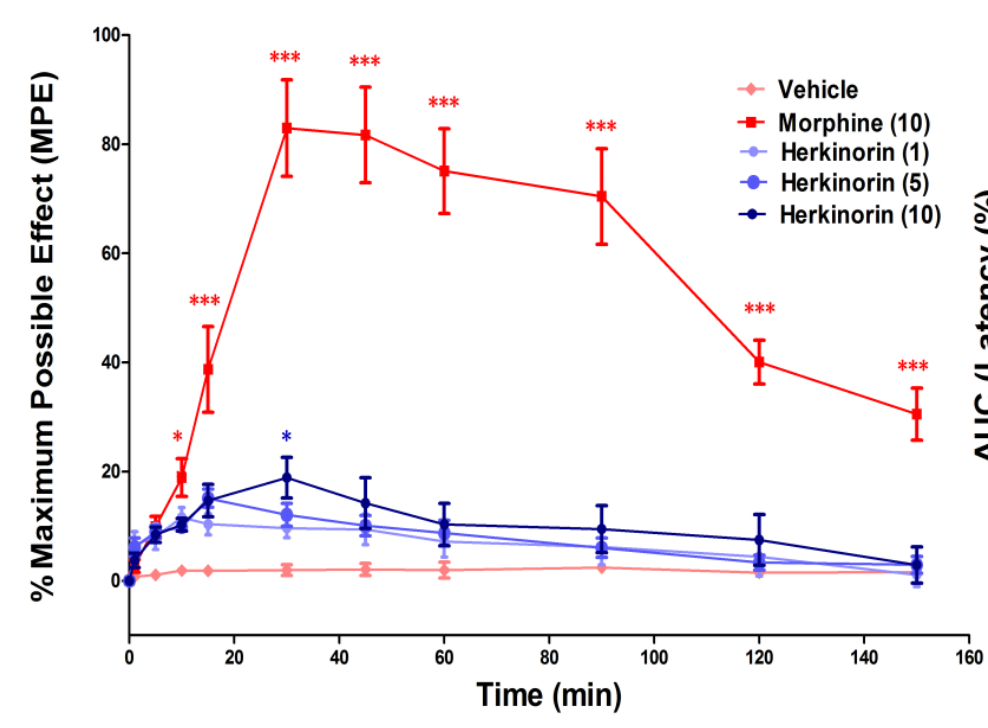

B

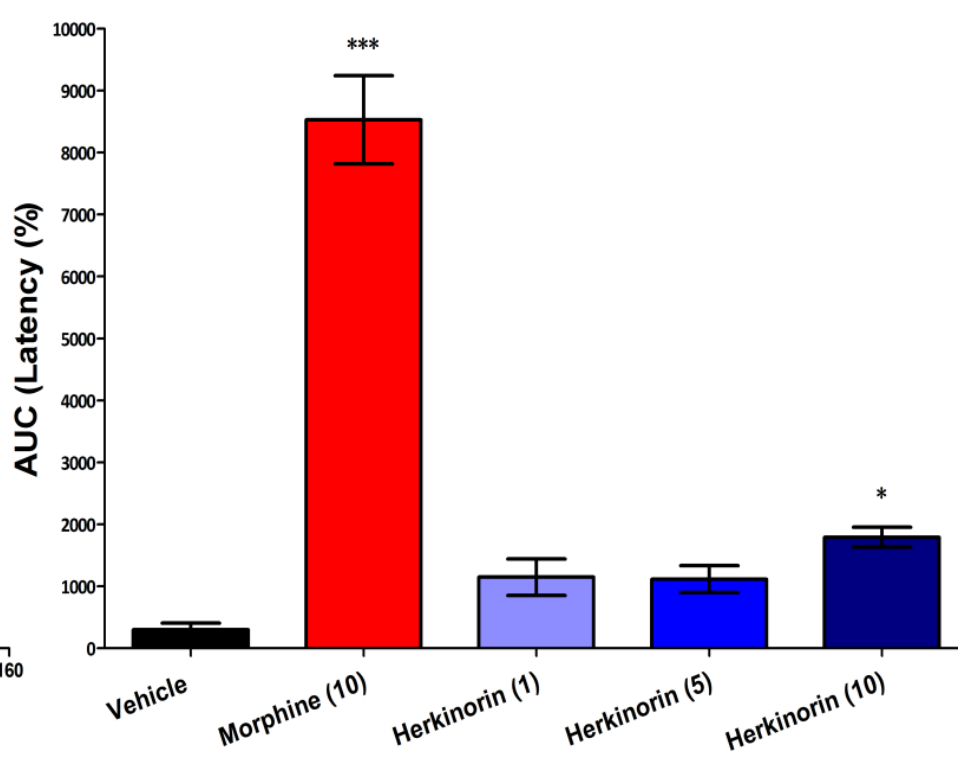

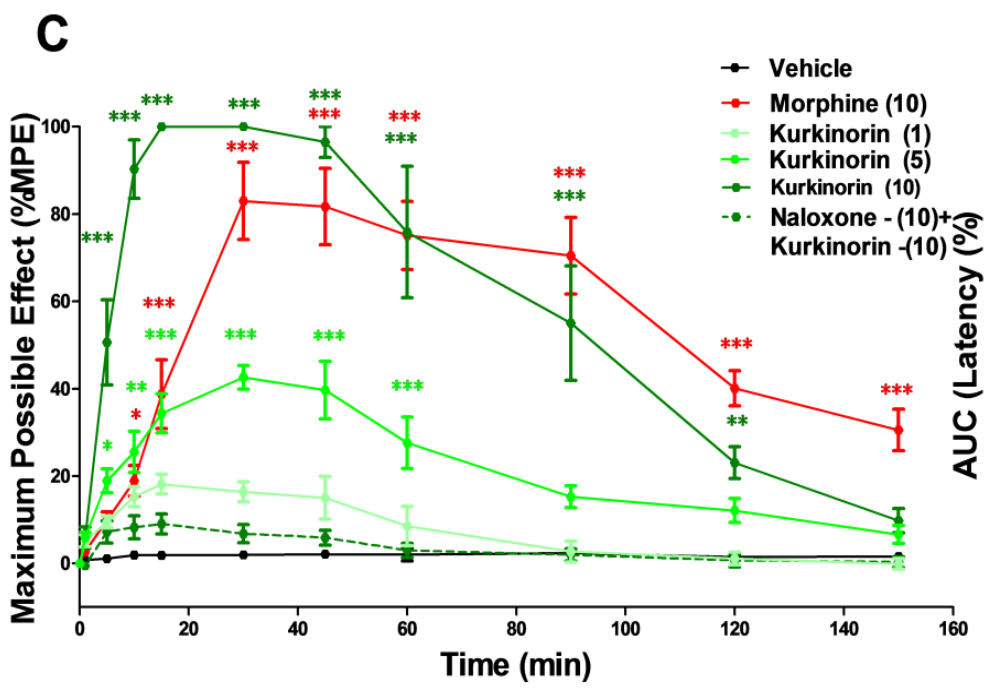

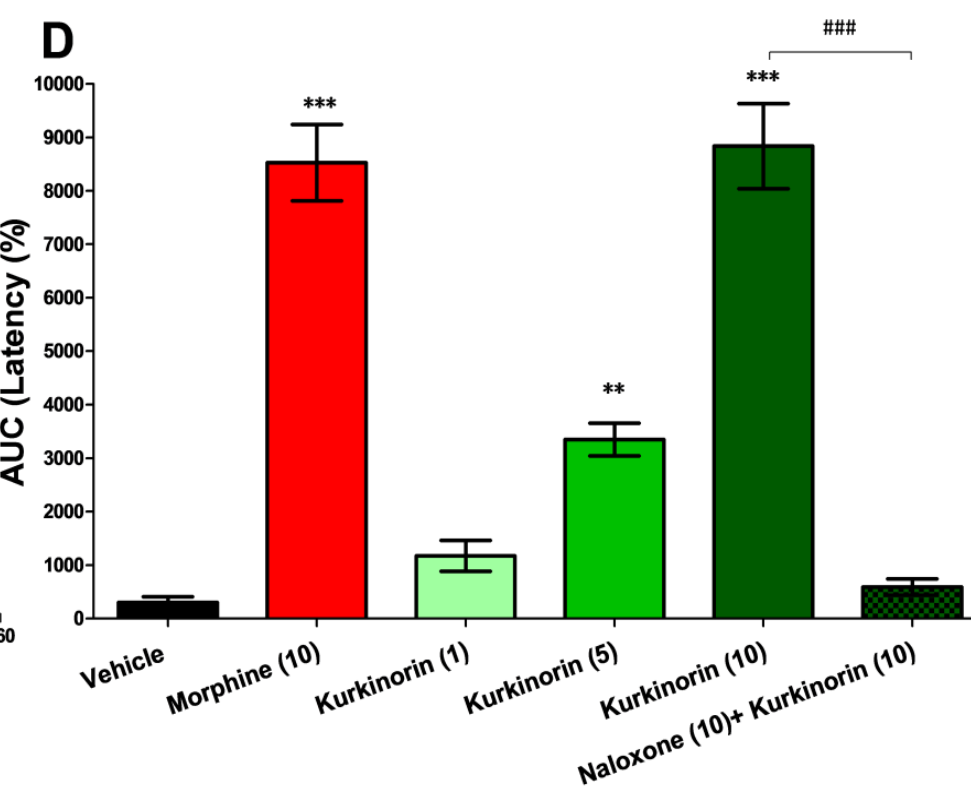

Figure 7: Dose-dependent and time-course effects of herkinorin and kurkinorin in the $50^{\circ} \mathrm{C}$ warm water tailwithdrawal assay.

The tail-withdrawal latency is expressed as the percentage maximum possible effect (\%MPE \pm SEM) at each time-point and calculated based on pre-drug latencies measured before drug administration. (A) Herkinorin $(10 \mathrm{mg} / \mathrm{kg})$ has small but significant effect at $30 \mathrm{~min}$. (B) AUC analysis showed that herkinorin shows a small but significant analgesic effect at $10 \mathrm{mg} / \mathrm{kg}$. (C) Kurkinorin showed significant antinociceptive effects at 5 (for short duration from $10 \mathrm{~min}$ to $60 \mathrm{~min}$ ) and $10 \mathrm{mg} / \mathrm{kg}$ (a quick onset and long duration of action from $5 \mathrm{~min}$ to $120 \mathrm{~min}$ ) which demonstrated similar to the effects of morphine at $10 \mathrm{mg} / \mathrm{kg}$ and no significant effects of kurkinorin $(10 \mathrm{mg} / \mathrm{kg})$ with prior s.c. injection with naloxone 10 $\mathrm{mg} / \mathrm{kg}$. (D) AUC analysis revealed significant effects of kurkinorin at 5 and $10 \mathrm{mg} / \mathrm{kg}$ and morphine $10 \mathrm{mg} / \mathrm{kg}$. AUC one-way ANOVA followed by Dunnett's test to compare herkinorin, kurkinorin and morphine with the vehicle. Two-way repeated measures ANOVA with Bonferroni post-test was done to compare herkinorin, kurkinorin and morphine treated mice with vehicle $\left({ }^{*} p<0.05,{ }^{* *} p<0.01,{ }^{* * *} p<0.001\right)(\mathrm{n}=5-9)$. 


\subsection{Analgesic effects in the intra-dermal formalin assay}

The intra-dermal formalin assay was used to assess the antinociceptive and antiinflammatory effects of kurkinorin and herkinorin. This assay showed biphasic effects; phase I nociceptive pain (0-10 $\mathrm{min})$ and phase II inflammatory pain (20-60 min) (Figure 8). The antinociceptive effects of herkinorin 1 and $10 \mathrm{mg} / \mathrm{kg}$ were compared with positive pain control (vehicle i.p. with intra-dermal $2 \%$ formalin injection).

Vehicle/formalin-treated mice, receiving no analgesic, showed significant pain scores at all time points from 5-60 min compared to non-formalin treated, negative pain controls $(p<0.001)$. Herkinorin $(10 \mathrm{mg} / \mathrm{kg})$ produced a significant reduction in pain behaviour at 20, 30-60 min compared to vehicle/formalin-treated mice $(p<0.001)$. Herkinorin (1 $\mathrm{mg} / \mathrm{kg}$ ) only attenuated pain scores at $30,40 \mathrm{~min}(p<0.001)$ and $45 \mathrm{~min}(p<0.01)$. A significant time -effect $[F(17,527)=15.63, p<0.0001]$, and the effect of drug $[F(4,527)=236, p<0.0001]$ were revealed (repeated measures two-way ANOVA with Bonferroni's post-test, Figure 8A). Herkinorin (1 and $10 \mathrm{mg} / \mathrm{kg}$ ) did not produce any antinociceptive effect in phase I pain, however, it produced a small but significant attenuation of phase II pain $(13.08 \%)(p<0.001)[F(4,27)=344.5, p<0.0001]$ (one-way ANOVA with Bonferroni's post-test to compare the drugs with vehicle, Figure $8 B \& C)$. ${ }^{*} p<0.05, * * p<0.01, * * * p<0.001$ compared to vehicle; ${ }^{\# \#} p<0.001$ negative PBS control compared with positive formalin control. 


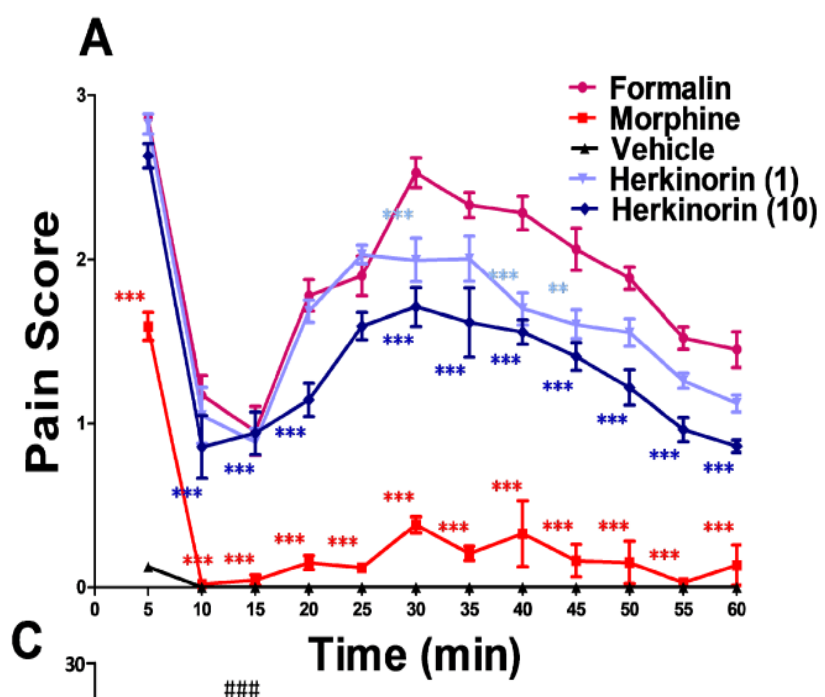

B
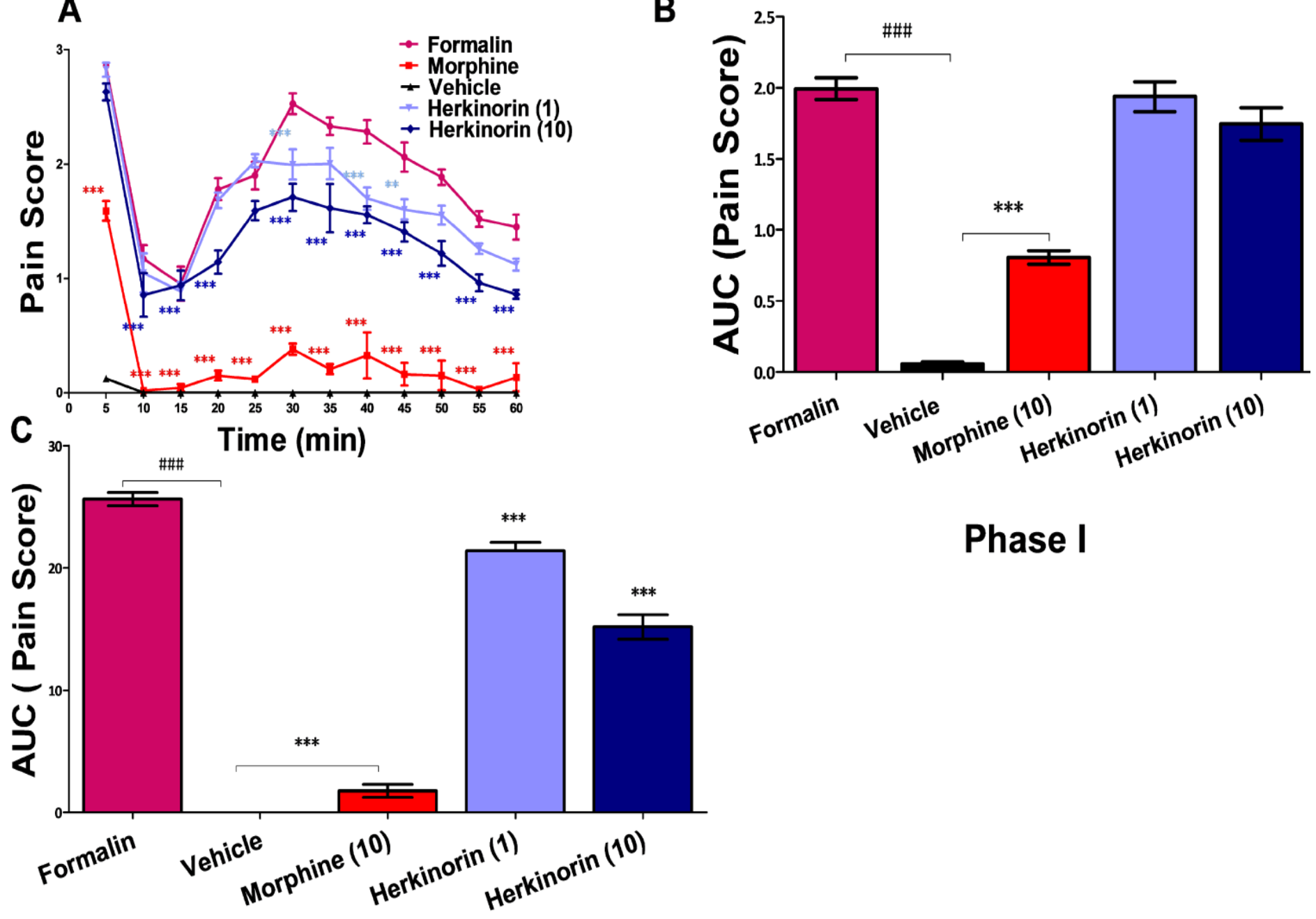

Phase I

\section{Phase II}

Figure 8: Intra-dermal formalin assay in mice using morphine and herkinorin.

Behaviour scores counted every 5 min following 2\% intra-dermal formalin. (A) Morphine and herkinorin $(10 \mathrm{mg} / \mathrm{kg}$ ) blocked the pain behaviours (RM- two-way ANOVA with Bonferroni post-hoc test to compare with +ve pain control), (B) \& (C). Herkinorin showed significance in phase II pain, and morphine showed significance in both pains. One-way ANOVA with Bonferroni post-hoc test to compare herkinorin and morphine with +ve pain control. -Ve pain, vehicle treated mice with PBSinjected in the paw compared with +Ve pain, values represent mean $\pm \operatorname{SEM}(n=6-10)\left({ }^{*} p<0.05\right.$, $\left.{ }^{* *} p<0.01,{ }^{* * *} p<0.001\right)(\mathrm{n}=6-10)\left({ }^{\# \#} p<0.001\right)$. 
Kurkinorin $(10 \mathrm{mg} / \mathrm{kg})$ showed a significant reduction of pain scores at all time points (from 5-60 $\mathrm{min}$ ) compared to the positive pain control (vehicle/formalin-treated mice) $(p<0.001)$, whereas kurkinorin at $5 \mathrm{mg} / \mathrm{kg}$ was significant at 5 and $20 \mathrm{~min}(p<0.01), 10$ and 30-60 min $(p<0.001)$ (Figure 9A). Whilst kurkinorin (1 mg/kg) didn't have any effect on phase I, it significantly attenuated phase II pain $(p<p<0.001)$ (a time effect $[F(17,646)=130.96, p<0.0001]$, drug effect $[F(5,646)=227.55, p<0.0001]$ (repeated measures two-way ANOVA with Bonferroni's post-test). Naloxone $(10 \mathrm{mg} / \mathrm{kg})$ pre-treated mice showed significance $(p<0.001)$ at all time-points (from 5-60 min) when compared with kurkinorin $(10 \mathrm{mg} / \mathrm{kg})$ and no significance when compared with positive formalin control (a time effect $[F(17,561)=89.25, p<0.0001]$ and drug effect $[F(4,561)=122.35$, $p<0.0001$ ] (repeated measures two-way ANOVA with Bonferroni's post-test, Figure 9A). AUC analysis showed that kurkinorin ( 5 and $10 \mathrm{mg} / \mathrm{kg}$ ) significantly attenuated phase I and phase II pain $(p<0.001)$ whereas kurkinorin $(1 \mathrm{mg} / \mathrm{kg})$ showed a significant reduction in phase II pain (Figure 9B\&C). AUC analysis also showed that naloxone pre-treatment inhibited both phase I $(p<0.05)[F(3,24)=97.87, p<0.0001]$ (one-way ANOVA with Bonferroni's post-test, Figure $9 B \& C$ ) and phase II pain $[F(3,24)=115.1, p<0.0001]$ (oneway ANOVA with Bonferroni's post-test) compared to kurkinorin (10 mg/kg) alone. 


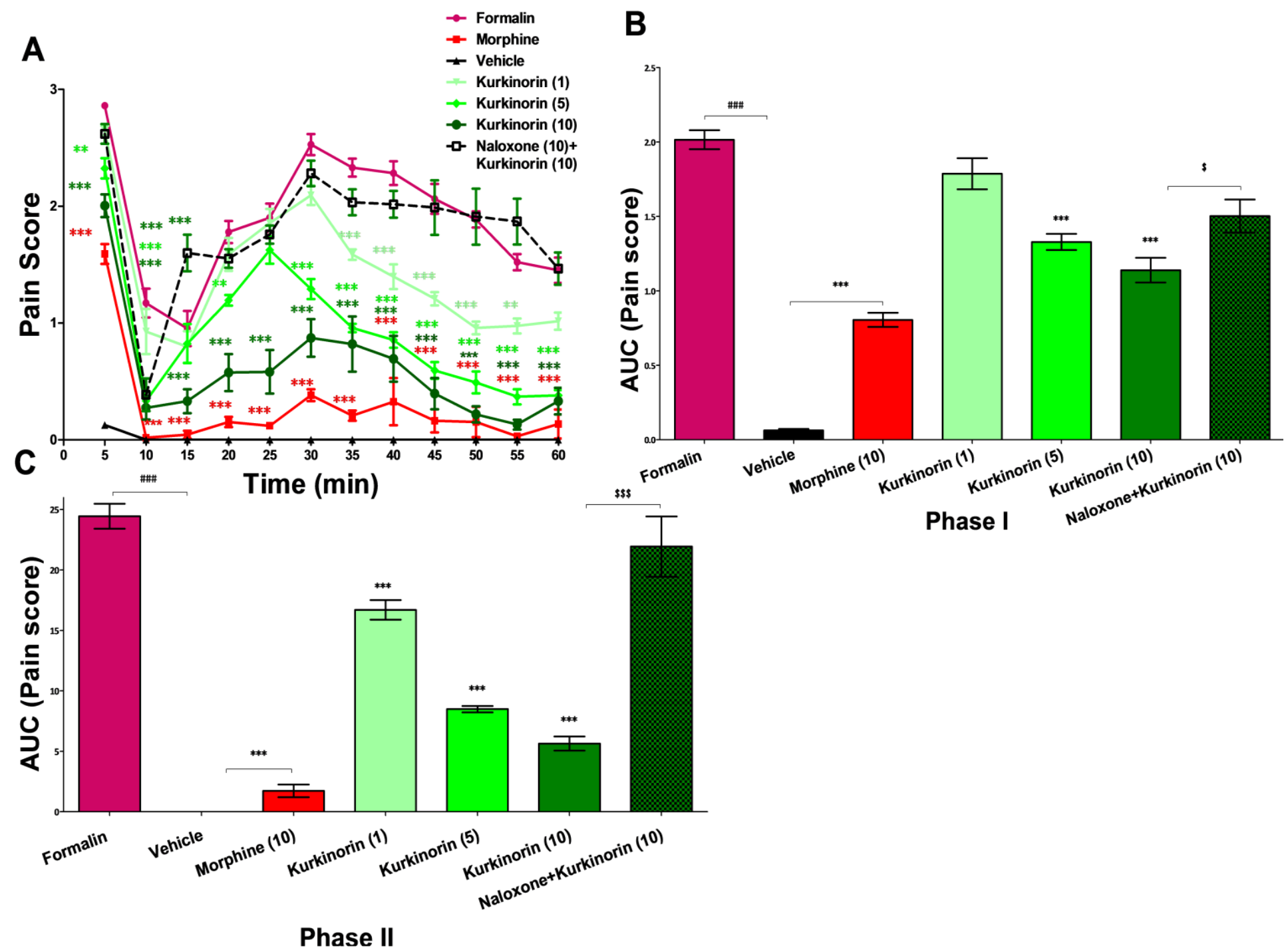

Figure 9: Kurkinorin showed antinociceptive effects in the $2 \%$ intra-dermal formalin assay.

(A) Time-course of formalin-induced pain behaviours of mice treated with vehicle, morphine (10 $\mathrm{mg} / \mathrm{kg}$ ) and kurkinorin (1, 5 and $10 \mathrm{mg} / \mathrm{kg})$. Morphine $(10 \mathrm{mg} / \mathrm{kg}$ ) and kurkinorin (5 and $10 \mathrm{mg} / \mathrm{kg}$ ) significantly blocked the formalin-induced pain behaviours. (B) \& (C) Total analgesic effect of kurkinorin on phase I and phase II pain though area under the curve (AUC) analysis. Repeated measures two-way ANOVA with Bonferroni post-hoc test were conducted to compare with +ve pain control, one-way ANOVA followed by Bonferroni post-hoc test (AUC) was done to compare with +ve pain control, -ve pain, vehicle treated mice with PBS-injected in the paw compared with +ve pain, vehicle treated mice with $2 \%$ formalin injected in the paw. Kurkinorin $(10 \mathrm{mg} / \mathrm{kg})$ pretreated with naloxone showed significant blockage of kurkinorin induced antinociception. Kurkinorin with naloxone completely reversed kurkinorin's effects in both phase I and phase II. $(n=6-10)\left({ }^{\# \#} p<0.001\right)$. $\left({ }^{*} p<0.05,{ }^{* *} p<0.01,{ }^{* * *} p<0.001\right)\left({ }^{\$} p<0.05,{ }^{\$ \$ \$} p<0.001\right)$. 


\subsection{Effects of herkinorin and kurkinorin on oedema}

The effects of our novel MOPr agonists on paw oedema $(\mathrm{mm})$ were determined by calliper measurements before and after $2 \%$ intra-dermal formalin administration. Formalin-treated mice showed significant oedema formation $(91.5 \%$, SEM \pm 0.22 , $(p<0.001)$ compared to PBS-treated controls. Mice pre-treated with morphine $(10 \mathrm{mg} / \mathrm{kg})$ 5 min before formalin showed significantly reduced oedema $(64.9 \%, \mathrm{SEM} \pm 1.2, p<0.001$, Figure 9A). In contrast, herkinorin (1 and $10 \mathrm{mg} / \mathrm{kg}$ ) showed no significant reduction in oedema formation $(24 \%, \mathrm{SEM} \pm 2 \%$ and $15 \%, \operatorname{SEM} \pm 3 \%)[F(2,18)=0.6559, p=0.5309]$ (one-way ANOVA with Dunnet's post-hoc test, Figure 9A). Kurkinorin (1 mg/kg) reduced paw swelling by $55 \%, \mathrm{SEM} \pm 3 \mathrm{~B} \%, p<0.05)$ and kurkinorin $(5 \mathrm{mg} / \mathrm{kg}$ ) reduced paw oedema by $52 \%, \mathrm{SEM} \pm 1 \%, p<0.05)$. A significant reduction of paw oedema was seen with kurkinorin $(10 \mathrm{mg} / \mathrm{kg}$ ) when compared to mice receiving only formalin and vehicle by 75 . $\%,( \pm 1)[F(5,36)=8.684, p<0.0001]$ (one-way ANOVA with Dunnet's post-hoc test, Figure 9B). There was no significant change in paw oedema in formalin-treated controls that received pretreatment with naloxone. Kurkinorin $(10 \mathrm{mg} / \mathrm{kg})$ was found to significantly attenuate oedema compared to opioid-antagonist treated controls (naloxone pretreatment) $[F(2,20)=10.16, p=0.0009]$ (one-way ANOVA with Dunnet's post-hoc test, Figure 9B). 
A

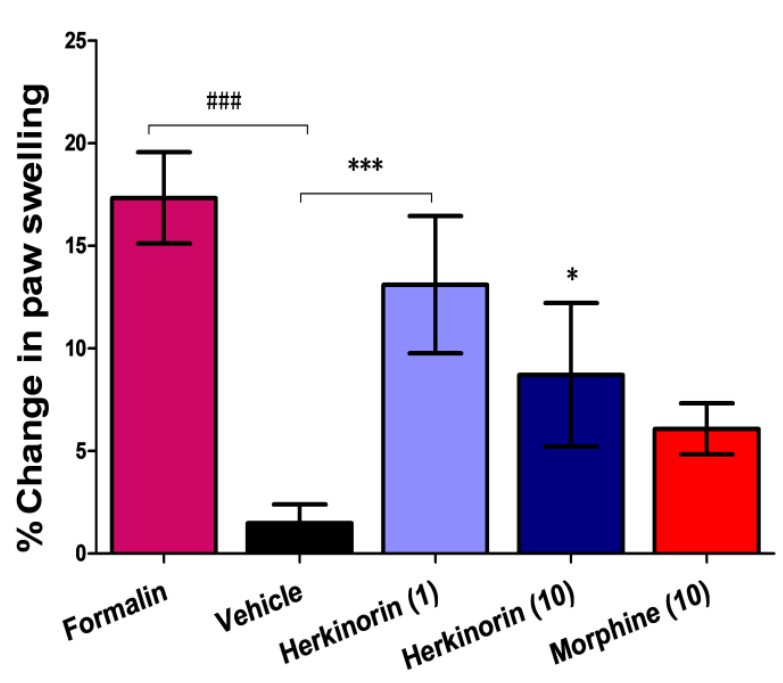

B

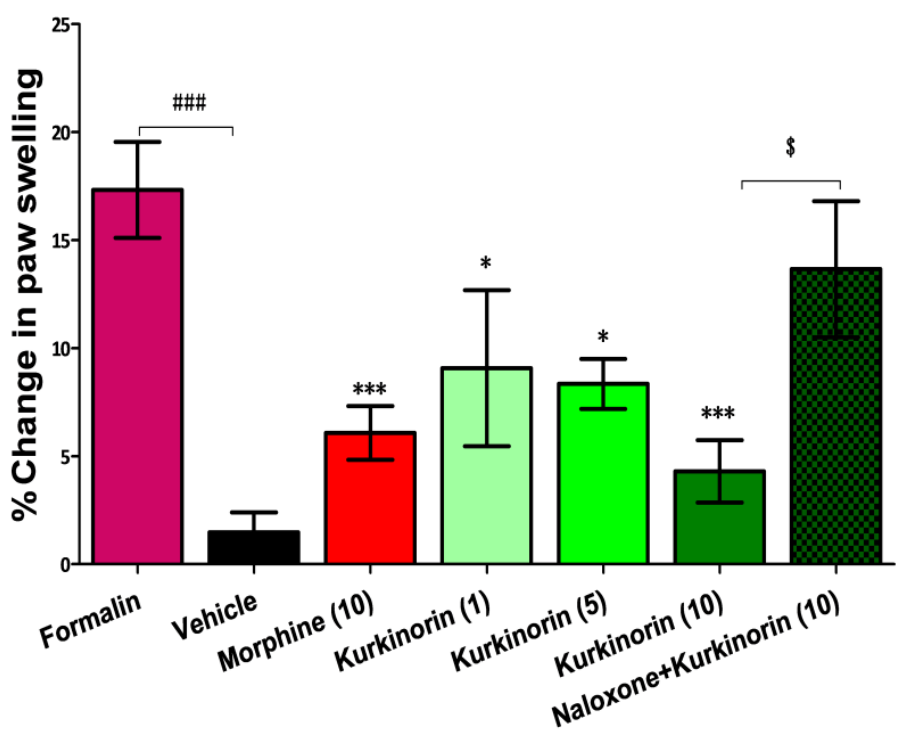

Figure 10: Effects of herkiorin and kurkinorin on paw oedema

(A) Herkinorin (1 and $10 \mathrm{mg} / \mathrm{kg}$ ) showed paw oedema with no significance when compared with formalin. (B) Kurkinorin - 1, 5 and $10 \mathrm{mg} / \mathrm{kg}$ and morphine- $10 \mathrm{mg} / \mathrm{kg}$ showed no significant paw oedema. Pretreatment with naloxone $-10 \mathrm{mg} / \mathrm{kg}$ ) with kurkinorin produced significant paw swelling. Results are presented as mean \pm SEM of the percentage change in paw height for each drug and controls ( $n=6-12$ ). One-way ANOVA followed by Dunnet's post-hoc test to compare against positive pain. -Ve pain, vehicle treated mice with PBS-injected in the paw compared with +ve pain, vehicle treated mice with $2 \%$ formalin injected in the paw ( ${ }^{\# \#} p<0.001$ ). Kurkinorin (10 $\mathrm{mg} / \mathrm{kg}$ ) was compared with naloxone $(10 \mathrm{mg} / \mathrm{kg})\left({ }^{\$} p<0.05\right) .\left({ }^{*} p<0.05,{ }^{* *} p<0.01,{ }^{* * *} p<0.001\right)(\mathrm{n}=6$ 12) 


\subsection{Measurement of locomotor activity and sedation using the accelerating rotarod assay}

To evaluate potential sedative and motor co-ordination effects of our novel MOPr agonist we compared kurkinorin with morphine on the accelerating rotarod and the latency to fall was recorded. Time-course analysis of latency to fall showed that Kurkinorin had impaired motor performance at the $15^{\text {th }}$ min and no effect at any other time point up to $180 \mathrm{~min}$ (Figure 11). In contrast, morphine produced significant motor impairment between $15 \mathrm{~min}$ and $60 \min [F(2,80)=61.79, p<0.001]$ (repeated measures two-way ANOVA with Bonferroni's post-test, Figure 10A). Kurkinorin was significantly different from morphine at 30, 45 and 60 min time-points $[F(14,105)=9.66, p<0.001]$ (repeated measures two-way ANOVA with Bonferroni's post-test, Figure 10A). The overall motor performance effects of kurkinorin $(10 \mathrm{mg} / \mathrm{kg}$, i.p.) and morphine $(10 \mathrm{mg} / \mathrm{kg}$, i.p.) were also assessed using the area under the curve (AUC). Kurkinorin showed no significant differences compared to vehicle-treated mice whereas morphine produced significant motor impairment $[F(2,15)=21.15, p<0.0001]$ (one-way ANOVA with Bonferroni's post-test to compare the drugs with the vehicle, Figure 10B). 


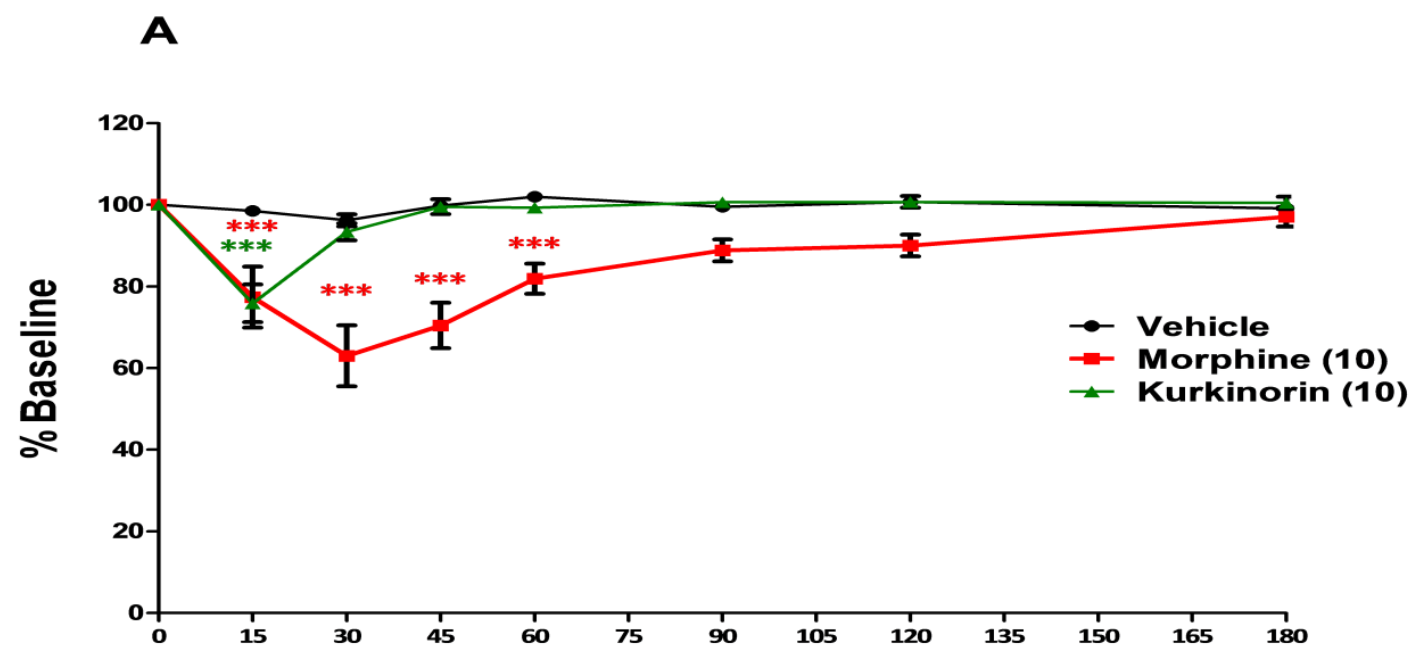

B

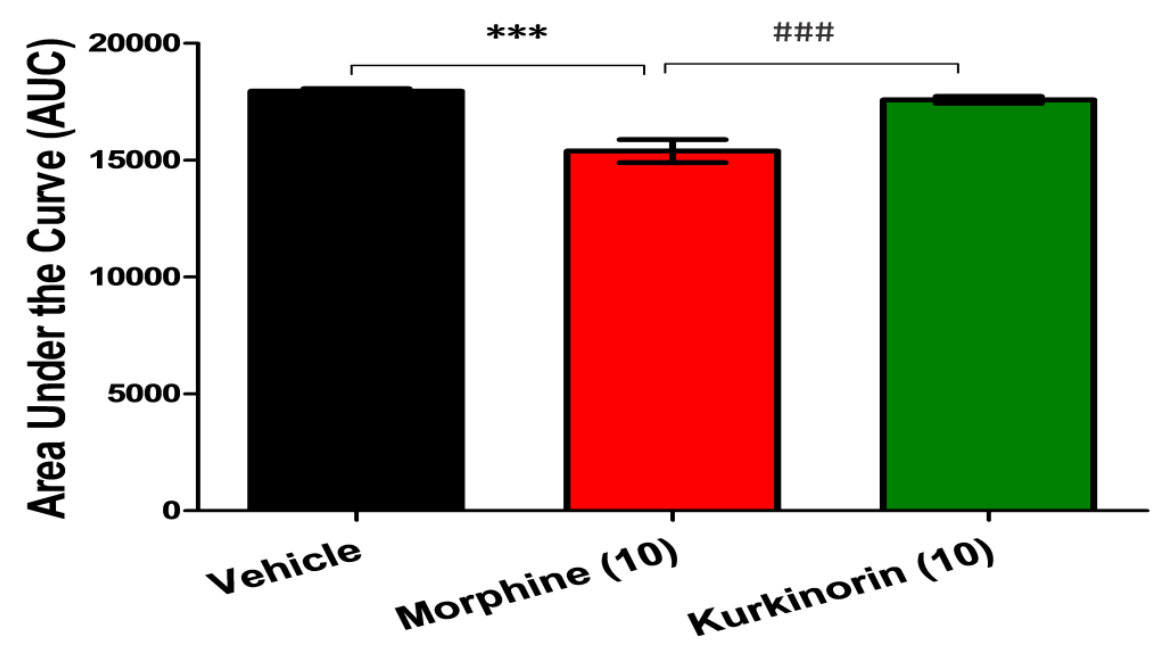

Figure 11: Measurement of locomotor activity and sedation using accelerating rotarod assay

(A) Morphine showed a significant motor impairment at 15, 30, 45 and 60 min whereas kurkinorin showed a significant motor impairment at $15 \mathrm{~min}$. (B) AUC analysis showed morphine significantly impaired motor coordination and kurkinorin showing no significant effect. Significant differences observed when compared kurkinorin with morphine. Results are mean \pm SEM of falloff latencies of mice ( $n=6$ per group). Repeated measures, two-way ANOVA with Bonferroni posthoc analysis drugs compared to the vehicle. One-way ANOVA with Bonferroni's test to compare the drugs with vehicle $\left({ }^{*} p<0.05,{ }^{* *} p<0.01,{ }^{* * *} p<0.001\right)$, kurkinorin compared with morphine

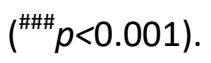




\subsection{Rewarding properties of herkinorin and kurkinorin using conditioned place preference}

The conditioned place preference test (CPP) uses Pavlovian conditioning to evaluate the rewarding effects of a drug (C. Stein, 2013). Here we examined place preference following kurkinorin $(5 \mathrm{mg} / \mathrm{kg})$, herkinorin $(5 \mathrm{mg} / \mathrm{kg}$ ) and morphine $(5 \mathrm{mg} / \mathrm{kg})$. The CPP conditioning score was measured by calculating the differences in the time spent drugpaired box between the pre-conditioning and the post-conditioning phases (expressed as \%). The amount of time spent in the drug-paired chamber following, morphine, kurkinorin and herkinorin are shown in Figure 11A and the CPP score in Figure 11B. Rats treated with morphine showed place preference to the paired chamber and produced a significant increase in rewarding effects compared with vehicle-treated rats $[F(3,46)=$ $6.573, p<0.001$ ] (one-way ANOVA with Newman-Keuls multiple comparison tests). There was no significant place preference seen with herkinorin, kurkinorin or in vehicle-treated controls. Morphine showed significant place preference, and this increase in place preference was significantly different to kurkinorin $(p<0.01)$, and herkinorin $(p<0.05)(5$ $\mathrm{mg} / \mathrm{kg},[F(7,98)=0.0010 p<0.01](\mathrm{n}=6-18)$ ( Figure 11). 

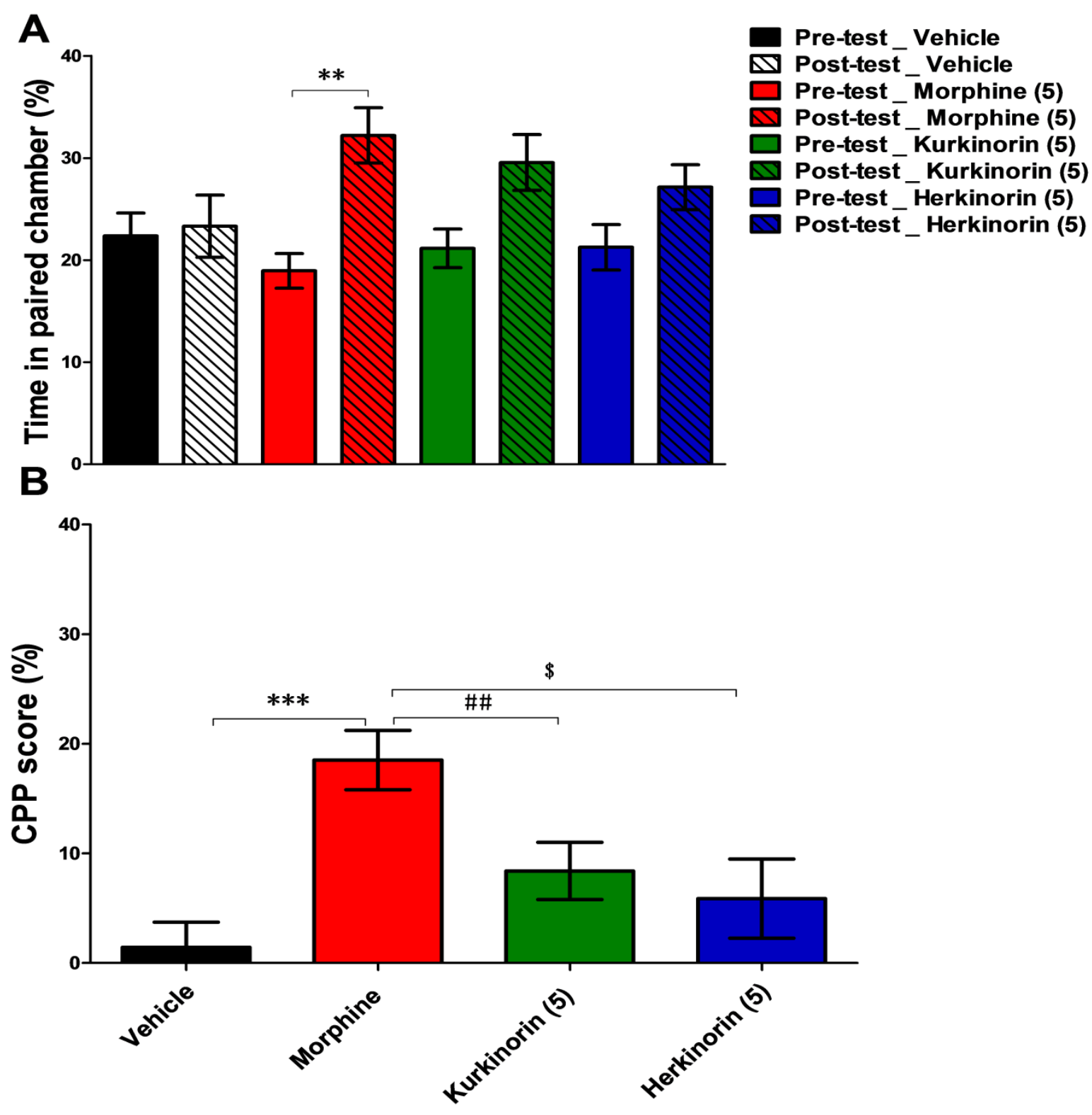

Figure 12: Conditioned place preference assay

(A) Time spent in the paired compartments in pre- conditioning and post-conditioning tests. Rats treated with kurkinorin and herkinorin showed a significant decrease in time spent in the drug-paired chamber whereas morphine-treated rats showed significant preference in the morphine-paired compartment (one-way ANOVA with Bonferroni's post-test). (B) Kurkinorin and herkinorin showed less preference when compared to morphine at $5 \mathrm{mg} / \mathrm{kg}$. Data are expressed as the means $\pm \mathrm{SEM}$. One-Way ANOVA followed by Newman-Keuls Multiple Comparison Test $(n=6-18)$ to compare the vehicle. Morphine $\left({ }^{* * *} p<\right.$ $0.001)$ when compared to vehicle and the kurkinorin showed very less preference than morphine $(* * p<$ $0.01)$ when compared to vehicle. Herkinorin also showed less preference when compared to morphine $\left({ }^{*} p<0.05\right) .(5)$ denotes $5 \mathrm{mg} / \mathrm{kg}$. 


\subsection{Effects of herkinorin and kurkinorin on body temperature}

The effects of herkinorin, kurkinorin and morphine on body temperature were measured using a thermal rectal probe. Herkinorin and kurkinorin produced no significant changes in temperature. However, hypothermic effects were seen following morphine at 10,30 , $60,90,120$ and $150 \min [F(8,264)=8.74, p<0.0001]$ (repeated measures two-way ANOVA with Bonferroni's post-test, Figure 12). 

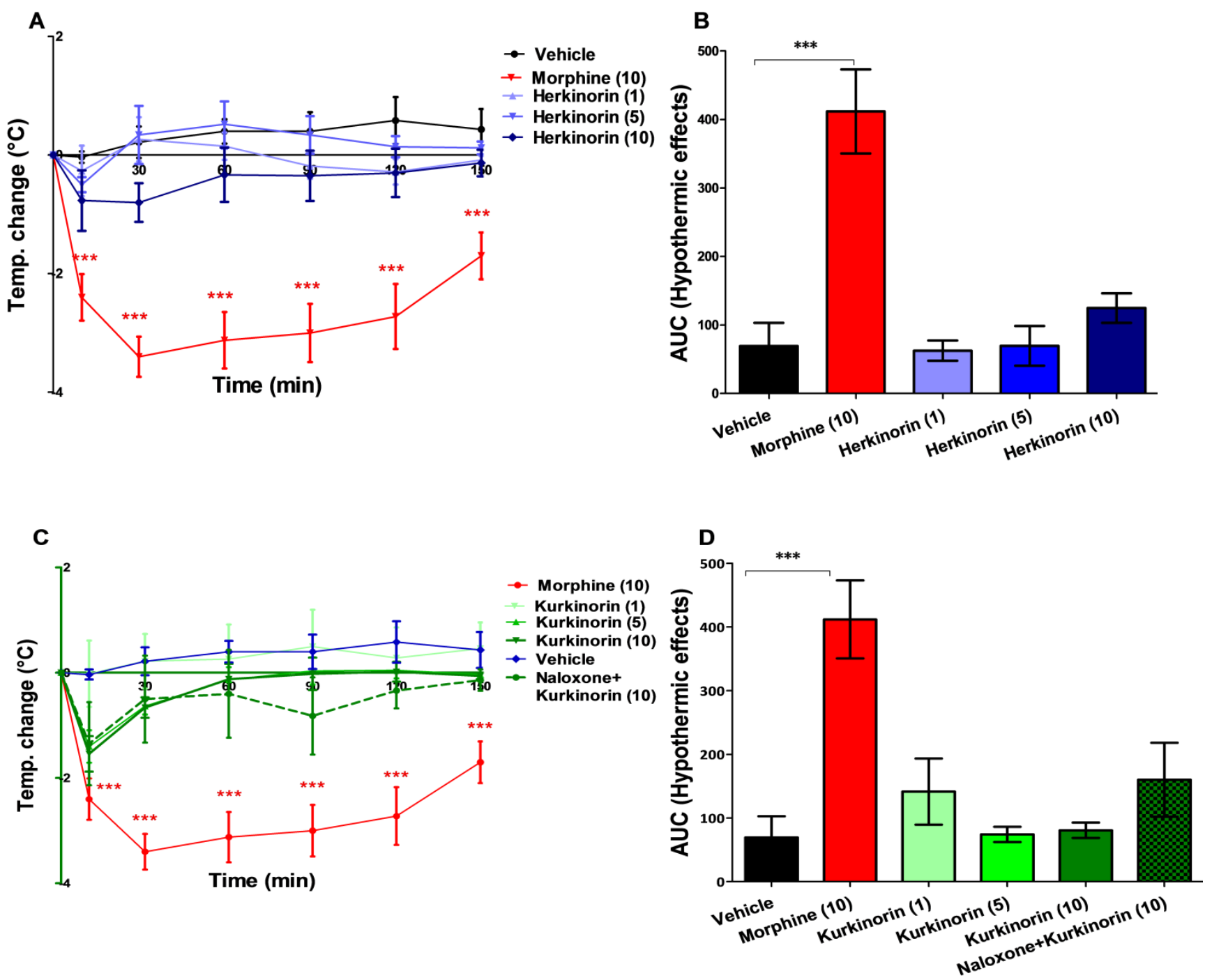

Figure 13: Effects of herkinorin and kurkinorin on core body temperature.

Core body temperature measurements Morphine shows a significant decrease in body temperature whereas (A) Herkinorin and (B) kurkinorin showed no significant changes compared to vehicle-treated mice. Data is presented as mean \pm SEM, $(n=6-10)$. Two-way ANOVA Repeated measures followed by Bonferroni's post-hoc test. ${ }^{* * *} p<0.001$ was carried out. 


\section{Discussion}

Current MOPr pharmacotherapies for pain, while effective in treating acute pain are less effective in treating chronic pain. Morphine and fentanyl are gold-standard treatments for acute severe pain and post-operative pain (Bounes, Charpentier, Houze-Cerfon, Bellard, \& Ducassé, 2008; Grond et al., 2007; Intimisi, 2002; Pergolizzi et al., 2008; Rapp, Ready, \& Nessly, 1995; Eugene R Viscusi et al., 2004; C. L. Wu \& Raja, 2011). However, these drugs have known for their adverse effects which include excessive sedation (Cherny et al., 2001; Intimisi, 2002; Stoelting \& Miller, 2007; Swegle \& Logemann, 2006), tolerance (Berge \& Hole, 1981; Detweiler, Rohde, \& Basbaum, 1995; Gutstein, Trujillo, \& Akil, 1995; Way, Lou, \& Shen, 1969), respiratory depression (Etches, Sandler, \& Daley, 1989; Romberg et al., 2003; Thompson et al., 1995), constipation (Camilleri, 2011; Droney et al., 2008; Friedman \& Buono, 2001; Ricardo Buenaventura, Rajive Adlaka, \& Nalini Sehgal, 2008), drug dependence (Aceto, Dewey, Portoghese, \& Takemori, 1986; Klein et al., 2009; Sánchez-Blázquez, GarcíaEspaña, \& Garzón, 1997; Suzuki, Narita, Takahashi, Misawa, \& Nagase, 1992; Takemori, DeLander, \& Portoghese, 1987), vomiting (Benyamin et al., 2008; M. J Cousins, 1984) and hyperalgesia (Tumati et al., 2012) which has hampered the use of these drugs for long-term treatment of moderate to severe pain and chronic pain. Around 2.1 million Americans abuse opioids and approximately 44 deaths a day is attributed to opioid overdose which is higher than the number of deaths attributed to road accidents in the US (Dodington, Violano, Baum, \& Bechtel, 2016; Okie, 2010; Paulozzi, 2012; Trang et al., 2015). Similarly, in New Zealand, around 100,000 individuals use opioids for recreational purposes (Mason, Hewitt, \& Stefanogiannis, 2010) and around 29,200 people were reported to be dependent on 
opioids. Expenditure to New Zealand is estimated to be $\$ 601$ million each year (McFadden, 2016) due to drug abuse. Developing analgesic drugs with significant antinociceptive effects and reduced adverse effects is a big scientific challenge. Despite the advanced research and searching for new targets for pain management, opioids remain the gold standard analgesics. As a continuation of the search for a drug with potential analgesic effect and reduced side-effects, we evaluated a compound called kurkinorin, which is an MOPr activating analogue of the KOPr agonist, Sal A. The aim of this study was to evaluate kurkinorin for antinociceptive effects and side-effects.

Herkinorin was the first Sal A analogue developed that activated the MOPr but was found to be ineffective in attenuating centrally mediated nociceptive processes. Previous studies demonstrated that herkinorin has 4-fold selectivity for MOPr over KOPr and is 98 -fold more selective for MOPr than DOPr (Harding et al., 2005). Both In vitro (C. E. Groer et al., 2007; Rowan et al., 2014; K. Tidgewell et al., 2008; H. Xu et al., 2008) and in vivo studies (Butelman et al., 2008; Ji et al., 2013; Lamb et al., 2012), revealed that herkinorin has limited potency $\left(E C_{50}=39.0 \pm 4.0 \mathrm{nM}\right.$ at $\left.\mathrm{MOPr}\right)($ Crowley et al., 2016). Moreover, the antinociceptive effects of herkinorin showed that it is active only when injected into the site of injury in rats in the formalin paw withdrawal test, a model for peripheral antinociception for inflammatory pain (Lamb et al., 2012). Due to its limited ability to exert centrally mediated effects \& peripherally restricted action, insufficient potency, and selectivity, herkinorin cannot be used for further research on complex pain, attenuation of centrally mediated pain pathways and drug of abuse.

Further structural modification of herkinorin by our collaborator (Prof. Prisinzano and his team in Univesity of Kansas, USA) led to the development of kurkinorin. Kurkinorin was 
synthesised by introducing an additional degree of unsaturation between C2 and C3 positions. In vitro functional assay which measures the forskolin-induced cAMP accumulation in $\mathrm{CHO}$ cells revealed that kurkinorin was extremely highly selective for $\operatorname{MOPr}(>8,000$-fold selectivity) at $10 \mu \mathrm{M}$ (Crowley et al., 2016). The selectivity was higher than that of morphine (66-fold selective over KOPr) and herkinorin (4.25-fold selective over KOPr) and the potency was similar to DAMGO (a MOPr agonist with high potency and selectivity for MOPr) (Table 2).

Kurkinorin was investigated for its antinociceptive and side-effects and was compared with morphine and herkinorin. Table 4 gives an overview of the time-course of antinociceptive effects and side-effects of each drug. 


\subsection{Antinociceptive effects}

The positive control morphine is known to produce central analgesic effects via activation of the MOPr. The centrally mediated responses including the reflexes have been studied through rapid tail-withdrawal from a thermal heat stimulus (Laura M Bohn, Lefkowitz, \& Caron, 2002; Cesselin et al., 1999; Heinricher \& Morgan, 1999; Millan, 2002; Yeung \& Rudy, 1980). Gades, Danneman, Wixson, and Tolley (2000) reported that morphine produced analgesic effects in mice at $10 \mathrm{~min}$ and the highest level of analgesia was recorded until 90 min using warm water tail-withdrawal assay (Gades et al., 2000). In our study, we found that morphine $(10 \mathrm{mg} / \mathrm{kg})$ significantly increased the tail-withdrawal latencies between 10 and $180 \mathrm{~min}$; the maximal significant analgesic effects was between $30-90 \mathrm{~min}$ with the peak effect at $30 \mathrm{~min}$ (Figure $7 \mathrm{~A} \& \mathrm{C}$ ). Our findings are in agreement with numerous previous studies that have demonstrated that morphine $(10 \mathrm{mg} / \mathrm{kg}$, i.p. and s.c.) produces significant antinociceptive effects with peak action at 30 min using tail-withdrawal assay (temperature from 49.3 to $55^{\circ} \mathrm{C}$ ) in mice (Adongo, Mante, Woode, Ameyaw, \& Kukuia, 2014; Dewan, Sangraula, \& Kumar, 2000; Gades et al., 2000; Hosseinzadeh, Haddadkhodaparast, \& Arash, 2003; Loguinov, Anderson, Crosby, \& Yukhananov, 2001; Lowery et al., 2011; Pakulska \& Czarnecka, 2009). Similarly, morphine at $5 \mathrm{mg} / \mathrm{kg}$ (Patil \& Kulkarni, 1999) and high doses above $10 \mathrm{mg} / \mathrm{kg}$ have also been reported to produce significant antinociceptive effects ( $\mathrm{T}$. Xu et al., 2013). Furthermore, in recent studies, morphine has been consistently shown to have peak effects at 30 min in rats (DeWire et al., 2013) and mice (Manglik et al., 2016) in multiple tests including tail-flick and/or hot plate assays. 
Few novel MOPr agonists such as TRV130 and PZM21 have been investigated recently and are currently undergoing clinical trials. TRV130 showed similar dose-dependant analgesic effects to morphine in the male Sprague-Dawley rats utilising tail-withdrawal assay using radiant heat. Both morphine and TRV130 showed peak analgesia at $30 \mathrm{~min}$ and similar duration of action at approximately $90 \mathrm{~min}$ in a hot-plate assay (DeWire et al., 2013).

\subsubsection{Antinociceptive effects of kurkinorin}

This is the first report of the antinociceptive effects of kurkinorin utilising warm-water tailwithdrawal assay in mice. On comparison, kurkinroin (72.9\% of maximum possible analgesic effects) showed similar antinociceptive effects as morphine at $10 \mathrm{mg} / \mathrm{kg}$ (65.3\% of maximum possible analgesic effects) (Figure 7C\&D). Our results have demonstrated that kurkinorin produced dose-dependent antinociception and the peak action was at 30 min post administration, which correlates with morphine's well-documented analgesic action.

The analgesic effects produced by morphine $(10 \mathrm{mg} / \mathrm{kg})$ have been shown previously to be prevented in naloxone pre-administered mice (10 mg/kg) (Kao et al., 2010; Loguinov et al., 2001). Similarly, the antinociceptive effects of herkinorin were also blocked by naloxone (10 $\mathrm{mg} / \mathrm{kg}$, s.c.) in a rat model of formalin-induced inflammatory pain reported previously (Lamb et al., 2012). Here we show similar effects with kurkinrorin. In Figure 7C we show that the antinociceptive effects of kurkinorin were prevented by naloxone $(10 \mathrm{mg} / \mathrm{kg}$ ) preadministration in the warm-water tail-withdrawal assay. This shows that the effects of kurkinorin are due to opioid receptor activation. Taken together, in addition to high potency and selectivity towards MOPr through binding assays, kurkinorin exhibited its centrally 
mediated spinal nociceptive responses through warm-water tail-withdrawal assay. However, the limitation of this assay is that warm-water tail-withdrawal assay is used to assess the centrally mediated antinociceptive effects of MOPr agonist and is not useful to assess the peripheral mechanism of pain. Therefore, an intra-dermal formalin test was carried out as in the below section.

\subsubsection{Intra-dermal formalin test and paw oedema}

This is the first evaluation of kurkinorin in models of pain and inflammation in vivo. Our results show that kurkinorin exhibits dose-response effects similar to morphine with a reduction in both phase I pain between 0-10 min and phase II pain observed between 20-60 $\min ($ Figure $9 \mathrm{~B}, p<0.001)$. Unlike morphine and kurkinorin, herkinorin did not show any pain reduction in phase I but showed significant pain reduction in phase II of the test $(p<0.01)$. Our study also shows dose-dependent attenuation of formalin-induced pain from 5-60 min post kurkinorin i.p. injection. Kurkinorin at $1 \mathrm{mg} / \mathrm{kg}$ did not produce any antinociception while at 5 and $10 \mathrm{mg} / \mathrm{kg}$, antinociception effects were observed in both phases. This, in turn, reveals that kurkinorin produces a morphine-like antinociceptive effect (both peripherally and centrally mediated) even at a lower dose rate of $5 \mathrm{mg} / \mathrm{kg}$. Our positive control consisted of vehicle/formalin-treated mice which exhibited significant pain scores in phase I and phase II between 5-60 min when compared to non-formalin treated, negative pain controls $(p<0.001)$ (Figure 8\&9). Administration of morphine $(10 \mathrm{mg} / \mathrm{kg}$, i.p. $)$ attenuated both phase I and phase II nociceptive pain responses (Figure 8\&9). This is consistent with previous reports that tested morphine using mice as reviewed by Barrot (2012). Previous studies by Lamb et al. (2012) demonstrated that the intraplantar injection of herkinorin and morphine 
in the right hind paw 5 min before the administration of $1.25 \%$ concentrated formalin (100 ul) in the same hind paw plantar region attenuated formalin-induced flinching behaviour. Furthermore, herkinorin was shown to produce antinociception in both phases and showed decreased tolerance liability compared to morphine. Whereas, in our study herkinorin showed antinociception in phase II alone in mice in the intra-dermal injection of $20 \mathrm{ul}$ of $2 \%$ of formalin with a systemic (i.p.) injection of herkinorin. Other possible reasons for this observation may be the differences in species, route of administration of herkinorin, its duration of effects in mice and rats, dosing intervals (Gades et al., 2000; Gallantine \& Meert, 2005), concentration and volume of formalin. Herkinorin was ineffective through systemic administration and effective in ipsilateral administration (C. E. Groer et al., 2007; Lamb et al., 2012). Hence, herkinorin is effective in producing peripherally restricted antinociception when administered at the site of action.

Kurkinorin's in vivo antinociceptive effects were reversed by naloxone and similar testing conducted using herkinorin and naloxone showed that herkinorin's antinociceptive effects were blocked by naloxone in rats (Lamb et al., 2012). While comparing paw oedema reduction results, kurkinorin reduced paw swelling significantly as same as morphine in a dose-dependent manner, while herkinorin produced less swelling but no significant reduction irrespective of dose rate. Treatment with opioid antagonist naloxone reversed the effects of kurkinorin (68.5\% difference between kurkinorin and kurkinorin pretreated with naloxone) while morphine showed $70 \%$ difference in rats (White-Gbadebo \& Holtzman, 1994) which suggests that kurkinorin's effects are opioid receptor mediated.

Intraplantar injection of formalin in the hind paw of rodents induces a local inflammatory reaction and oedema due to increased vascular permeability (Hong \& Abbott, 1995). 
Numerous studies have shown that morphine reduces inflammation and oedema when administered systemically (Amann, Lanz, \& Schuligoi, 2002; Hall, Jagher, Schaeublin, \& Wiesenberg, 1996; Sacerdote, Bianchi, \& Panerai, 1996; Whiteside, Boulet, \& Walker, 2005). Furthermore, previous studies have shown that the systemic administration of morphine activates the MOPr in peripheral and central regions, which reduce the pain and oedema after the intra-dermal injection in the hind paw (Amann et al., 2002; Sacerdote et al., 1996). Hence, the antinociceptive and anti-oedematous effects of morphine are in consistent with previous studies. In a recent study, the MOPr agonist PZM21 showed significant antinociceptive effects in a formalin injection nociception assay even though it produced no effect in the tail-flick assay. The authors suggested that this was likely due to the activation of supraspinal reflexes of descending inhibitory circuits (Manglik et al., 2016). The authors also speculated that it is uncertain if PZM21's is more biased towards MOPr versus other opioid receptors or other GPCRs which is an unusual CNS distribution phenomenon or if PZM21 may possess some other signalling property. This warrants further investigation of PZM21 to be reported as a MOPr biased agonist.

\subsubsection{Role of MOPr in antinociception}

Many current pain pharmacotherapy targets the MOPr. MOPr agonists with both beneficial analgesic effects and on target side effects, also mediated mediate via activation of the MOPr made developing improved therapies based on pharmacology deemed fruitless. Although, GPCR's functional coupling with more than one heterotrimeric G-protein was known for several years, it was discovered that single GPCR can be biased or functionally selective towards one particular G-protein in the mid 1990s, and that GPCRs could signal through G-protein or $\beta$-arrestin-mediated pathways a few years later (James W Wisler, Xiao, 
Thomsen, \& Lefkowitz, 2014). The biased ligands hence can selectively activate either Gprotein or $\beta$-arrestin pathway and produce respective effects. These pathways are associated with the preclinical effects of MOPr agonists where GPCR receptors are associated with analgesic effects, and $\beta$-arrestins are associated with producing side-effects (Zoran Rankovic et al., 2016). Moreover, MOPr agonists including morphine and etorphine promote GPCR desensitisation and produce tolerance where morphine has less effect on promoting receptor phosphorylation, and MOPr internalisation (L. M. Bohn et al., 2004; Whistler \& von Zastrow, 1998).

The activation of MOPr G-protein coupling without the recruitment of $\beta$-arrestin2 will enhance the antinociceptive effects with fewer side-effects and vice versa (L. M. Bohn et al., 1999; K. M. Raehal \& Bohn, 2011; Kirsten M Raehal et al., 2005; Zoran Rankovic et al., 2016). This was documented in mice lacking $\beta$-arrestin2 where they displayed increased and prolonged antinociception following morphine treatment with reduced MOPr side-effects such as respiratory depression and constipation compared to wild-type mice (Laura M. Bohn et al., 2000; Laura M. Bohn et al., 2007; L. M. Bohn et al., 1999; K. M. Raehal \& Bohn, 2011). Similarly, chronic treatment of morphine in $\beta$-arrestin2 knockout mice demonstrated reduced MOPr desensitisation and tolerance (Laura M. Bohn et al., 2000; L. M. Bohn et al., 1999).

A study was carried out to determine if herkinorin and kurkinorin recruited $\beta$-arrestin2 when used for pain treatment and they used $\beta$-arrestin2 enzyme fragment

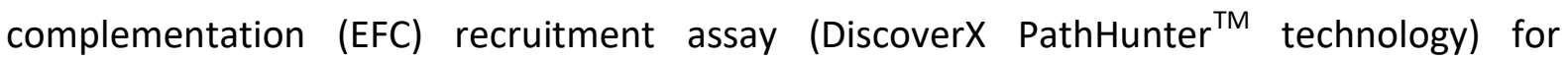
determining the same (Crowley et al., 2016). It was revealed that herkinorin activated MOPr with weak-recruitment of $\beta$-arrestin2 $\left(\mathrm{EC}_{50}>3400 \mathrm{nM}\right.$, an efficacy of $72 \%$ and bias factor 
0.95: a bias factor less than 1 indicates biased towards Cyclic AMP/G protein pathway). This was compared to another MOPr agonist, DAMGO (centrally mediated, $\mathrm{EC}_{50}>42 \mathrm{nM}$, the efficacy of $97 \%$ and bias factor 1 ) that recruits $\beta$-arrestin2 with high potency (Crowley et al., 2016). Although herkinorin has been declared to be the first GPCR biased MOPr peripherally mediated ligand, which produces little receptor phosphorylation without recruiting $\beta$ arrestin2 using fluorescent whole cell imaging (L. M. Bohn et al., 2004; C. E. Groer et al., 2007), (Crowley et al., 2016) recently showed that herkinorin weakly recruits $\beta$-arrestin2. Kurkinorin, on the other hand, was found to recruit $\beta$-arrestin2 to a very minimal extent $\mathrm{EC}_{50}>140 \mathrm{nM}$, the efficacy of $96 \%$ and bias factor 0.57 ) compared to DAMGO (Crowley et al., 2016). Morphine has been shown to have an $\mathrm{EC}_{50}>380 \mathrm{nM}$, an efficacy of $38 \%$ and bias factor of 0.36 . The authors state that although kurkinorin recruits $\beta$ arrestin 2 relatively higher than morphine, the molecular nature of its reduced side effect profile in vivo is still unclear. Some of the recent developments include TRV130, PZM21 and Mitragynine pseudoindoxyl (MOPr agonists) as mentioned earlier; TRV130 was biased to G-protein signalling pathway, promoted less GRK - mediated receptor phosphorylation and produced low levels of $\beta$-arrestin2 recruitment with no indication of MOPr internalisation (X. T. Chen et al., 2013). However, the antinociceptive assays such as the tail flick assay, and hot plate assay did not agree with each other for this compound, which raises uncertainties around the mode of action. Although PZM21 was identified as a G-protein biased MOPr ligand with potent KOPr antagonist activity (Manglik et al., 2016), that is structurally similar to TRV130, the signalling pathways are still unclear as mentioned elsewhere in this thesis (Manglik et al., 2016). Mitragynine pseudoindoxyl is G-protein biased with KOPr and DOPr antagonism, and this compound produced significant antinociceptive effects in rat tail-flick and hot-plate 
assays with reduced side-effects (Váradi et al., 2016). However, the authors acknowledge that the signalling pathway still needs clear elucidation. Collectively, all these recent drugs and research suggest that further investigations are needed to confirm these drugs' signalling pathways, their receptor selectivity, and their side-effects until then they cannot be used for clinical studies.

\section{Limitations}

Numerous factors have been recognised to influence preclinical models in the evaluation of analgesia. For example, a recent study reported that the antinociceptive experiments conducted by male researchers in rodents revealed a trigger to alter the pain behaviour and temperature changes while no such changes were recorded with female experimenters (Sorge et al., 2014). It was also suggested by the authors that the reason for this physiological stress effects might be due to the male-induced increased concentration of hormone, an androgen that might have caused the stress-induced antinociceptive effect. In the current study, we undertook suitable precautionary measures to avoid stress related nociception from occurring. As a male observer, I habituated the mice to my presence prior to the recording of analgesia for 60 min followed by handling the mice and did not leave the room during experiments. I used virkon (brand details mentioned in method section), a cleaning disinfectant to clean the mouse restrainers followed by water and paper towels to remove urine odours in the restrainer, which may affect the behaviour of mice. Our study evaluated pain in male mice (strains of rats and mice are discussed in the methods section). Ideally, as kurkinorin is a novel compound, it needs to be tested in more than one animal 
species with large sample sizes to generate robust data covering species differences, handling influences, experimenters induced effects and restrainer cleaning effects.

\subsection{Side-effect profile}

\subsubsection{Sedation}

The rotarod assay is a behavioural performance test that is used to test balance, and motor coordination in rodents and was first described in 1957 by Dunham and Miya (1957). Because MOPr agonists are known to have sedative effects, we utilised this test to measure the sedative and motor coordination impairment effects of kurkinorin in comparison to morphine in mice.

In figure $11 \mathrm{~A}$, systemic administration of morphine $(10 \mathrm{mg} / \mathrm{kg}$, i.p.) to mice demonstrated significant sedative/motor impairment effects from $15 \mathrm{~min}$ to $60 \mathrm{~min}$ post-injection. This is supported by numerous previous studies showing morphine's impaired performance in this test at $20 \mathrm{~min}$ (Stone et al., 2014). Kurkinorin, at the same dose (10 mg/kg) produced a motor impairment only at $15 \mathrm{~min}$. Area Under the Curve (AUC) analysis showed that there were no significant motor impairment effects noticed in kurkinorin. Similar sedative effects have also been reported in rats following morphine (10 $\mathrm{mg} / \mathrm{kg}$, s.c.) administration between 30 - 60 min (Gallantine \& Meert, 2005; Kenneth J. Valenzano et al., 2005) which support the findings of our study with morphine.

Morphine produced motor incoordination when administered for analgesia has been investigated extensively by previous researchers (Lotfipour et al., 2013; Luger et al., 2002; Sora et al., 1997; Kenneth J Valenzano et al., 2005; Whiteside, Gottshall, et al., 
2005). Taken together, the centrally mediated antinociception produced by kurkinorin demonstrated no significant motor impairment in contrast to morphine.

\subsubsection{Core body temperature}

The dopaminergic neurotransmitters system plays an important role in the maintenance of normal body temperature. DA plays an important role in core-body temperature, and the activation of the MOPr is known to alter the release DA neurotransmitter levels (Adler et al., 1988; Bligh, 1979; M. R. Zarrindast \& Tabatabai, 1992). DA's involvement in MOPr induced body temperature changes has been demonstrated in previous studies where systemic administration of centrally acting MOPr agonists was shown to decrease the core-body temperature in mice (A. Baker \& Meert, 2003; A. K. Baker \& Meert, 2002; Rosow et al., 1980; Trulson \& Arasteh, 1985; M.-R. Zarrindast \& Zarghi, 1992). Furthermore, MOPr mediated hypothermia has been demonstrated using morphine and fentanyl where hypothermia produced by these two compounds were antagonised by the non-specific opioid antagonist naloxone (Adler et al., 1988; A. Baker \& Meert, 2003). Studies revealed that the systemic administration of morphine produces biphasic effects on core body temperature in mice; high doses (>10 mg/kg) cause hypothermia whereas low doses cause hyperthermia (Adler et al., 1988; A. K. Baker \& Meert, 2002; Rosow et al., 1980). Furthermore, morphine administration at $10 \mathrm{mg} / \mathrm{kg}$ (i.p.) in mice revealed hypothermic effects in earlier well-documented studies (Koek, France, \& Javors, 2012; Wong \& Bentley, 1979). Consistent with this, in the present study, we evaluated core body temperature to see whether kurkinorin possessed similar effects as those of morphine. Unlike morphine which produced significant hypothermic effects from $10-150$ min post injection, kurkinorin 
did not produce any significant changes in body temperature in mice. Considering the adverse effects due to opioid-induced hypothermia which has been shown to involve DA, administration of centrally mediated MOPr should be undertaken with extra precautions while kurkinorin's lack of effects in modulating temperature is promising.

We acknowledge that core body temperature was measured after one min of tailwithdrawal assay at $0,10,30,60,90,120$ and 150 min using rectal thermal probes, which could have been unpleasant to the animals. This in turn may have induced stress and anxiety to the animals and may have influenced the core body temperature. A new method of temperature recording without involving animal handling may be helpful to explain whether or not core body temperature could be significantly influenced by rectal thermal probes induced anxiety.

\subsubsection{Rewarding effects}

The CPP paradigm is frequently used to assess the rewarding properties of drugs of abuse. This method utilises the association of the rewarding stimuli to a specific environment using visual and tactile cues. If animals were found to spend more time in the drug-paired compartment than in vehicle-paired compartment, this was shown to be indicative of rewarding effects of that drug (Piepponen, Kivastik, Katajamaki, Zharkovsky, \& Ahtee, 1997; Sanchis-Segura \& Spanagel, 2006; Schechter \& Calcagnetti, 1993). Here we show that morphine $(5 \mathrm{mg} / \mathrm{kg}$ ) (Figure 12) produced significant place preference. This finding is consistent with previous studies those that showed that morphine produced significant CPP in rats $(5 \mathrm{mg} / \mathrm{kg}$, i.p.) (Morales, Perez-Garcia, Herradon, \& Alguacil, 2007; 
Randall, Kraemer, \& Bardo, 1998; Rutten, De Vry, Bruckmann, \& Tzschentke, 2010), mice (Alavi, Hosseinzadeh, Shamsizadeh, \& Roohbakhsh, 2016; Vindenes, Handal, Ripel, Boix, \& Mørland, 2006; M.-R. Zarrindast, Bahreini, \& Adl, 2002) and rhesus monkeys (J. Wang et al., 2012; X. Wu et al., 2016).

The choice of animal model for exploring CPP was very crucial for our study. The model should respond to compounds in a way that the responses should be comparable to humans and should also be a suitable representative of physiological processes to be translated to humans. Also, ease of handling and adaptability to handling procedures are some of the criteria that should be borne in mind while choosing the animal models. Sprague-Dawley rats are easy to handle and for conditioning due to their mild temperamental nature, making them suitable for conducting CPP compared to mice (Allan, Wu, Paxton, \& Savage, 1998; Lucke-Wold, 2011). Moreover, a rat model is referred to as a standard model for developing CPP in preclinical studies of novel drugs as reviewed by Lucke-Wold (2011). Sprague-Dawley rats are reliable for experiments using novel graded drugs as well as for studies that involve preconditioning procedures (Matsuzawa, Suzuki, \& Misawa, 2000; Philpot, Badanich, \& Kirstein, 2003). Therefore, Sprague-Dawley rats were used as CPP model.

In line with our hypothesis that kurkinorin may possess bias signalling and exhibit analgesic effects with reduced side-effects, the rewarding effect was significantly lower in kurkinorin (5 mg/kg) treated rats compared to morphine $(p<0.01)$ (Figure 12). Our data clearly shows that kurkinorin demonstrated significantly less rewarding effect than morphine and there are no significant differences in rewarding properties compared with vehicle-treated rats. Whereas, herkinorin $(5 \mathrm{mg} / \mathrm{kg})$ did not show any place preference 
(Figure 12) and herkinorin's rewarding effect was non-significant compared to morphine. However, we would not expect place preference to be observed for herkinorin as this compound has been shown previously to be centrally inactive, either due to its rapid metabolism, or inability to cross the blood-brain barrier (Butelman et al., 2008).

Recently published data, performed in our laboratory also showed that morphine (10 $\mathrm{mg} / \mathrm{kg}$ ) produced significantly increased place preference compared to herkinorin (10 $\mathrm{mg} / \mathrm{kg}$ ) and kurkinorin $(10 \mathrm{mg} / \mathrm{kg}$ )(Crowley et al., 2016). Place preference assays using morphine did not find any significant differences in the number of compartments (Morales et al., 2007). On the other hand, morphine required more conditioning than cocaine to yield relative preference (Parker, 1992; Parker, Tomlinson, Horn, \& Erb, 1994). Social play is a pleasurable and rewarding characteristic (Trezza, Baarendse, \& Vanderschuren, 2010) influenced by morphine's effects which are very well exhibited by Wistar rats than Sprague-Dawley rats (Vanderschuren, Achterberg, \& Trezza, 2016). In this study, the positive control morphine produced a distinct CPP which is in accordance with some previous studies (Jolanta Kotlińska \& Biała, 1998; J. Kotlińska \& Biała, 1999; Kotlinska, Pachuta, Dylag, \& Silberring, 2007; Tzschentke, 2007) in contrast to herkinorin and kurkinorin that did not produce significant CPP. Recently, the MOPr biased agonist, mitragynine pseudoindoxyl did not show any rewarding effect in mice at $3.2 \mathrm{mg} / \mathrm{kg}$, i.p. when compared to morphine (10 mg/kg, i.p.)(Váradi et al., 2016) whereas TRV130 and PZM21 (the other MOPr biased agonists) produced CPP but were non-significant compared to vehicle (Manglik et al., 2016; E. R Viscusi et al., 2016). 
Studies by Laura M Bohn et al. (2002) demonstrated that morphine-induced tolerance was significantly less in $\beta$ - arrestin knockout mice using tail-withdrawal assay. Furthermore, in the warm-water tail-withdrawal assay they found enhanced antinociceptive response with a lesser degree of side-effects (tolerance) compared to wild-type mice. The authors also reported a reduction in morphine-induced locomotor activity in $\beta$-arrestin knockout mice. This, in turn, raises a speculation that $\beta$-arrestin recruitment may play an important role in morphine's side-effects, which include tolerance and motor impairment. This supports our hypothesis that development of Gprotein biased agonists that recruit less or no $\beta$-arrestin, such as kurkinorin may have reduced side-effects. We have shown this with kurkinorin in our current study with reduced sedative and motor incoordination effects seen in mice (igure 11). Therefore, this enhancement was correlated with an increased MOPr coupling in the spinal cord (Laura M Bohn et al., 2002). Although in our study, we did not use $\beta$-arrestin2 knock-out (Barr2-KO) mice, our lab results with kurkinorin did not show any tolerance whereas morphine showed clear tolerance within 6 days when tested through warm water tailwithdrawal assay (Crowley et al., 2016).

Kurkinorin will have to be subjected for further clinical trials to support our hypothesis of kurkinorin being a biased MOPr agonist with reduced side-effects like the recent clinical translation study conducted for TRV130 to support their hypothesis of TRV130 being a biased ligand for MOPr (Siuda, Carr lii, Rominger, \& Violin, 2017). This will further enhance our understanding of the mechanism of action of kurkinorin and strongly support the reason for conducting further research on this compound. 


\section{Conclusion}

MOPr agonists show not only attenuation of acute thermal nociceptive and inflammatory pain but also reduced side-effects. Our preclinical study of centrally acting, selective, and potent novel MOPr agonist, kurkinorin showed greater antinociceptive effects with reduced side-effects including reward and sedation. Furthermore, published information from our USA collaborators and our lab revealed that kurkinorin acts on MOPr and produces G-protein biased effects with less $\beta$-arrestin2 recruitment (Crowley et al., 2016). This, in turn, demonstrated the non-tolerance property of kurkinorin as against morphine, which proves that kurkinorin can be a promising candidate and template for developing pain pharmacotherapeutics replacing morphine.

\section{Future directions}

Kurkinorin produced similar antinociceptive effects as morphine based on two standard tests such as warm-water tail-withdrawal and intra-dermal formalin assays, and the tests have shown to produce the dose-dependent increase of antinociceptive effects at 1,5 and $10 \mathrm{mg} / \mathrm{kg}$. However, a detailed investigation has to be undertaken using additional combined antinociceptive tests to explore the reproducibility of the results as kurkinorin demonstrated centrally mediated antinociceptive effects with reduced sedative, rewarding effects and less tolerance. The above preclinical models are satisfactory for the preliminary screening and understanding of how kurkinorin exerts its effects, but further dose-response 
models with kurkinorin would allow us to understand the therapeutic potential in more depth for pain management.

The preliminary cellular studies revealed high selectivity to MOPr, and its activation at MOPr signalled G-protein mediated pathway with less $\beta$-arrestin recruitment by kurkinorin (Crowley et al., 2016). However, this pathway should be further studied in detail to ensure the same using different animal models. The centrally mediated antinociceptive action of kurkinorin did not produce significant sedative effects when compared to morphine, however, the insignificant sedative effects need to be evaluated further to ensure it is a negligible effect and a detailed study is mandatory to clarify the potential unclear reasons for this effect of kurkinroin with further animal models and large number of trials.

Furthermore, kurkinorin has to be evaluated for other side-effects such as respiratory depression and gastrointestinal side-effects including constipation as produced by morphine as it is centrally mediated. The emerging research stated that opioids interact with the innate immune receptor, Toll-like receptor 4 (TLR4) and its signalling pathway (Farzi et al., 2015) and TLR4 may contribute to opioid-induced constipation. The association of TLRs with pain have also been studied where it was found that the TLR4 has a role in the initiation of the preclinical model of neuropathic pain and the pharmacological blockage of TLR4 to prevent and reverse the preclinical model of neuropathic pain which is reviewed by Nicotra, Loram, Watkins, and Hutchinson (2012).

It has been reviewed that the lack of translational progress in the field of pain is frustrating because of the inability to develop new clinically effective compounds despite gaining huge basic knowledge by using animal models (Mogil, 2009). As a consequence rethinking and re- 
examination of animal models for evaluating pain relief drugs are warranted. Although there is a wide range of animal models including mutants that resemble clinical pain status, drug dependence and side-effects, the complexity of the pain phenomenon makes it difficult to understand the underlying mechanisms of pain relief which vary quite significantly based on sex, species, strains, handling and experimental procedures. Sprague -Dawley rats and mice have been the best suitable models for pain and translational studies. However, different strains show different sensitivity towards pain relief drugs, for example, C57BL/6 genetic background has been found to be very insensitive to pain as reviewed by (Mogil, 2009) and hence they should not be used as pain models. Similarly, female rats and mice are more sensitive to pain than their male counterparts which has to be considered while choosing animals for pain studies. Kurkinorin being a novel compound it should be tested for sex dependency, species and strain dependency in addition to other influencing factors.

Agonists that signal receptors towards G-protein coupling pathway without $\beta$-arrestin recruitment produce significant analgesic effects with fewer side-effects (L. M. Bohn et al., 2004; Laura M. Bohn et al., 2000), and centrally mediated kurkinorin is shown to be biased towards G-protein coupling pathway with $\beta$-arrestin recruitment (to a lesser extent) with no tolerance as well as no significant sedative and rewarding effects (Crowley et al., 2016). Therefore, the mechanism through which kurkinorin exerts its analgesic effects without side-effects is unclear which needs further investigation. Furthermore, the possibility of the immunosuppressive property of kurkinorin should be studied as it has been documented that opioids, such as morphine, produced immunomodulatory effects and that modular effects may alter immune responsiveness to microbial agents (Cabral, 2006). 
It should be noted that there have been recent advances in pain studies including functional magnetic resonance imaging ( $\mathrm{fMRI}$ ) that examines the real-time feedback which is used to improve control over pain (reviewed by (Worley, 2016)). Similarly, transcranial magnetic stimulation (TMS) is being used to determine various brain regions that affect pain processing. Development of brain-based biomarkers have been identified as promising tools to better distinguish pain and no pain, and this field has been shown to be an integral part of neuro-prognosis (Worley, 2016). As additional assays to preclinical studies, these recently advanced tests may be performed in an effort to understand kurkinorin's mode of action for producing analgesia, which will improve our understanding. Kurkinorin will serve as a very good pain therapeutic candidate provided its mechanism of action be explored using advanced techniques mentioned above and tested against a range of approved pain models for its successful translation for human trials. 
Table 4: Summary of antinociceptive and side effects of compounds used in this study

\begin{tabular}{|c|c|c|c|c|c|c|c|c|}
\hline \multirow{3}{*}{$\begin{array}{c}\text { Drug } \\
\text { (mg/kg) }\end{array}$} & \multicolumn{4}{|c|}{ Central analgesic effect } & \multicolumn{3}{|c|}{$\begin{array}{c}\text { Analgesic activity \& } \\
\text { Anti-inflammatory activity }\end{array}$} & \multirow{3}{*}{\begin{tabular}{|c|}
$\begin{array}{c}\text { Side effect } \\
\text { profile }\end{array}$ \\
$\begin{array}{c}\text { Accelerating } \\
\text { Rotarod }\end{array}$ \\
\end{tabular}} \\
\hline & \multirow{2}{*}{$\begin{array}{c}\text { Tail- } \\
\text { withdrawal } \\
\text { assay (min) }\end{array}$} & \multirow[b]{2}{*}{ AUC } & \multicolumn{2}{|c|}{ Intra-dermal formalin } & \multirow[b]{2}{*}{ Paw oedema } & \multirow[b]{2}{*}{ Core-body temp } & \multirow{2}{*}{$\begin{array}{l}\text { Conditioned } \\
\text { place } \\
\text { preference }\end{array}$} & \\
\hline & & & Phase I & Phase II & & & & \\
\hline $\begin{array}{l}\text { Morphine } \\
\text { (10) }\end{array}$ & $* * *(15-150)$ & $* * *$ & $* * *$ & $* * *$ & $* * *$ & $* * *$ & $* * *$ & $* * *(15-60)$ \\
\hline $\begin{array}{l}\text { Kurkinorin } \\
\text { (1) }\end{array}$ & 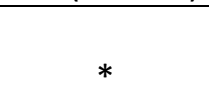 & - & $\mathrm{N}$ & $\begin{array}{l}* * *(35-50) \\
* *(55)\end{array}$ & * & $\mathrm{N}$ & - & 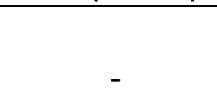 \\
\hline $\begin{array}{l}\text { Kurkinorin } \\
\text { (5) }\end{array}$ & $\begin{array}{l}* *(10,60) \\
* * *(15-45)\end{array}$ & $* *$ & $* *(5), * * *(10)$ & $* * *(20,30-60)$ & $*$ & $\mathrm{~N}$ & $\mathrm{~N}$ & - \\
\hline $\begin{array}{l}\text { Kurkinorin } \\
\text { (10) }\end{array}$ & $\begin{array}{c}* * *(5-90 \\
\min ), *(120)\end{array}$ & $* * *$ & $* * *$ & $* * *$ & $* * *$ & $\mathrm{~N}$ & - & $* * *(15)$ \\
\hline $\begin{array}{l}\text { Herkinorin } \\
\text { (1) }\end{array}$ & $\mathrm{N}$ & - & $\mathrm{N}$ & $* * *(30,40), * *(45)$ & $\mathrm{N}$ & $\mathrm{N}$ & - & - \\
\hline $\begin{array}{l}\text { Herkinorin } \\
\text { (5) }\end{array}$ & $\mathrm{N}$ & - & - & - & - & $\mathrm{N}$ & $\mathrm{N}$ & - \\
\hline $\begin{array}{l}\text { Herkinorin } \\
\text { (10) }\end{array}$ & $*(30)$ & * & $\mathrm{N}$ & $* * *(20,30-60)$ & $\mathrm{N}$ & $\mathrm{N}$ & - & - \\
\hline
\end{tabular}

\footnotetext{
$* \quad=p<0.05$

$* * \quad=p<0.01$

$* * * \quad=p<0.001$

- $\quad=$ Not tested

$\mathrm{N} \quad=$ Not significant
} 


\section{References}

Abbott, F. V., Franklin, K. B., \& Westbrook, R. F. (1995). The formalin test: scoring properties of the first and second phases of the pain response in rats. Pain, 60(1), 91-102.

Aceto, M. D., Dewey, W. L., Portoghese, P., \& Takemori, A. (1986). Effects of $\beta$ funaltrexamine ( $\beta$-FNA) on morphine dependence in rats and monkeys. European journal of pharmacology, 123(3), 387-393.

Adler, M., Geller, E., Rosow, C., \& Cochin, J. (1988). The opioid system and temperature regulation. Annual review of pharmacology and toxicology, 28(1), 429-449.

Adongo, D. W., Mante, P. K., Woode, E., Ameyaw, E. O., \& Kukuia, K. K. E. (2014). Effects of hyrdroethanolic leaf extract of Pseudospondias microcarpa (A. Rich.) Engl.(Anacardiaceae) on the central nervous system in mice. The Journal of Phytopharmacology, 6(3), 410-417.

Ahmed, S. H., Kenny, P. J., Koob, G. F., \& Markou, A. (2002). Neurobiological evidence for hedonic allostasis associated with escalating cocaine use. Nature neuroscience, 5(7), 625-626.

Ahmedzai, S. (1997). New approaches to pain control in patients with cancer. European Journal of Cancer, 33, S8-S14.

Alavi, M. S., Hosseinzadeh, H., Shamsizadeh, A., \& Roohbakhsh, A. (2016). The effect of O1602 , an atypical cannabinoid, on morphine-induced conditioned place preference and physical dependence. Pharmacological Reports, 68(3), 592-597. doi:http://dx.doi.org/10.1016/i.pharep.2015.12.009

Allan, A. M., Wu, H., Paxton, L. L., \& Savage, D. D. (1998). Prenatal ethanol exposure alters the modulation of the gamma-aminobutyric acidA1 receptor-gated chloride ion channel in adult rat offspring. J Pharmacol Exp Ther, 284(1), 250-257.

Allouche, S., Noble, F., \& Marie, N. (2014). Opioid receptor desensitization: mechanisms and its link to tolerance. Frontiers in Pharmacology, 5(280). doi:10.3389/fphar.2014.00280

Aloisi, A. M., Albonetti, M. E., \& Carli, G. (1995). Behavioural effects of different intensities of formalin pain in rats. Physiology \& behavior, 58(3), 603-610.

Amann, R., Lanz, I., \& Schuligoi, R. (2002). Effects of Morphine on Oedema and Tissue Concentration of Nerve Growth Factor in Experimental Inflammation of the Rat Paw. Pharmacology, 66(3), 169-172.

American Pain Society. (2000). Pain assessment and treatment in the managed care environment. The Case Manager, 11(5), 50-53.

Athanasos, P., Smith, C. S., White, J. M., Somogyi, A. A., Bochner, F., \& Ling, W. (2006). Methadone maintenance patients are cross-tolerant to the antinociceptive effects of very high plasma morphine concentrations. Pain, 120(3), 267-275.

Baker, A., \& Meert, T. (2003). Morphine and d-Amphetamine Nullify Each Others' Hypothermic Effects in Mice. Pharmacology \& Toxicology, 92(2), 64-70. doi:10.1034/j.1600-0773.2003.t01-1-920202.x

Baker, A. K., \& Meert, T. F. (2002). Functional Effects of Systemically Administered Agonists and Antagonists of $\mu, \delta$, and $\mathrm{k}$ Opioid Receptor Subtypes on Body Temperature in 
Mice. Journal of Pharmacology and Experimental Therapeutics, 302(3), 1253-1264. doi:10.1124/jpet.102.037655

Bals-Kubik, R., Ableitner, A., Herz, A., \& Shippenberg, T. S. (1993). Neuroanatomical sites mediating the motivational effects of opioids as mapped by the conditioned place preference paradigm in rats. Journal of Pharmacology and Experimental Therapeutics, 264(1), 489-495.

Balthazar, C. H., Leite, L. H., Ribeiro, R. M., Soares, D. D., \& Coimbra, C. C. (2010). Effects of blockade of central dopamine D1 and D2 receptors on thermoregulation, metabolic rate and running performance. Pharmacol Rep, 62(1), 54-61.

Barrot, M. (2012). Tests and models of nociception and pain in rodents. Neuroscience, 211, 39-50. doi:http://dx.doi.org/10.1016/j.neuroscience.2011.12.041

Basbaum, A. I., Bautista, D. M., Scherrer, G., \& Julius, D. (2009). Cellular and Molecular Mechanisms of Pain. Cell, 139(2), 267-284. doi:http://dx.doi.org/10.1016/i.cell.2009.09.028

Belfer, I. (2013). Nature and Nurture of Human Pain. Scientifica, 2013, 19. doi:10.1155/2013/415279

Belfer, I., Schreiber, K. L., Shaffer, J. R., Shnol, H., Blaney, K., Morando, A., . . Ahrendt, G. (2013). Persistent postmastectomy pain in breast cancer survivors: analysis of clinical, demographic, and psychosocial factors. The Journal of Pain, 14(10), 11851195.

Benarroch, E. E. (2015). Ion channels in nociceptors Recent developments. Neurology, 84(11), 1153-1164.

Benyamin, R., Trescot, A. M., Datta, S., Buenaventura, R., Adlaka, R., Sehgal, N., . . Vallejo, R. (2008). Opioid complications and side effects. Pain Physician, 11(2 Suppl), S105120.

Berge, O.-G., \& Hole, K. (1981). Tolerance to the antinociceptive effect of morphine in the spinal rat. Neuropharmacology, 20(7), 653-657.

Berger, A. C., \& Whistler, J. L. (2010). How to design an opioid drug that causes reduced tolerance and dependence. Annals of neurology, 67(5), 559-569.

Bernards, C. M., Knowlton, S. L., Schmidt, D. F., Depaso, W. J., Lee, M. K., McDonald, S. B., \& Bains, O. S. (2009). Respiratory and sleep effects of remifentanil in volunteers with moderate obstructive sleep apnea. Anesthesiology, 110(1), 41-49. doi:10.1097/ALN.0b013e318190b501

Berry, P. H., Chapman, C., Covington, E., Dahl, J., Katz, J., Miaskowski, C., \& McLean, M. (2001). Pain: current understanding of assessment, management, and treatments. National Pharmaceutical Council and the Joint Commission for the Accreditation of Healthcare Organizations, VA, USA, b44.

Besse, D., Lombard, M. C., \& Besson, J. M. (1991). Autoradiographic distribution of $\mu, \delta$ and $\mathrm{K}$ opioid binding sites in the superficial dorsal horn, over the rostrocaudal axis of the rat spinal cord. Brain Research, 548(1-2), 287-291. doi:http://dx.doi.org/10.1016/0006-8993(91)91134-M

Blake, D. W., Yew, C. Y., Donnan, G. B., \& Williams, D. L. (2009). Postoperative analgesia and respiratory events in patients with symptoms of obstructive sleep apnoea. Anaesthesia and Intensive Care, 37(5), 720-725.

Bligh, J. (1979). The central neurology of mammalian thermoregulation. Neuroscience, 4(9), 1213-1216. 
Blyth, F. M., March, L. M., Brnabic, A. J., Jorm, L. R., Williamson, M., \& Cousins, M. J. (2001). Chronic pain in Australia: a prevalence study. Pain, 89(2), 127-134.

Bohm, S., Grady, E., \& Bunnett, N. (1997). Regulatory mechanisms that modulate signalling by G-protein-coupled receptors. Biochem. J, 322, 1-18.

Bohn, L., Dykstra, L., Lefkowitz, R., Caron, M., \& Barak, L. (2004). Relative opioid efficacy is determined by the complements of the $\mathrm{G}$ protein-coupled receptor desensitization machinery. Molecular Pharmacology, 66(1), 106-112.

Bohn, L. M., Gainetdinov, R. R., Lin, F.-T., Lefkowitz, R. J., \& Caron, M. G. (2000). Mu opioid receptor desensitization by [beta]-arrestin-2 determines morphine tolerance but not dependence. Nature, 408(6813), 720-723.

Bohn, L. M., Groer, C. E., Tidgewell, K., Moyer, R., Harding, W. W., \& Prisinzano, T. E. (2007). $\mathrm{Mu}$ opioid receptor activation without arrestin-interactions; a pharmacological approach. Faseb Journal, 21(5), A426-A426.

Bohn, L. M., Lefkowitz, R. J., \& Caron, M. G. (2002). Differential mechanisms of morphine antinociceptive tolerance revealed in Barrestin-2 knock-out mice. The Journal of neuroscience, 22(23), 10494-10500.

Bohn, L. M., Lefkowitz, R. J., Gainetdinov, R. R., Peppel, K., Caron, M. G., \& Lin, F. T. (1999). Enhanced morphine analgesia in mice lacking beta-arrestin 2. Science, 286(5449), 2495-2498.

Bonci, A., Bernardi, G., Grillner, P., \& Mercuri, N. B. (2003). The dopamine-containing neuron: maestro or simple musician in the orchestra of addiction? Trends in Pharmacological Sciences, 24(4), 172-177. doi:http://dx.doi.org/10.1016/S0165$\underline{6147(03) 00068-3}$

Bonin, R. P., \& Orser, B. A. (2008). GABA A receptor subtypes underlying general anesthesia. Pharmacology Biochemistry and behavior, 90(1), 105-112.

Bounes, V., Charpentier, S., Houze-Cerfon, C.-H., Bellard, C., \& Ducassé, J. L. (2008). Is there an ideal morphine dose for prehospital treatment of severe acute pain? A randomized, double-blind comparison of 2 doses. The American journal of emergency medicine, 26(2), 148-154.

Bozarth, M. A. (1987). Conditioned place preference: A parametric analysis using systemic heroin injections Methods of assessing the reinforcing properties of abused drugs (pp. 241-273): Springer New York.

Brack, A., \& Stein, C. (2004). Potential links between leukocytes and antinociception. Pain, 111(1-2), 1-2.

Breivik, H., Collett, B., Ventafridda, V., Cohen, R., \& Gallacher, D. (2006). Survey of chronic pain in Europe: prevalence, impact on daily life, and treatment. European journal of pain, 10(4), 287-287.

Brownstein, M. J. (1993). A brief history of opiates, opioid peptides, and opioid receptors. Proceedings of the National Academy of Sciences, 90(12), 5391-5393.

Bruera, E., Chadwick, S., Brenneis, C., Hanson, J., \& MacDonald, R. N. (1987). Methylphenidate associated with narcotics for the treatment of cancer pain. Cancer treatment reports, 71(1), 67-70.

Bruijnzeel, A. W. (2009). kappa-Opioid receptor signaling and brain reward function. Brain research reviews, 62(1), 127-146.

Butelman, E. R., Rus, S., Simpson, D. S., Wolf, A., Prisinzano, T. E., \& Kreek, M. J. (2008). The effects of Herkinorin, the first $\mu$-selective ligand from a salvinorin a-derived scaffold, 
in a neuroendocrine biomarker assay in nonhuman primates. Journal of Pharmacology and Experimental Therapeutics, 327(1), 154-160. doi:10.1124/jpet.108.140079

Cabral, G. A. (2006). Drugs of abuse, immune modulation, and AIDS. Journal of neuroimmune pharmacology, 1(3), 280-295.

Calixto, J. B., Scheidt, C., Otuki, M., \& Santos, A. R. (2001). Biological activity of plant extracts: novel analgesic drugs. Expert opinion on emerging drugs, 6(2), 261-279.

Calvino, B. (1990). Differential effect of a chemical algogen on two nociceptive thresholds. Physiology \& behavior, 47(5), 907-910.

Camilleri, M. (2011). Opioid-Induced Constipation: Challenges and Therapeutic Opportunities. Am J Gastroenterol, 106(5), 835-842.

Carr, G., Phillips, A., \& Fibiger, H. (1988). Independence of amphetamine reward from locomotor stimulation demonstrated by conditioned place preference. Psychopharmacology, 94(2), 221-226.

Cesselin, F., Benoliel, J.-J., Bourgoin, S., Collin, E., Pohl, M., \& Hamon, M. (1999). Spinal mechanisms of opioid analgesia. Opioids in pain control: basic and clinical aspects. Cambridge University Press, Cambridge, 70-95.

Chen, X.T., Pitis, P., Liu, G., Yuan, C., Gotchev, D., Cowan, C. L., . . Yamashita, D. S. (2013). Structure-Activity Relationships and Discovery of a $\mathrm{G}$ Protein Biased $\mu$ Opioid Receptor Ligand, [(3-Methoxythiophen-2-yl)methyl](\{2-[(9R)-9-(pyridin-2-yl)-6oxaspiro-[4.5]decan-9-yl]ethyl\})amine (TRV130), for the Treatment of Acute Severe Pain. Journal of Medicinal Chemistry, 56(20), 8019-8031. doi:10.1021/jm4010829

Chen, Y., Mestek, A., Liu, J., Hurley, J. A., \& Yu, L. (1993). Molecular cloning and functional expression of a mu-opioid receptor from rat brain. Molecular Pharmacology, 44(1), 8-12.

Cherny, N., Ripamonti, C., Pereira, J., Davis, C., Fallon, M., McQuay, H., .. . Ventafridda, V. (2001). Strategies to manage the adverse effects of oral morphine: an evidencebased report. Journal of Clinical Oncology, 19(9), 2542-2554.

Choi, S. H., Koo, B. N., Nam, S. H., Lee, S. J., Kim, K. J., Kil, H. K., ... Jeon, D. H. (2008). Comparison of remifentanil and fentanyl for postoperative pain control after abdominal hysterectomy. Yonsei Medical Journal, 49(2), 204-210. doi:10.3349/ymj.2008.49.2.204

Clavelou, P., Dallel, R., Orliaguet, T., Woda, A., \& Raboisson, P. (1995). The orofacial formalin test in rats: effects of different formalin concentrations. Pain, 62(3), 295-301.

Clemons, M., Regnard, C., \& Appleton, T. (1996). Alertness, cognition and morphine in patients with advanced cancer. Cancer treatment reviews, 22(6), 451-468.

Coggeshall, R. E., \& Carlton, S. M. (1997). Receptor localization in the mammalian dorsal horn and primary afferent neurons. Brain Research Reviews, 24(1), 28-66. doi:http://dx.doi.org/10.1016/S0165-0173(97)00010-6

Coghill, R. C., Talbot, J. D., Evans, A. C., Meyer, E., Gjedde, A., Bushnell, M. C., \& Duncan, G. $\mathrm{H}$. (1994). Distributed processing of pain and vibration by the human brain. The Journal of neuroscience, 14(7), 4095-4108.

Collett, B. (1998). Opioid tolerance: the clinical perspective. British journal of anaesthesia, $81,58-68$. 
Contet, C., Kieffer, B. L., \& Befort, K. (2004). Mu opioid receptor: a gateway to drug addiction. Current Opinion in Neurobiology, 14(3), 370-378. doi:10.1016/j.conb.2004.05.005

Corrigall, W. A., \& Linseman, M. A. (1988). Conditioned place preference produced by intrahippocampal morphine. Pharmacology Biochemistry and Behavior, 30(3), 787-789.

Cousins, M. J. (1984). Intrathecal and Epidural Administration of Opioids. Anesthesiology, 61, 276-310.

Cousins, M. J. (2012). Unrelieved pain: a major health care priority. Medical journal of Australia, 196(6), 373-374.

Coux, O., Tanaka, K., \& Goldberg, A. L. (1996). Structure and functions of the $20 \mathrm{~S}$ and $26 \mathrm{~S}$ proteasomes. Annu Rev Biochem, 65, 801-847. doi:10.1146/annurev.bi.65.070196.004101

Crowley, R. S., Riley, A. P., Sherwood, A. M., Groer, C. E., Shivaperumal, N., Biscaia, M., ... Kivell, B. M. (2016). Synthetic Studies of Neoclerodane Diterpenes from Salvia divinorum: Identification of a Potent and Centrally Acting $\mu$ Opioid Analgesic with Reduced Abuse Liability. Journal of Medicinal Chemistry, 59(24), 11027-11038. doi:10.1021/acs.jmedchem.6b01235

Davies, E. C., Green, C. F., Taylor, S., Williamson, P. R., Mottram, D. R., \& Pirmohamed, M. (2009). Adverse drug reactions in hospital in-patients: a prospective analysis of 3695 patient-episodes. PLoS one, 4(2), e4439.

Deng, H. B., Yu, Y., Pak, Y., O'Dowd, B. F., George, S. R., Surratt, C. K., . . Wang, J. B. (2000). Role for the $C$-terminus in agonist-induced $\mu$ opioid receptor phosphorylation and desensitization. Biochemistry, 39(18), 5492-5499.

DePriest, A. Z., \& Miller, K. (2014). Oxycodone/Naloxone: Role in Chronic Pain Management, Opioid-Induced Constipation, and Abuse Deterrence. Pain and Therapy, 3(1), 1-15. doi:10.1007/s40122-014-0026-2

Detweiler, D. J., Rohde, D. S., \& Basbaum, A. I. (1995). The development of opioid tolerance in the formalin test in the rat. Pain, 63(2), 251-254.

Dewan, S., Sangraula, H., \& Kumar, V. L. (2000). Preliminary studies on the analgesic activity of latex of Calotropris procera. Journal of Ethnopharmacology, 73(1-2), 307-311. doi:http://dx.doi.org/10.1016/S0378-8741(00)00272-5

DeWire, S. M., Yamashita, D. S., Rominger, D. H., Liu, G., Cowan, C. L., Graczyk, T. M., . . . Violin, J. D. (2013). A G Protein-Biased Ligand at the mu-Opioid Receptor Is Potently Analgesic with Reduced Gastrointestinal and Respiratory Dysfunction Compared with Morphines. Journal of Pharmacology and Experimental Therapeutics, 344(3), 708717. doi:10.1124/jpet.112.201616

Dhawan, B. N., Cesselin, F., Raghubir, R., Reisine, T., Bradley, P. B., Portoghese, P. S., \& Hamon, M. (1996). International Union of Pharmacology. XII. Classification of opioid receptors. Pharmacol Rev, 48(4), 567-592.

Dickenson, A. H., \& Sullivan, A. F. (1987). Subcutaneous formalin-induced activity of dorsal horn neurones in the rat: differential response to an intrathecal opiate administered pre or post formalin. Pain, 30(3), 349-360.

Dodington, J., Violano, P., Baum, C. R., \& Bechtel, K. (2016). Drugs, guns and cars: how far we have come to improve safety in the United States; yet we still have far to go. Pediatric research. 
Dowell, D., Haegerich, T. M., \& Chou, R. (2016). CDC Guideline for Prescribing Opioids for Chronic Pain - United States. MMWR Recomm Rep 2016, 65, 1-49. Retrieved from doi:DOI: http://dx.doi.org/10.15585/mmwr.rr6501e1

Droney, J., Ross, J., Gretton, S., Welsh, K., Sato, H., \& Riley, J. (2008). Constipation in cancer patients on morphine. Supportive Care in Cancer, 16(5), 453-459. doi:10.1007/s00520-007-0373-1

Dubuisson, D., \& Dennis, S. G. (1978). The formalin test: a quantitative study of the analgesic effects of morphine, meperidine, and brain stem stimulation in rats and cats. Pain, 4, 161-174.

Dunham, N. W., \& Miya, T. S. (1957). A note on a simple apparatus for detecting neurological deficit in rats and mice. J Am Pharm Assoc Am Pharm Assoc (Baltim), 46, 208-209.

Eisenberg, D. M., Kessler, R. C., Foster, C., Norlock, F. E., Calkins, D. R., \& Delbanco, T. L. (1993). Unconventional medicine in the United States--prevalence, costs, and patterns of use. New England Journal of Medicine, 328(4), 246-252.

Etches, R. C., Sandler, A. N., \& Daley, M. D. (1989). Respiratory depression and spinal opioids. Canadian journal of anaesthesia, 36(2), 165-185.

Farzi, A., Halicka, J., Mayerhofer, R., Fröhlich, E. E., Tatzl, E., \& Holzer, P. (2015). Toll-like receptor 4 contributes to the inhibitory effect of morphine on colonic motility in vitro and in vivo. Scientific reports, 5.

FDA. (2014). Recommended warning for over the counter Acetaminophen containing drug products and labeling statements regarding serious skin reactions. USA: U.S. Department of Health and Human Services.

Ferguson, S. S. (2001). Evolving concepts in G protein-coupled receptor endocytosis: the role in receptor desensitization and signaling. Pharmacol Rev, 53(1), 1-24.

Field, M. J., \& Cassel, C. K. (1997). Approaching death: improving care at the end of life: National Academies Press.

Fields, H. L., \& Margolis, E. B. (2015). Understanding opioid reward. Trends in neurosciences, $38(4), 217-225$.

Fishman, S. M. (2007). Recognizing pain management as a human right: a first step. Anesthesia \& Analgesia, 105(1), 8-9.

Freye, E., \& Latasch, L. (2003). [Development of opioid tolerance--molecular mechanisms and clinical consequences]. Anasthesiologie, Intensivmedizin, Notfallmedizin, Schmerztherapie: AINS, 38(1), 14-26.

Friedman, J. D., \& Buono, F. A. D. (2001). Opioid antagonists in the treatment of opioidinduced constipation and pruritus. Annals of Pharmacotherapy, 35(1), 85-91.

Gades, N. M., Danneman, P. J., Wixson, S. K., \& Tolley, E. A. (2000). The magnitude and duration of the analgesic effect of morphine, butorphanol, and buprenorphine in rats and mice. Journal of the American Association for Laboratory Animal Science, 39(2), 8-13.

Gallantine, E. L., \& Meert, T. F. (2005). A Comparison of the Antinociceptive and Adverse Effects of the $\mu$-Opioid Agonist Morphine and the $\delta$-Opioid Agonist SNC80. Basic \& clinical pharmacology \& toxicology, 97(1), 39-51.

Gallup, \& Organization. (1999). Gallup survey: May 21-June 9, 1999. Retrieved from

Gardea, M. A., \& Gatchel, R. J. (2000). Interdisciplinary treatment of chronic pain. Current review of pain, $4(1), 18-23$. 
Gaskin, D. J., \& Richard, P. (2011). Relieving pain in America : a blueprint for transforming prevention, care, education, and research. Washington, D.C.: National Academies Press.

Gaskin, D. J., \& Richard, P. (2012). The Economic Costs of Pain in the United States. The Journal of Pain, 13(8), 715-724. doi:http://dx.doi.org/10.1016/i.jpain.2012.03.009

Geffeney, Shana L., \& Goodman, Miriam B. (2012). How We Feel: Ion Channel Partnerships that Detect Mechanical Inputs and Give Rise to Touch and Pain Perception. Neuron, 74(4), 609-619. doi:http://dx.doi.org/10.1016/i.neuron.2012.04.023

Goldstein, A., \& Naidu, A. (1989). Multiple opioid receptors: ligand selectivity profiles and binding site signatures. Molecular Pharmacology, 36(2), 265-272.

Gouardères, C., Cros, J., \& Quirion, R. (1985). Autoradiographic localization of mu, delta and kappa opioid receptor binding sites in rat and guinea pig spinal cord. Neuropeptides, 6(4), 331-342.

Groer, C. E., Tidgewell, K., Moyer, R. A., Harding, W. W., Rothman, R. B., Prisinzano, T. E., \& Bohn, L. M. (2007). An opioid agonist that does not induce mu-opioid receptor Arrestin interactions or receptor internalization. Molecular Pharmacology, 71(2), 549-557. doi:10.1124/mol.106.028258

Grond, S., Hall, J., Spacek, A., Hoppenbrouwers, M., Richarz, U., \& Bonnet, F. (2007). lontophoretic transdermal system using fentanyl compared with patient-controlled intravenous analgesia using morphine for postoperative pain management + . British journal of anaesthesia, 98(6), 806-815.

Grossman, M., Basbaum, A., \& Fields, H. (1982). Afferent and efferent connections of the rat tail flick reflex (a model used to analyze pain control mechanisms). Journal of Comparative Neurology, 206(1), 9-16.

Gutstein, H. B., Trujillo, K. A., \& Akil, H. (1995). Does chronic nociceptive stimulation alter the development of morphine tolerance? Brain research, 680(1), 173-179.

Hackler, L., Zadina, J. E., Ge, L.-J., \& Kastin, A. J. (1997). Isolation of Relatively Large Amounts of Endomorphin-1 and Endomorphin-2 From Human Brain Cortex. Peptides, 18(10), 1635-1639. doi:http://dx.doi.org/10.1016/S0196-9781(97)00259-3

Hajhashemi, V., Ghannadi, A., \& Jafarabadi, H. (2004). Black cumin seed essential oil, as a potent analgesic and antiinflammatory drug. Phytotherapy Research, 18(3), 195-199.

Hall, T. J., Jagher, B., Schaeublin, M., \& Wiesenberg, I. (1996). The analgesic drug buprenorphine inhibits osteoclastic bone resorption in vitro, but is proinflammatory in rat adjuvant arthritis. Inflammation Research, 45(6), 299-302. doi:10.1007/BF02280995

Harding, W. W., Tidgewell, K., Byrd, N., Cobb, H., Dersch, C. M., Butelman, E. R., . . . Prisinzano, T. E. (2005). Neoclerodane diterpenes as a novel scaffold for mu opioid receptor ligands. J Med Chem, 48(15), 4765-4771. doi:10.1021/jm048963m

Hayes, R. L., Bennett, G. J., Newlon, P. G., \& Mayer, D. J. (1978). Behavioral and physiological studies of non-narcotic analgesia in the rat elicited by certain environmental stimuli. Brain research, 155(1), 69-90.

Health, M. o. (2008). A Portrait of Health: Key results of the 2006/07. Retrieved from Wellington:

Heinricher, M. M., \& Morgan, M. M. (1999). Supraspinal mechanisms of opioid analgesia. Opioids in pain control: basic and clinical aspects University Press, Cambridge, 46-69. 
Helms, J. E., \& Barone, C. P. (2008). Physiology and treatment of pain. Critical care nurse, 28(6), 38-49.

Herndon, C. M., Jackson, K. C., \& Hallin, P. A. (2002). Management of Opioid-Induced Gastrointestinal Effects in Patients Receiving Palliative Care. Pharmacotherapy: The Journal of Human Pharmacology and Drug Therapy, 22(2), 240-250.

Holden, J. E., Jeong, Y., \& Forrest, J. M. (2005). The endogenous opioid system and clinical pain management. AACN Clin Issues, 16(3), 291-301.

Hong, Y., \& Abbott, F. V. (1995). Peripheral opioid modulation of pain and inflammation in the formalin test. Eur J Pharmacol, 277(1), 21-28.

Horan, P., Taylor, J., Yamamura, H. I., \& Porreca, F. (1992). Extremely long-lasting antagonistic actions of nor-binaltorphimine (nor-BNI) in the mouse tail-flick test. Journal of Pharmacology and Experimental Therapeutics, 260(3), 1237-1243.

Horvath, G. (2000). Endomorphin-1 and endomorphin-2: pharmacology of the selective endogenous $\mu$-opioid receptor agonists. Pharmacology \& Therapeutics, 88(3), 437463. doi:http://dx.doi.org/10.1016/S0163-7258(00)00100-5

Hosseinzadeh, H., Haddadkhodaparast, M. H., \& Arash, A. R. (2003). Antinociceptive, antiinflammatory and acute toxicity effects of Salvia leriifolia Benth. seed extract in mice and rats. Phytotherapy Research, 17(4), 422-425.

Hosseinzadeh, H., \& Younesi, H. M. (2002). Antinociceptive and anti-inflammatory effects of Crocus sativus L. stigma and petal extracts in mice. BMC pharmacology, 2(1), 1-8.

Hudgel, D. W., \& Devadatta, P. (1984). Decrease in functional residual capacity during sleep in normal humans. Journal of Applied Physiology Respiratory Environmental and Exercise Physiology, 57(5), 1319-1322.

Hudgel, D. W., Martin, R. J., Johnson, B., \& Hill, P. (1984). Mechanics of the respiratory system and breathing pattern during sleep in normal humans. Journal of Applied Physiology Respiratory Environmental and Exercise Physiology, 56(1), 133-137.

Hughes, J. (1975). Isolation of an endogenous compound from the brain with pharmacological properties similar to morphine. Brain research, 88(2), 295-308.

Hunskaar, S., \& Hole, K. (1987). The formalin test in mice: dissociation between inflammatory and non-inflammatory pain. Pain, 30(1), 103-114.

IASP, I. a. f. t. S. o. P.-. (1986). Classification of chronic pain. Descriptors of chronic pain syndromes and definition of pain terms. Retrieved from

Ignatavicius DA, \& Workman, M. (2006). Medical-Surgical Nursing/Critical Thinking for Collaborative Care (5th ed ed.). PA: Philadelphia.

Intimisi, C. E. (2002). Clinical pharmacology of opioids for pain. Clin J Pain, 18, S3-S13.

Jaeger, T. V., \& van der Kooy, D. (1996). Separate neural substrates mediate the motivating and discriminative properties of morphine. Behavioral neuroscience, 110(1), 181.

Janecka, A., Fichna, J., \& Janecki, T. (2004). Opioid receptors and their ligands. Current topics in medicinal chemistry, 4(1), 1-17.

Ji, F., Wang, Z., Ma, N., Riley, J., Armstead, W. M., \& Liu, R. (2013). Herkinorin dilates cerebral vessels via kappa opioid receptor and cyclic adenosine monophosphate (cAMP) in a piglet model. Brain Res, 1490, 95-100.

doi:10.1016/j.brainres.2012.10.024

Joazeiro, C. A., \& Hunter, T. (2000). Biochemistry. Ubiquitination--more than two to tango. Science, 289(5487), 2061-2062. 
Johnson, S. W., \& North, R. A. (1992). Opioids excite dopamine neurons by hyperpolarization of local interneurons. Journal of Neuroscience, 12(2), 483-488.

Julius, D., \& Basbaum, A. I. (2001). Molecular mechanisms of nociception. Nature, 413(6852), 203-210.

Kao, J. H., Chen, S. L., Ma, H. I., Law, P. Y., Tao, P. L., \& Loh, H. H. (2010). Intrathecal Delivery of a Mutant $\mu$-Opioid Receptor Activated by Naloxone as a Possible Antinociceptive Paradigm. Journal of Pharmacology and Experimental Therapeutics, 334(3), 739-745. doi:10.1124/jpet.109.165399

Kelly, E. (2013). Efficacy and ligand bias at the mu-opioid receptor. British Journal of Pharmacology, 169(7), 1430-1446. doi:10.1111/bph.12222

Kelly, E., Bailey, C. P., \& Henderson, G. (2008). Agonist-selective mechanisms of GPCR desensitization. British Journal of Pharmacology, 153(S1), S379-S388.

Kenakin, T. (1995). Agonist-receptor efficacy II: agonist trafficking of receptor signals. Trends in pharmacological sciences, 16(7), 232-238.

Keogh, E., McCracken, L. M., \& Eccleston, C. (2005). Do men and women differ in their response to interdisciplinary chronic pain management? Pain, 114(1), 37-46.

Khan, H., Saeed, M., Khan, M. A., Dar, A., \& Khan, I. (2010). The antinociceptive activity of Polygonatumverticillatum rhizomes in pain models. Journal of ethnopharmacology, 127(2), 521-527.

Kidd, B. L., \& Urban, L. A. (2001). Mechanisms of inflammatory pain. British journal of anaesthesia, 87(1), 3-11. doi:10.1093/bja/87.1.3

Kieffer, B. L. (1999). Opioids: first lessons from knockout mice. Trends in pharmacological sciences, 20(1), 19-26.

Kieffer, B. L., Befort, K., Gaveriaux-Ruff, C., \& Hirth, C. G. (1992). The delta-opioid receptor: isolation of a cDNA by expression cloning and pharmacological characterization. Proc Natl Acad Sci U S A, 89(24), 12048-12052.

Kieffer, B. L., \& Evans, C. J. (2009). Opioid receptors: from binding sites to visible molecules in vivo. Neuropharmacology, 56 Suppl 1, 205-212. doi:10.1016/j.neuropharm.2008.07.033

Kim, I.-M., Tilley, D. G., Chen, J., Salazar, N. C., Whalen, E. J., Violin, J. D., \& Rockman, H. A. (2008). $\beta$-Blockers alprenolol and carvedilol stimulate $\beta$-arrestin-mediated EGFR transactivation. Proceedings of the National Academy of Sciences, 105(38), 1455514560. doi:10.1073/pnas.0804745105

Klein, G., Rossi, G. C., Waxman, A. R., Arout, C., Juni, A., Inturrisi, C. E., \& Kest, B. (2009). The contribution of MOR-1 exons 1-4 to morphine and heroin analgesia and dependence. Neuroscience letters, 457(3), 115-119.

Koek, W., France, C. P., \& Javors, M. A. (2012). Morphine-induced motor stimulation, motor incoordination, and hypothermia in adolescent and adult mice. Psychopharmacology, 219(4), 1027-1037.

Kohout, T. A., \& Lefkowitz, R. J. (2003). Regulation of G protein-coupled receptor kinases and arrestins during receptor desensitization. Molecular Pharmacology, 63(1), 9-18.

Koob, G. F., \& Moal, M. L. (1997). Drug Abuse: Hedonic Homeostatic Dysregulation. Science, 278(5335), 52-58. doi:10.1126/science.278.5335.52

Kotlińska, J., \& Biała, G. (1998). Effects of the NMDA/glycine receptor antagonist, L-701,324, on morphine-and cocaine-induced place preference. Polish journal of pharmacology, 51(4), 323-330. 
Kotlińska, J., \& Biała, G. (1999). Effects of the NMDA/glycine receptor antagonist, L-701,324, on morphine- and cocaine-induced place preference. Polish Journal of Pharmacology, 51(4), 323-330.

Kotlinska, J., Pachuta, A., Dylag, T., \& Silberring, J. (2007). Neuropeptide FF (NPFF) reduces the expression of morphine- but not of ethanol-induced conditioned place preference in rats. Peptides, 28(11), 2235-2242. doi:http://dx.doi.org/10.1016/i.peptides.2007.08.006

Koulousakis, A., Kuchta, J., Bayarassou, A., \& Sturm, V. (2007). Intrathecal opioids for intractable pain syndromes Operative Neuromodulation (pp. 43-48): Springer.

Kumar, L., Barker, C., \& Emmanuel, A. (2014). Opioid-induced constipation: pathophysiology, clinical consequences, and management. Gastroenterol Res Pract, 2014, 141737. doi:10.1155/2014/141737

Kurz, A. (2008). Physiology of Thermoregulation. Best Practice \& Research Clinical Anaesthesiology, 22(4), 627-644. doi:http://dx.doi.org/10.1016/j.bpa.2008.06.004

Kurz, A., \& Sessler, D. I. (2003). Opioid-induced bowel dysfunction. Drugs, 63(7), 649-671.

Kwak, J. Y., Jung, J. Y., Hwang, S. W., Lee, W. T., \& Oh, U. (1998). A capsaicin-receptor antagonist, capsazepine, reduces inflammation-induced hyperalgesic responses in the rat: evidence for an endogenous capsaicin-like substance. Neuroscience, 86(2), 619-626. doi:http://dx.doi.org/10.1016/S0306-4522(98)00012-8

Lalanne, L., Ayranci, G., Kieffer, B. L., \& Lutz, P.-E. (2014). The Kappa Opioid Receptor: From Addiction to Depression, and Back. Frontiers in Psychiatry, 5(170). doi:10.3389/fpsyt.2014.00170

Lamb, K., Tidgewell, K., Simpson, D. S., Bohn, L. M., \& Prisinzano, T. E. (2012). Antinociceptive effects of herkinorin, a MOP receptor agonist derived from salvinorin $A$ in the formalin test in rats: new concepts in mu opioid receptor pharmacology: from a symposium on new concepts in mu-opioid pharmacology. Drug and alcohol dependence, 121(3), 181-188.

Latimer, L. G., Duffy, P., \& Kalivas, P. W. (1987). Mu opioid receptor involvement in enkephalin activation of dopamine neurons in the ventral tegmental area. Journal of Pharmacology and Experimental Therapeutics, 241(1), 328-337.

Lefkowitz, R. J., \& Shenoy, S. K. (2005). Transduction of receptor signals by ß-arrestins. Science, 308(5721), 512-517.

Loeser, J. D. (2012). Relieving pain in America. The Clinical journal of pain, 28(3), 185-186.

Loguinov, A. V., Anderson, L. M., Crosby, G. J., \& Yukhananov, R. Y. (2001). Gene expression following acute morphine administration. Physiological Genomics, 6(3), 169-181.

Lotfipour, S., Byun, J. S., Leach, P., Fowler, C. D., Murphy, N. P., Kenny, P. J., . . Boulter, J. (2013). Targeted deletion of the mouse $\alpha 2$ nicotinic acetylcholine receptor subunit gene (Chrna2) potentiates nicotine-modulated behaviors. The Journal of Neuroscience, 33(18), 7728-7741.

Lowery, J. J., Raymond, T. J., Giuvelis, D., Bidlack, J. M., Polt, R., \& Bilsky, E. J. (2011). In Vivo Characterization of MMP-2200, a Mixed $\delta / \mu$ Opioid Agonist, in Mice. Journal of Pharmacology and Experimental Therapeutics, 336(3), 767-778. doi:10.1124/jpet.110.172866

Luccarini, P., Childeric, A., Gaydier, A.-M., Voisin, D., \& Dallel, R. (2006). The Orofacial Formalin Test in the Mouse: A Behavioral Model for Studying Physiology and 
Modulation of Trigeminal Nociception. The Journal of Pain, 7(12), 908-914. doi:http://dx.doi.org/10.1016/j.jpain.2006.04.010

Lucke-Wold, B. (2011). The Varied Uses of Conditioned Place Preference in Behavioral Neuroscience Research: An Investigation of Alcohol Administration in Model Organisms. Impulse (Columbia, SC), 2011.

Luger, N. M., Sabino, M. A. C., Schwei, M. J., Mach, D. B., Pomonis, J. D., Keyser, C. P., ... Yaksh, T. L. (2002). Efficacy of systemic morphine suggests a fundamental difference in the mechanisms that generate bone cancer vs. inflammatory pain. Pain, 99(3), 397-406.

Luttrell, L. M., \& Lefkowitz, R. J. (2002). The role of $\beta$-arrestins in the termination and transduction of G-protein-coupled receptor signals. Journal of cell science, 115(3), 455-465.

Malmberg, A. B., \& Yaksh, T. L. (1992). Antinociceptive actions of spinal nonsteroidal antiinflammatory agents on the formalin test in the rat. Journal of Pharmacology and Experimental Therapeutics, 263(1), 136-146.

Manglik, A., Lin, H., Aryal, D. K., McCorvy, J. D., Dengler, D., Corder, G., . . Hübner, H. (2016). Structure-based discovery of opioid analgesics with reduced side effects. Nature, 537(7619), 185-190.

Manzanedo, C., Aguilar, M. A., Rodríguez-Arias, M., \& Miñarro, J. (2005). Sensitization to the rewarding effects of morphine depends on dopamine. NeuroReport, 16(2), 201-205.

Mao, J., Price, D. D., \& Mayer, D. J. (1994). Thermal hyperalgesia in association with the development of morphine tolerance in rats: roles of excitatory amino acid receptors and protein kinase C. J Neurosci, 14(4), 2301-2312.

Mao, J., Sung, B., Ji, R. R., \& Lim, G. (2002). Chronic morphine induces downregulation of spinal glutamate transporters: implications in morphine tolerance and abnormal pain sensitivity. J Neurosci, 22(18), 8312-8323.

Marchand, F., Perretti, M., \& McMahon, S. B. (2005). Role of the Immune system in chronic pain. Nat Rev Neurosci, 6(7), 521-532.

Marchand, S. (2008). The physiology of pain mechanisms: from the periphery to the brain. Rheumatic Disease Clinics of North America, 34(2), 285-309.

Marderstein, E. L., \& Delaney, C. P. (2008). Management of postoperative ileus: focus on alvimopan. Therapeutics and clinical risk management, 4(5), 965.

Mason, K., Hewitt, A., \& Stefanogiannis, N. (2010). Drug Use in New Zealand. Key Results of the 2007/08. Wellington: Ministry of Health.

Matsuzawa, S., Suzuki, T., \& Misawa, M. (2000). Ethanol, but not the anxiolytic drugs buspirone and diazepam, produces a conditioned place preference in rats exposed to conditioned fear stress. Pharmacol Biochem Behav, 65(2), 281-288.

Matthes, H. W. D., Maldonado, R., Simonin, F., Valverde, O., Slowe, S., Kitchen, I., . . Kieffer, B. L. (1996). Loss of morphine-induced analgesia, reward effect and withdrawal symptoms in mice lacking the [micro]-opioid-receptor gene. Nature, 383(6603), 819823.

Max, M. B., Donovan, M., Miaskowski, C. A., Ward, S. E., Gordon, D., Bookbinder, M., . . Thaler, H. T. (1995). Quality improvement guidelines for the treatment of acute pain and cancer pain. Jama, 274(23), 1874-1880.

McDonald, J., \& Lambert, D. (2005). Opioid receptors. Continuing Education in Anaesthesia, Critical Care \& Pain, 5(1), 22-25. doi:10.1093/bjaceaccp/mki004 
McFadden, C. (2016). Research Report: The New Zealand Drug Harm Index 2016. Wellington: Ministry of Health: The New Zealand Drug Harm Index

McNamara, C. R., Mandel-Brehm, J., Bautista, D. M., Siemens, J., Deranian, K. L., Zhao, M., . . . Fanger, C. M. (2007). TRPA1 mediates formalin-induced pain. Proceedings of the National Academy of Sciences, 104(33), 13525-13530. doi:10.1073/pnas.0705924104

McNicol, E., Horowicz-Mehler, N., Fisk, R. A., Bennett, K., Gialeli-Goudas, M., Chew, P. W., . . . Carr, D. (2003). Management of opioid side effects in cancer-related and chronic noncancer pain: a systematic review. The Journal of Pain, 4(5), 231-256.

Meghani, S. H., Byun, E., \& Gallagher, R. M. (2012). Time to Take Stock: A Meta-Analysis and Systematic Review of Analgesic Treatment Disparities for Pain in the United States. Pain Medicine, 13(2), 150-174.

Melief, E. J., Miyatake, M., Bruchas, M. R., \& Chavkin, C. (2010). Ligand-directed c-Jun Nterminal kinase activation disrupts opioid receptor signaling. Proceedings of the National Academy of Sciences, 107(25), 11608-11613.

Meunier, J.-C. (1997). Nociceptin/orphanin FQ and the opioid receptor-like ORL1 receptor. European Journal of Pharmacology, 340(1), 1-15. doi:http://dx.doi.org/10.1016/S0014-2999(97)01411-8

Meunier, J.-C., Mollereau, C., Toll, L., Suaudeau, C., Moisand, C., Alvinerie, P., . . . Monsarrat, B. (1995). Isolation and structure of the endogenous agonist of opioid receptor-like ORL1 receptor.

Middleton, J., McGrail, S., \& Stringer, K. (2016). Drug related deaths in England and Wales: British Medical Journal Publishing Group.

Millan, M. J. (2002). Descending control of pain. Progress in neurobiology, 66(6), 355-474.

Minami, M., Toya, T., Katao, Y., Maekawa, K., Nakamura, S., Onogi, T., .. . Satoh, M. (1993). Cloning and expression of a cDNA for the rat kappa-opioid receptor. FEBS Lett, 329(3), 291-295.

Mogil, J. S. (2009). Animal models of pain: progress and challenges. Nat Rev Neurosci, 10(4), 283-294.

Mogri, M., Desai, H., Webster, L., Grant, B. J. B., \& Mador, J. M. (2009). Hypoxemia in patients on chronic opiate therapy with and without sleep apnea. Sleep and Breathing, 13(1), 49-57. doi:10.1007/s11325-008-0208-4

Monsef, H. R., Ghobadi, A., Iranshahi, M., \& Abdollahi, M. (2004). Antinociceptive effects of Peganum harmala L. alkaloid extract on mouse formalin test. J Pharm Pharm Sci, 7(1), 65-69.

Montes-Sandoval, L. (1999). An analysis of the concept of pain. Journal of advanced Nursing, 29(4), 935-941.

Morales, L., Perez-Garcia, C., Herradon, G., \& Alguacil, L. F. (2007). Place conditioning in a two- or three-conditioning compartment apparatus: a comparative study with morphine and U-50,488. Addiction Biology, 12(3/4), 482-484. doi:10.1111/j.13691600.2007.00071.x

Mori, T., Shibasaki, Y., Matsumoto, K., Shibasaki, M., Hasegawa, M., Wang, E., ... Suzuki, T. (2013). Mechanisms That Underlie $\mu$-Opioid Receptor Agonist-Induced Constipation: Differential Involvement of $\mu$-Opioid Receptor Sites and Responsible Regions. Journal of Pharmacology and Experimental Therapeutics, 347(1), 91-99.

doi:10.1124/jpet.113.204313 
Morley, J. S. (2000). New perspectives in our use of opioids. Paper presented at the Pain Forum.

Moulin, D. E., Clark, A. J., Speechley, M., \& Morley-Forster, P. K. (2002). Chronic pain in Canada--prevalence, treatment, impact and the role of opioid analgesia. Pain Res Manag, 7(4), 179-184.

Nagasako, E. M., Oaklander, A. L., \& Dworkin, R. H. (2003). Congenital insensitivity to pain: an update. Pain, 101(3), 213-219.

Nelson, A. D., \& Camilleri, M. (2015). Chronic opioid induced constipation in patients with nonmalignant pain: challenges and opportunities. Therapeutic Advances in Gastroenterology, 8(4), 206-220. doi:10.1177/1756283X15578608

Nicotra, L., Loram, L. C., Watkins, L. R., \& Hutchinson, M. R. (2012). Toll-like receptors in chronic pain. Experimental neurology, 234(2), 316-329.

NIH. (2016). Misuse of Prescription Drugs. Retrieved from USA:

Nugent, F. S., Penick, E. C., \& Kauer, J. A. (2007). Opioids block long-term potentiation of inhibitory synapses. Nature, 446(7139), 1086-1090. doi:http://www.nature.com/nature/journal/v446/n7139/suppinfo/nature05726 S1. $\underline{\mathrm{html}}$

Ochoa, J. L. (2009). Neuropathic pain: redefinition and a grading system for clinical and research purposes. Neurology, 72(14), 1282-1283.

Okie, S. (2010). A flood of opioids, a rising tide of deaths. N Engl J Med, 363(21), 1981-1985. doi:10.1056/NEJMp1011512

Olds, M. (1982). Reinforcing effects of morphine in the nucleus accumbens. Brain research, 237(2), 429-440.

Olmstead, M. C., \& Franklin, K. B. J. (1997). The development of a conditioned place preference to morphine: Effects of microinjections into various CNS sites. Behavioral Neuroscience, 111(6), 1324-1334. doi:10.1037/0735-7044.111.6.1324

Ortiz, M. I., Molina, M., \#xed, Asunci, a., \#xf3, Romero, n., . . . C. L. (2012). Analgesic Drugs Combinations in the Treatment of Different Types of Pain. Pain Research and Treatment, 2012, 2. doi:10.1155/2012/612519

Ospina, M., \& Harstall, C. (2003). Multidisciplinary pain programs for chronic pain: evidence from systematic reviews: Citeseer.

Otuki, M. F., Lima, F. V., Malheiros, A., Cechinel-Filho, V., Monache, F. D., Yunes, R. A., \& Calixto, J. B. (2001). Evaluation of the antinociceptive action caused by ether fraction and a triterpene isolated from resin of Protium kleinii. Life Sciences, 69(19), 22252236. doi:http://dx.doi.org/10.1016/S0024-3205(01)01310-8

Pacheco, D. F., Klein, A., Perez, A. C., Pacheco, C., de Francischi, J. N., Reis, G., \& Duarte, I. (2009). Central antinociception induced by mu-opioid receptor agonist morphine, but not delta-or kappa-, is mediated by cannabinoid CB1 receptor. British Journal of Pharmacology, 158(1), 225-231.

Pakulska, W., \& Czarnecka, E. (2009). Influence of oxcarbazepine on the antinociceptive action of morphine and metamizole in mice. Acta Pol. Pharm, 66, 715-722.

Pang, C., Tsang, S., \& Yang, J. (2001). Effects of melatonin, morphine and diazepam on formalin-induced nociception in mice. Life sciences, 68(8), 943-951.

Park, S. M., Chen, M., Schmerberg, C. M., Dulman, R. S., Rodriguiz, R. M., Caron, M. G., . . Wetsel, W. C. (2016). Effects of [beta]-Arrestin-Biased Dopamine D2 Receptor 
Ligands on Schizophrenia-Like Behavior in Hypoglutamatergic Mice.

Neuropsychopharmacology, 41(3), 704-715. doi:10.1038/npp.2015.196

Parker, L. A. (1992). Place conditioning in a three-or four-choice apparatus: role of stimulus novelty in drug-induced place conditioning. Behavioral neuroscience, 106(2), 294.

Parker, L. A., Tomlinson, T., Horn, D., \& Erb, S. M. (1994). Relative strength of place conditioning produced by cocaine and morphine assessed in a three-choice paradigm. Learning and Motivation, 25(1), 83-94.

Patapoutian, A., Tate, S., \& Woolf, C. J. (2009). Transient receptor potential channels: targeting pain at the source. Nat Rev Drug Discov, 8(1), 55-68.

Patel, S. B., \& Kress, J. P. (2012). Sedation and Analgesia in the Mechanically Ventilated Patient. American Journal of Respiratory and Critical Care Medicine, 185(5), 486-497. doi:10.1164/rccm.201102-0273Cl

Patil, C., \& Kulkarni, S. (1999). The morphine sparing effect of physostigmine. Methods Find Exp Clin Pharmacol, 21(8), 523.

Paulozzi, L. J. (2012). Prescription drug overdoses: a review. Journal of safety research, 43(4), 283-289.

Pediatrics, A. A. o. (2001). The assessment and management of acute pain in infants, children, and adolescents. Pediatrics, 108(3), 793.

Pergolizzi, J., Böger, R. H., Budd, K., Dahan, A., Erdine, S., Hans, G., . . Raffa, R. B. (2008). Opioids and the management of chronic severe pain in the elderly: consensus statement of an International Expert Panel with focus on the six clinically most often used World Health Organization Step III opioids (buprenorphine, fentanyl, hydromorphone, methadone, morphine, oxycodone). Pain Practice, 8(4), 287-313.

Perks, S. M., \& Clifton, P. G. (1997). Reinforcer revaluation and conditioned place preference. Physiology \& behavior, 61(1), 1-5.

Philpot, R. M., Badanich, K. A., \& Kirstein, C. (2003). Place Conditioning: Age-Related Changes in the Rewarding and Aversive Effects of Alcohol. Alcoholism: Clinical and Experimental Research, 27(4), 593-599.

Piepponen, T. P., Kivastik, T., Katajamaki, J., Zharkovsky, A., \& Ahtee, L. (1997). Involvement of opioid mu 1 receptors in morphine-induced conditioned place preference in rats. Pharmacol Biochem Behav, 58(1), 275-279.

Pierce, K. L., \& Lefkowitz, R. J. (2001). Classical and new roles of $\beta$-arrestins in the regulation of G-protein-coupled receptors. Nature reviews neuroscience, 2(10), 727-733.

Porreca, F., \& Ossipov, M. H. (2009). Nausea and vomiting side effects with opioid analgesics during treatment of chronic pain: mechanisms, implications, and management options. Pain Medicine, 10(4), 654-662.

Pradhan, A. A., Smith, M. L., Kieffer, B. L., \& Evans, C. J. (2012). Ligand-directed signalling within the opioid receptor family. British Journal of Pharmacology, 167(5), 960-969. doi:10.1111/j.1476-5381.2012.02075.x

Prisinzano, T. E. (2005). Psychopharmacology of the hallucinogenic sage Salvia divinorum. Life Sciences, 78(5), 527-531.

Prisinzano, T. E., \& Rothman, R. B. (2008). Salvinorin A analogs as probes in opioid pharmacology. Chem. Rev, 108(5), 1732-1743.

Prisinzano, T. E., Tidgewell, K., \& Harding, W. W. (2005). k opioids as potential treatments for stimulants dependence. AAPS Journal, $7(3)$. 
Przewłocki, R., \& Przewłocka, B. (2001). Opioids in chronic pain. European journal of pharmacology, 429(1), 79-91.

Raehal, K. M., \& Bohn, L. M. (2005). Mu opioid receptor regulation and opiate responsiveness. The AAPS journal, 7(3), E587-E591.

Raehal, K. M., \& Bohn, L. M. (2011). The role of beta-arrestin2 in the severity of antinociceptive tolerance and physical dependence induced by different opioid pain therapeutics. Neuropharmacology, 60(1), 58-65. doi:10.1016/j.neuropharm.2010.08.003

Raehal, K. M., Schmid, C. L., Groer, C. E., \& Bohn, L. M. (2011). Functional Selectivity at the $\mu$-Opioid Receptor: Implications for Understanding Opioid Analgesia and Tolerance. Pharmacological Reviews, 63(4), 1001-1019. doi:10.1124/pr.111.004598

Raehal, K. M., Walker, J. K., \& Bohn, L. M. (2005). Morphine side effects in $\beta$-arrestin 2 knockout mice. Journal of Pharmacology and Experimental Therapeutics, 314(3), 1195-1201.

Ramachandran, S. K., Haider, N., Saran, K. A., Mathis, M., Kim, J., Morris, M., \& O'Reilly, M. (2011). Life-threatening critical respiratory events: A retrospective study of postoperative patients found unresponsive during analgesic therapy. Journal of Clinical Anesthesia, 23(3), 207-213. doi:10.1016/j.jclinane.2010.09.003

Randall, C. K., Kraemer, P. J., \& Bardo, M. T. (1998). Morphine-Induced Conditioned Place Preference in Preweanling and Adult Rats. Pharmacology Biochemistry and Behavior, 60(1), 217-222. doi:http://dx.doi.org/10.1016/S0091-3057(97)00585-6

Rankovic, Z., Brust, T. F., \& Bohn, L. M. (2016). Biased agonism: An emerging paradigm in GPCR drug discovery. Bioorganic \& Medicinal Chemistry Letters, 26(2), 241-250. doi:http://dx.doi.org/10.1016/i.bmcl.2015.12.024

Rapp, S. E., Ready, L. B., \& Nessly, M. L. (1995). Acute pain management in patients with prior opioid consumption: a case-controlled retrospective review. Pain, 61(2), 195201.

Raynor, K., Kong, H., Chen, Y., Yasuda, K., Yu, L., Bell, G. I., \& Reisine, T. (1994). Pharmacological characterization of the cloned kappa-, delta-, and mu-opioid receptors. Molecular Pharmacology, 45(2), 330-334.

Raynor, K., Kong, H., Law, S., Heerding, J., Tallent, M., Livingston, F., . . Reisine, T. (1996). Molecular biology of opioid receptors. NIDA Res Monogr, 161, 83-103.

Reinscheid, R. K., Nothacker, H.-P., Bourson, A., Ardati, A., Henningsen, R. A., Bunzow, J. R., . . Civelli, O. (1995). Orphanin FQ: a neuropeptide that activates an opioidlike $G$ protein-coupled receptor. Science, 270(5237), 792-794.

Reissig, J. E., \& Rybarczyk, A. M. (2005). Pharmacologic treatment of opioid-induced sedation in chronic pain. Annals of Pharmacotherapy, 39(4), 727-731.

Reiter, E., \& Lefkowitz, R. J. (2006). GRKs and $\beta$-arrestins: roles in receptor silencing, trafficking and signaling. Trends in endocrinology \& metabolism, 17(4), 159-165.

Rezayof, A., Zarrindast, M.-R., Sahraei, H., \& Haeri-Rohani, A. (2003). Involvement of dopamine receptors of the dorsal hippocampus on the acquisition and expression of morphine-induced place preference in rats. Journal of Psychopharmacology, 17(4), 415-423.

Ricardo Buenaventura, M., Rajive Adlaka, M., \& Nalini Sehgal, M. (2008). Opioid complications and side effects. Pain physician, 11, S105-S120. 
Rodríguez-Arias, M., Broseta, I., Aguilar, M. A., \& Miñarro, J. (2000). Lack of specific effects of selective D1 and D2 dopamine antagonists vs. risperidone on morphine-induced hyperactivity. Pharmacology Biochemistry and Behavior, 66(1), 189-197. doi:10.1016/S0091-3057(00)00207-0

Romberg, R., Sarton, E., Teppema, L., Matthes, H. W. D., Kieffer, B. L., \& Dahan, A. (2003). Comparison of morphine-6-glucuronide and morphine on respiratory depressant and antinociceptive responses in wild type and $\mu$-opioid receptor deficient mice. British journal of anaesthesia, 91(6), 862-870. doi:10.1093/bja/aeg279

Romero, A., Miranda, H. F., \& Puig, M. M. (2010). Analysis of the opioid-opioid combinations according to the nociceptive stimulus in mice. Pharmacol Res, 61(6), 511-518. doi:10.1016/j.phrs.2010.02.011

Rosenbaum, D. M., Rasmussen, S. G., \& Kobilka, B. K. (2009). The structure and function of G-protein-coupled receptors. Nature, 459(7245), 356-363.

Rosenberg, P., \& Heinonen, E. (1983). Differential sensitivity of A and C nerve fibres to longacting amide local anaesthetics. British journal of anaesthesia, 55(2), 163-167.

Rosland, J. H., Tjølsen, A., Mæhle, B., \& Hole, K. (1990). The formalin test in mice: effect of formalin concentration. Pain, 42(2), 235-242. doi:http://dx.doi.org/10.1016/03043959(90)91167-H

Rosow, C. E., Miller, J. M., Pelikan, E. W., \& Cochin, J. (1980). Opiates and thermoregulation in mice. I. Agonists. J Pharmacol Exp Ther, 213(2), 273-283.

Roth, B. L., Baner, K., Westkaemper, R., Siebert, D., Rice, K. C., Steinberg, S., . . Rothman, R. B. (2002). Salvinorin A: A potent naturally occurring nonnitrogenous $\mathrm{K}$ opioid selective agonist. Proceedings of the National Academy of Sciences, 99(18), 1193411939. doi:10.1073/pnas.182234399

Rowan, M. P., Bierbower, S. M., Eskander, M. A., Szteyn, K., Por, E. D., Gomez, R., . . Jeske, N. A. (2014). Activation of mu opioid receptors sensitizes transient receptor potential vanilloid type 1 (TRPV1) via beta-arrestin-2-mediated cross-talk. PLoS one, 9(4), e93688. doi:10.1371/journal.pone.0093688

Ruan, X. (2007). Drug-related side effects of long-term intrathecal morphine therapy. Pain Physician, 10(2), 357.

Ruffolo Jr, R. R., Nichols, A., Stadel, J., \& Hieble, J. (1993). Pharmacologic and therapeutic applications of alpha2-adrenoceptor subtypes. Annual Review of pharmacology and Toxicology, 33(1), 243-279.

Rutten, K., De Vry, J., Bruckmann, W., \& Tzschentke, T. M. (2010). Effects of the NOP receptor agonist Ro65-6570 on the acquisition of opiate- and psychostimulantinduced conditioned place preference in rats. European Journal of Pharmacology, 645(1-3), 119-126. doi:10.1016/j.ejphar.2010.07.036

Sacerdote, P., Bianchi, M., \& Panerai, A. E. (1996). Involvement of $\beta$-endorphin in the modulation of paw inflammatory edema in the rat. Regulatory Peptides, 63(2-3), 7983. doi:http://dx.doi.org/10.1016/0167-0115(96)00014-6

Sakurada, T., Katsumata, K., Yogo, H., Tan-No, K., Sakurada, S., \& Kisara, K. (1993). Antinociception induced by CP 96,345, a non-peptide NK-1 receptor antagonist, in the mouse formalin and capsaicin tests. Neuroscience letters, 151(2), 142-145.

Salamone, J. D., \& Correa, M. (2012). The mysterious motivational functions of mesolimbic dopamine. Neuron, 76(3), 470-485. 
Sánchez-Blázquez, P., García-España, A., \& Garzón, J. (1997). Antisense Oligodeoxynucleotides to Opioid Mu andDelta Receptors Reduced Morphine Dependence in Mice: Role of Delta-2 Opioid Receptors. Journal of Pharmacology and Experimental Therapeutics, 280(3), 1423-1431.

Sanchis-Segura, C., \& Spanagel, R. (2006). REVIEW: Behavioural assessment of drug reinforcement and addictive features in rodents: an overview. Addiction Biology, 11(1), 2-38. doi:10.1111/j.1369-1600.2006.00012.x

Santos, A., \& Calixto, J. (1997). Further evidence for the involvement of tachykinin receptor subtypes in formalin and capsaicin models of pain in mice. Neuropeptides, 31(4), 381-389.

Santos, A. R., \& Calixto, J. B. (1997). Ruthenium red and capsazepine antinociceptive effect in formalin and capsaicin models of pain in mice. Neuroscience letters, 235(1), 73-76.

Satinoff, E. (1978). Neural organization and evolution of thermal regulation in mammals. Several hierarchically arranged integrating systems may have evolved to achieve precise thermoregulation. Science, 201(435 O), 16-22.

Sawynok, J., Reid, A. R., \& Liu, J. (2013). Spinal and peripheral adenosine A<sub> $1</$ sub> receptors contribute to antinociception by tramadol in the formalin test in mice. European journal of pharmacology, 714(1), 373-378.

Sayyah, M., Saroukhani, G., Peirovi, A., \& Kamalinejad, M. (2003). Analgesic and anti-inflammatory activity of the leaf essential oil of Laurus nobilis Linn. Phytotherapy Research, 17(7), 733-736.

Schechter, M. D., \& Calcagnetti, D. J. (1993). Trends in place preference conditioning with a cross-indexed bibliography; 1957-1991. Neuroscience \& Biobehavioral Reviews, 17(1), 21-41.

Schmid, C. L., Raehal, K. M., \& Bohn, L. M. (2008). Agonist-directed signaling of the serotonin $2 A$ receptor depends on $\beta$-arrestin- 2 interactions in vivo. Proceedings of the National Academy of Sciences, 105(3), 1079-1084.

Schug, S. A., \& Manopas, A. (2007). Update on the role of non-opioids for postoperative pain treatment. Best Practice \& Research Clinical Anaesthesiology, 21(1), 15-30.

Schulz, S., Mayer, D., Pfeiffer, M., Stumm, R., Koch, T., \& Höllt, V. (2004). Morphine induces terminal $\mu$-opioid receptor desensitization by sustained phosphorylation of serine-375. The EMBO journal, 23(16), 3282-3289.

Sessler, C. N., Gosnell, M. S., Grap, M. J., Brophy, G. M., O'Neal, P. V., Keane, K. A., . . . Elswick, R. K. (2002). The Richmond Agitation-Sedation Scale. American Journal of Respiratory and Critical Care Medicine, 166(10), 1338-1344. doi:10.1164/rccm.2107138

Shannon, H. E., Eberle, E. L., \& Peters, S. C. (2005). Comparison of the effects of anticonvulsant drugs with diverse mechanisms of action in the formalin test in rats. Neuropharmacology, 48(7), 1012-1020.

Shenoy, S. K., Drake, M. T., Nelson, C. D., Houtz, D. A., Xiao, K., Madabushi, S., . . L Lefkowitz, R. J. (2006). $\beta$-Arrestin-dependent, $G$ protein-independent ERK1/2 activation by the $\beta 2$ adrenergic receptor. Journal of Biological Chemistry, 281(2), 1261-1273.

Shenoy, S. K., \& Lefkowitz, R. J. (2005). Receptor-specific ubiquitination of $\beta$-arrestin directs assembly and targeting of seven-transmembrane receptor signalosomes. Journal of Biological Chemistry, 280(15), 15315-15324. 
Shibata, M., Ohkubo, T., Takahashi, H., \& Inoki, R. (1989). Modified formalin test: characteristic biphasic pain response. Pain, 38(3), 347-352.

Shippenberg, T. S., Bals-Kubik, R., \& Herz, A. (1993). Examination of the neurochemical substrates mediating the motivational effects of opioids: role of the mesolimbic dopamine system and D-1 vs. D-2 dopamine receptors. Journal of Pharmacology and Experimental Therapeutics, 265(1), 53-59.

Shoaib, M., Spanagel, R., Stohr, T., \& Shippenberg, T. (1995). Strain differences in the rewarding and dopamine-releasing effects of morphine in rats. Psychopharmacology, 117(2), 240-247.

Shook, J. E., Pelton, J. T., Hruby, V. J., \& Burks, T. F. (1987). Peptide opioid antagonist separates peripheral and central opioid antitransit effects. J Pharmacol Exp Ther, 243(2), 492-500.

Sim, L. J., Selley, D. E., Dworkin, S. I., \& Childers, S. R. (1996). Effects of chronic morphine administration on mu opioid receptor-stimulated [35S] GTPgammaS autoradiography in rat brain. The Journal of neuroscience, 16(8), 2684-2692.

Siuda, E. R., Carr lii, R., Rominger, D. H., \& Violin, J. D. (2017). Biased mu-opioid receptor ligands: a promising new generation of pain therapeutics. Current Opinion in Pharmacology, 32, 77-84. doi:http://dx.doi.org/10.1016/i.coph.2016.11.007

Slatkin, N. E., Rhiner, M., \& Bolton, T. M. (2001). Donepezil in the treatment of opioidinduced sedation: report of six cases. Journal of pain and symptom management, 21(5), 425-438.

Sora, I., Takahashi, N., Funada, M., Ujike, H., Revay, R. S., Donovan, D. M., . . Uhl, G. R. (1997). Opiate receptor knockout mice define $\mu$ receptor roles in endogenous nociceptive responses and morphine-induced analgesia. Proceedings of the National Academy of Sciences, 94(4), 1544-1549.

Sorge, R. E., Martin, L. J., Isbester, K. A., Sotocinal, S. G., Rosen, S., Tuttle, A. H., . . Kadoura, B. (2014). Olfactory exposure to males, including men, causes stress and related analgesia in rodents. Nature methods, 11(6), 629-632.

Spanagel, R., Herz, A., \& Shippenberg, T. S. (1992). Opposing tonically active endogenous opioid systems modulate the mesolimbic dopaminergic pathway. Proceedings of the National Academy of Sciences, 89(6), 2046-2050.

Spetea, M., Bohotin, C. R., Asim, M. F., Stübegger, K., \& Schmidhammer, H. (2010). In vitro and in vivo pharmacological profile of the 5-benzyl analogue of 14methoxymetopon, a novel $\mu$ opioid analgesic with reduced propensity to alter motor function. European Journal of Pharmaceutical Sciences, 41(1), 125-135.

Spyraki, C., Nomikos, G. G., Galanopoulou, P., \& Daïfotis, Z. (1988). Drug-induced place preference in rats with 5,7-dihydroxytryptamine lesions of the nucleus accumbens. Behavioural Brain Research, 29(1), 127-134. doi:http://dx.doi.org/10.1016/01664328(88)90060-5

Spyraki, C., Nomikos, G. G., \& Varonos, D. D. (1987). Intravenous cocaine-induced place preference: attenuation by haloperidol. Behavioural brain research, 26(1), 57-62.

Steeds, C. E. (2009). The anatomy and physiology of pain. Surgery (Oxford), 27(12), 507-511. doi:http://dx.doi.org/10.1016/i.mpsur.2009.10.013

Stein, C. (2013). Opioids, sensory systems and chronic pain. Eur J Pharmacol, 716(1-3), 179187. doi:10.1016/j.ejphar.2013.01.076 
Stein, C., \& Küchler, S. (2013). Targeting inflammation and wound healing by opioids. Trends in pharmacological sciences, 34(6), 303-312.

Sternini, C. (2001). III. $\mu$-Opioid receptors in the enteric nervous system. American Journal of Physiology-Gastrointestinal and Liver Physiology, 281(1), G8-G15.

Stewart, J. J., Weisbrodt, N. W., \& Burks, T. F. (1978). Central and peripheral actions of morphine on intestinal transit. J Pharmacol Exp Ther, 205(3), 547-555.

Stoelting, R. K., \& Miller, R. (2007). Opioids. Basics of Anesthesia, 5, 116.

Stone, L. S., German, J. P., Kitto, K. F., Fairbanks, C. A., \& Wilcox, G. L. (2014). Morphine and Clonidine Combination Therapy Improves Therapeutic Window in Mice: Synergy in Antinociceptive but Not in Sedative or Cardiovascular Effects. PLOS ONE, 9(10), e109903. doi:10.1371/journal.pone.0109903

Sturgeon, J. A. (2014). Psychological therapies for the management of chronic pain. Psychology research and behavior management, 7, 115.

Sung, B., Lim, G., \& Mao, J. (2003). Altered expression and uptake activity of spinal glutamate transporters after nerve injury contribute to the pathogenesis of neuropathic pain in rats. $J$ Neurosci, 23(7), 2899-2910.

Suzuki, T., Narita, M., Takahashi, Y., Misawa, M., \& Nagase, H. (1992). Effects of norbinaltorphimine on the development of analgesic tolerance to and physical dependence on morphine. European journal of pharmacology, 213(1), 91-97.

Swegle, J. M., \& Logemann, C. (2006). Management of common opioid-induced adverse effects. American family physician, 74(8).

Takemori, A., DeLander, G. E., \& Portoghese, P. (1987). Role of the Spinal Cord in the Development of Opiate Tolerance and Dependence. Problems of Drug Dependence 1986, 42.

Tavani, A., Bianchi, G., Ferretti, P., \& Manara, L. (1980). Morphine is most effective on gastrointestinal propulsion in rats by intraperitoneal route: Evidence for local action. Life Sciences, 27(23), 2211-2217. doi:http://dx.doi.org/10.1016/00243205(80)90386-0

Teoh, N., \& Stjernsward, J. (1992). WHO cancer pain relief program-ten years on. IASP Newsletter, 5-6.

Terman, G. W., Jin, W., Cheong, Y.-P., Lowe, J., Caron, M. G., Lefkowitz, R. J., \& Chavkin, C. (2004). G-protein receptor kinase 3 (GRK3) influences opioid analgesic tolerance but not opioid withdrawal. British Journal of Pharmacology, 141(1), 55-64. doi:10.1038/sj.bjp.0705595

Thompson, P., Joel, S., John, L., Wedzicha, J., Maclean, M., \& Slevin, M. (1995). Respiratory depression following morphine and morphine-6-glucuronide in normal subjects. British journal of clinical pharmacology, 40(2), 145.

Thomson, L. M., Zeng, J., \& Terman, G. W. (2006). Differential effect of glutamate transporter inhibition on EPSCs in the morphine naive and morphine tolerant neonatal spinal cord slice. Neuroscience letters, 407(1), 64-69. doi:10.1016/j.neulet.2006.08.004

Tidgewell, K., Groer, C. E., Harding, W. W., Lozama, A., Schmidt, M., Marquam, A., . . Rothman, R. B. (2008). Herkinorin analogues with differential $\beta$-arrestin-2 interactions. Journal of Medicinal Chemistry, 51(8), 2421-2431.

Tjølsen, A., Berge, O.-G., Hunskaar, S., Rosland, J. H., \& Hole, K. (1992). The formalin test: an evaluation of the method. Pain, 51(1), 5-17. 
Todd, K. H., Deaton, C., D’Adamo, A. P., \& Goe, L. (2000). Ethnicity and analgesic practice. Annals of emergency medicine, 35(1), 11-16.

Trang, T., Al-Hasani, R., Salvemini, D., Salter, M. W., Gutstein, H., \& Cahill, C. M. (2015). Pain and Poppies: The Good, the Bad, and the Ugly of Opioid Analgesics. J Neurosci, 35(41), 13879-13888. doi:10.1523/JNEUROSCI.2711-15.2015

Tremblay, J., \& Hamet, P. (2010). Genetics of pain, opioids, and opioid responsiveness. Metabolism, 59, S5-S8.

Trezza, V., Baarendse, P. J., \& Vanderschuren, L. J. (2010). The pleasures of play: pharmacological insights into social reward mechanisms. Trends in pharmacological sciences, 31(10), 463-469.

Trulson, M. E., \& Arasteh, K. (1985). Morphine increases the activity of midbrain dopamine neurons in vitro. Eur J Pharmacol, 114(1), 105-109.

Tsuji, M., Nakagawa, Y., Ishibashi, Y., Yoshii, T., Takashima, T., Shimada, M., \& Suzuki, T. (1996). Activation of ventral tegmental GABAB receptors inhibits morphine-induced place preference in rats. Eur J Pharmacol, 313(3), 169-173.

Tumati, S., Largent-Milnes, T. M., Keresztes, A., Ren, J., Roeske, W. R., Vanderah, T. W., \& Varga, E. V. (2012). Repeated morphine treatment-mediated hyperalgesia, allodynia and spinal glial activation are blocked by co-administration of a selective cannabinoid receptor type-2 agonist. Journal of Neuroimmunology, 244(1-2), 23-31. doi:http://dx.doi.org/10.1016/i.jneuroim.2011.12.021

Tzschentke, T. M. (1998). Measuring reward with the conditioned place preference paradigm: a comprehensive review of drug effects, recent progress and new issues. Progress in neurobiology, 56(6), 613-672.

Tzschentke, T. M. (2007). Review on CPP: Measuring reward with the conditioned place preference (CPP) paradigm: update of the last decade. Addiction biology, 12(3-4), 227-462.

Tzschentke, T. M., \& Schmidt, W. J. (1995). N-methyl-D-aspartic acid-receptor antagonists block morphine-induced conditioned place preference in rats. Neuroscience letters, 193(1), 37-40.

UNODC. (2014). World Drug Report 2014. United Nations Office on Drugs and Crime.

Valenzano, K. J., Tafesse, L., Lee, G., Harrison, J. E., Boulet, J. M., Gottshall, S. L., . . . Whiteside, G. T. (2005). Pharmacological and pharmacokinetic characterization of the cannabinoid receptor 2 agonist, GW405833, utilizing rodent models of acute and chronic pain, anxiety, ataxia and catalepsy. Neuropharmacology, 48(5), 658-672. doi:http://dx.doi.org/10.1016/j.neuropharm.2004.12.008

Vanderschuren, L. J. M. J., Achterberg, E. J. M., \& Trezza, V. (2016). The neurobiology of social play and its rewarding value in rats. Neuroscience \& Biobehavioral Reviews, 70, 86-105. doi:http://dx.doi.org/10.1016/i.neubiorev.2016.07.025

Váradi, A., Marrone, G. F., Palmer, T. C., Narayan, A., Szabó, M. R., Le Rouzic, V., . . . Majumdar, S. (2016). Mitragynine/Corynantheidine Pseudoindoxyls As Opioid Analgesics with Mu Agonism and Delta Antagonism, Which Do Not Recruit $\beta$ Arrestin-2. Journal of Medicinal Chemistry, 59(18), 8381-8397. doi:10.1021/acs.jmedchem.6b00748

Vindenes, V., Handal, M., Ripel, Å., Boix, F., \& Mørland, J. (2006). Conditioned place preference induced by morphine and morphine-6-glucuronide in mice. 
Pharmacology Biochemistry and Behavior, 85(2), 292-297.

doi:http://dx.doi.org/10.1016/i.pbb.2006.08.010

Viscusi, E. R., Reynolds, L., Chung, F., Atkinson, L. E., \& Khanna, S. (2004). Patient-controlled transdermal fentanyl hydrochloride vs intravenous morphine pump for postoperative pain: a randomized controlled trial. Jama, 291(11), 1333-1341.

Viscusi, E. R., Webster, L., Kuss, M., Daniels, S., Bolognese, J. A., Zuckerman, S., . . . Skobieranda, F. (2016). A randomized, phase 2 study investigating TRV130, a biased ligand of the mu-opioid receptor, for the intravenous treatment of acute pain. Pain, 157, 264-272.

Wang, D., Teichtahl, H., Drummer, O., Goodman, C., Cherry, G., Cunnington, D., \& Kronborg, I. (2005). Central sleep apnea in stable methadone maintenance treatment patients. Chest, 128(3), 1348-1356. doi:10.1378/chest.128.3.1348

Wang, J., Wu, X., Li, C., Wei, J., Jiang, H., Liu, C., . . Ma, Y. (2012). Effect of morphine on conditioned place preference in rhesus monkeys. Addiction Biology, 17(3), 539-546. doi:10.1111/j.1369-1600.2010.00289.x

Way, E. L., Lou, H. H., \& Shen, F.-H. (1969). Simultaneous quantitative assessment of morphine tolerance and physical dependence Journal of Pharmacology and Experimental Therapeutics, 167(1), 1-8.

Webster, L., Andrews, M., \& Stoddard, G. (2003). Modafinil Treatment of Opioid-Induced Sedation. Pain Medicine, 4(2), 135-140.

Wheeler-Aceto, H., \& Cowan, A. (1991). Standardization of the rat paw formalin test for the evaluation of analgesics. Psychopharmacology, 104(1), 35-44.

Whistler, J. L., \& von Zastrow, M. (1998). Morphine-activated opioid receptors elude desensitization by beta-arrestin. Proc Natl Acad Sci U S A, 95(17), 9914-9919.

White-Gbadebo, D., \& Holtzman, S. (1994). Naloxone pretreatment blocks acute morphineinduced sensitization to naltrexone. Psychopharmacology, 114(2), 225-228.

Whiteside, G. T., Boulet, J. M., \& Walker, K. (2005). The role of central and peripheral $\mu$ opioid receptors in inflammatory pain and edema: a study using morphine and DiPOA ([8-(3, 3-diphenyl-propyl)-4-oxo-1-phenyl-1, 3, 8-triaza-spiro [4.5] dec-3-yl]acetic acid). Journal of Pharmacology and Experimental Therapeutics, 314(3), 12341240.

Whiteside, G. T., Gottshall, S. L., Boulet, J. M., Chaffer, S. M., Harrison, J. E., Pearson, M. S., . .. Valenzano, K. J. (2005). A role for cannabinoid receptors, but not endogenous opioids, in the antinociceptive activity of the CB 2-selective agonist, GW405833. European journal of pharmacology, 528(1), 65-72.

Wilwerding, M. B., Loprinzi, C. L., Mailliard, J. A., O'Fallon, J. R., Miser, A. W., van Haelst, C., . .. Athmann, L. M. (1995). A randomized, crossover evaluation of methylphenidate in cancer patients receiving strong narcotics. Supportive Care in Cancer, 3(2), 135-138.

Wisler, J. W., DeWire, S. M., Whalen, E. J., Violin, J. D., Drake, M. T., Ahn, S., . . Lefkowitz, R. J. (2007). A unique mechanism of $\beta$-blocker action: Carvedilol stimulates $\beta$-arrestin signaling. Proceedings of the National Academy of Sciences, 104(42), 16657-16662. doi:10.1073/pnas.0707936104

Wisler, J. W., Xiao, K., Thomsen, A. R., \& Lefkowitz, R. J. (2014). Recent developments in biased agonism. Current opinion in cell biology, 27, 18-24. 
Wojcik, C., \& Di Napoli, M. (2004). Ubiquitin-proteasome system and proteasome inhibition: new strategies in stroke therapy. Stroke, 35(6), 1506-1518. doi:10.1161/01.STR.0000126891.93919.4e

Wong, C.-L., \& Bentley, G. A. (1979). The effect of morphine pretreatment on hypothermia induced by morphine in mice. European journal of pharmacology, 53(4), 391-394.

Woolf, C. J. (2010). What is this thing called pain? The Journal of Clinical Investigation, 120(11), 3742-3744. doi:10.1172/JCl45178

Woolf, C. J., Bennett, G. J., Doherty, M., Dubner, R., Kidd, B., Koltzenburg, M., . . Torebjork, E. (1998). Towards a mechanism-based classification of pain? Pain, 77(3), 227-229.

Woolf, C. J., \& Ma, Q. (2007). Nociceptors - Noxious Stimulus Detectors. Neuron, 55(3), 353364. doi:http://dx.doi.org/10.1016/i.neuron.2007.07.016

Woolf, C. J., \& Salter, M. W. (2000). Neuronal Plasticity: Increasing the Gain in Pain. Science, 288(5472), 1765-1768. doi:10.1126/science.288.5472.1765

Worley, S. L. (2016). New Directions in the Treatment of Chronic Pain: National Pain Strategy Will Guide Prevention, Management, and Research. Pharmacy and Therapeutics, 41(2), 107.

Wu, C. L., \& Raja, S. N. (2011). Treatment of acute postoperative pain. The Lancet, 377(9784), 2215-2225.

Wu, X., Zhao, N., Bai, F., Li, C., Liu, C., Wei, J., .. . Wang, J. (2016). Morphine-induced conditioned place preference in rhesus monkeys: Resistance to inactivation of insula and extinction. Neurobiology of Learning and Memory, 131, 192-200. doi:http://dx.doi.org/10.1016/i.nlm.2016.04.005

Xi, Z.X., \& Stein, E. A. (1998). Nucleus accumbens dopamine release modulation by mesolimbic GABAA receptors-an in vivo electrochemical study. Brain Research, 798(1-2), 156-165. doi:http://dx.doi.org/10.1016/S0006-8993(98)00406-5

Xu, H., Partilla, J. S., Wang, X., Rutherford, J. M., Tidgewell, K., Prisinzano, T. E., ... Rothman, R. B. (2007). A comparison of noninternalizing (Herkinorin) and internalizing (DAMGO) $\mu$-opioid agonists on cellular markers related to opioid tolerance and dependence. Synapse, 61(3), 166-175. doi:10.1002/syn.20356

Xu, H., Wang, X., Partilla, J. S., Bishop-Mathis, K., Benaderet, T. S., Dersch, C. M., ... Rothman, R. B. (2008). Differential effects of opioid agonists on $G$ protein expression in $\mathrm{CHO}$ cells expressing cloned human opioid receptors. Brain Res Bull, 77(1), 49-54. doi:10.1016/j.brainresbull.2008.05.003

Xu, T., Li, Y., Wang, H., Xu, Y., Ma, L., Sun, T., . . Yu, J. (2013). Oxysophocarpine induces antinociception and increases the expression of GABAA 1 receptors in mice. Molecular medicine reports, $7(6), 1819-1825$.

Yaksh, T. L., Ozaki, G., McCumber, D., Rathbun, M., Svensson, C., Malkmus, S., \& Yaksh, M. C. (2001). An automated flinch detecting system for use in the formalin nociceptive bioassay. Journal of Applied Physiology, 90(6), 2386-2402.

Yan, F., \& Roth, B. L. (2004). Salvinorin A: A novel and highly selective k-opioid receptor agonist. Life Sciences, 75(22), 2615-2619. doi:10.1016/j.Ifs.2004.07.008

Yeung, J. C., \& Rudy, T. A. (1980). Sites of antinociceptive action of systemically injected morphine: involvement of supraspinal loci as revealed by intracerebroventricular injection of naloxone. Journal of Pharmacology and Experimental Therapeutics, 215(3), 626-632. 
Young-McCaughan, S., \& Miaskowski, C. (2001). Measurement of opioid-induced sedation. Pain Management Nursing, 2(4), 132-149. doi:http://dx.doi.org/10.1053/ipmn.2001.25169

Zarrindast, M.-R., Bahreini, T., \& Adl, M. (2002). Effect of imipramine on the expression and acquisition of morphine-induced conditioned place preference in mice. Pharmacology Biochemistry and Behavior, 73(4), 941-949. doi:http://dx.doi.org/10.1016/S0091-3057(02)00951-6

Zarrindast, M.-R., Farajzadeh, Z., Rostami, P., Rezayof, A., \& Nourjah, P. (2005). Involvement of the ventral tegmental area (VTA) in morphine-induced memory retention in morphine-sensitized rats. Behavioural brain research, 163(1), 100-106.

Zarrindast, M.-R., Rezayof, A., Sahraei, H., Haeri-Rohani, A., \& Rassouli, Y. (2003). Involvement of dopamine D1 receptors of the central amygdala on the acquisition and expression of morphine-induced place preference in rat. Brain research, 965(1), 212-221.

Zarrindast, M.-R., \& Zarghi, A. (1992). Morphine stimulates locomotor activity by an indirect dopaminergic mechanism: Possible D-1 and D-2 receptor involvement. General Pharmacology: The Vascular System, 23(6), 1221-1225. doi:http://dx.doi.org/10.1016/0306-3623(92)90315-B

Zarrindast, M. R., \& Tabatabai, S. A. (1992). Involvement of dopamine receptor subtypes in mouse thermoregulation. Psychopharmacology (Berl), 107(2-3), 341-346.

Zhang, J., Ferguson, S. S., Barak, L. S., Bodduluri, S. R., Laporte, S. A., Law, P.-Y., \& Caron, M. G. (1998). Role for $G$ protein-coupled receptor kinase in agonist-specific regulation of $\mu$-opioid receptor responsiveness. Proceedings of the National Academy of Sciences, 95(12), 7157-7162.

Zöllner, C., \& Schäfer, M. (2008). Opioids in anesthesia. Der Anaesthesist, 57(7), 729-742. doi:10.1007/s00101-008-1408-9

Zubieta, J.-K., Smith, Y. R., Bueller, J. A., Xu, Y., Kilbourn, M. R., Jewett, D. M., . . Stohler, C. S. (2001). Regional mu opioid receptor regulation of sensory and affective dimensions of pain. Science, 293(5528), 311-315. 